\title{
A critical review of the epidemiology of Agent Orange/TCDD and prostate cancer
}

\author{
Ellen T. Chang $\cdot$ Paolo Boffetta $\cdot$ Hans-Olov Adami • \\ Philip Cole $\cdot$ Jack S. Mandel
}

Received: 12 February 2014/ Accepted: 16 June 2014/Published online: 27 July 2014

(C) The Author(s) 2014. This article is published with open access at Springerlink.com

\begin{abstract}
To inform risk assessment and regulatory decision-making, the relationship between 2,3,7,8-tetrachlorodibenzo- $p$-dioxin (TCDD) and prostate cancer requires clarification. This article systematically and critically reviews the epidemiologic evidence on the association between exposure to TCDD or Agent Orange, a TCDD-contaminated herbicide used during the Vietnam War, and prostate cancer risk. Articles evaluated include 11 studies of three cohorts, four case-control or cross-sectional studies, and three case-only studies of military veterans with information on estimated Agent Orange or TCDD exposure; 13 studies of seven cohorts, one case-control study, and eight proportionate morbidity or
\end{abstract}

Electronic supplementary material The online version of this article (doi:10.1007/s10654-014-9931-2) contains supplementary material, which is available to authorized users.

E. T. Chang $(\bowtie)$. J. S. Mandel

Health Sciences Practice, Exponent, Inc., 149 Commonwealth

Drive, Menlo Park, CA 94025, USA

e-mail: echang@exponent.com

E. T. Chang

Division of Epidemiology, Department of Health Research and Policy, Stanford University School of Medicine, Stanford, CA, USA

\section{P. Boffetta}

Institute for Translational Epidemiology and the Tisch Cancer Institute, Icahn School of Medicine at Mount Sinai, New York, NY, USA

H.-O. Adami

Department of Epidemiology, Harvard School of Public Health, Boston, MA, USA

P. Cole

Department of Epidemiology, University of Alabama at Birmingham, Birmingham, AL, USA mortality studies of Vietnam veterans without information on Agent Orange exposure; 11 cohort studies of workers with occupational exposure to TCDD; and two studies of one community cohort with environmental exposure to TCDD. The most informative studies, including those of Vietnam veterans involved in Agent Orange spraying or other handling, herbicide manufacturing or spraying workers with occupational TCDD exposure, and community members exposed to TCDD through an industrial accident, consistently reported no significant increase in prostate cancer incidence or mortality. Only some potentially confounded studies of Vietnam veterans compared with the general population, studies with unreliable estimates of Agent Orange exposure, and analyses of selected subgroups of Vietnam veterans reported positive associations. Overall, epidemiologic research offers no consistent or convincing evidence of a causal relationship between exposure to Agent Orange or TCDD and prostate cancer. More accurate exposure assessment is needed in large epidemiologic studies to rule out a causal association more conclusively.

Keywords Prostate cancer - TCDD - Dioxin - Agent Orange $\cdot$ Veterans $\cdot$ Epidemiology
Abbreviations
2,4-D 2,4-Dichlorophenoxyacetic acid
2,4,5-T 2,4,5-Trichlorophenoxyacetic acid
Ah Aryl hydrocarbon
AUC Area under the curve
CDC Centers for Disease Control and Prevention
CI Confidence interval
HR Hazard ratio
IARC International Agency for Research on Cancer
IOM Institute of Medicine
NIOSH National Institute for Occupational Safety and Health 


$\begin{array}{ll}\text { NR } & \text { Not reported } \\ \text { OR } & \text { Odds ratio } \\ \text { PCP } & \text { Pentachlorophenol } \\ \text { PMR } & \text { Proportionate mortality ratio } \\ \text { PPB } & \text { Parts per billion } \\ \text { PPT } & \text { Parts per trillion } \\ \text { PSA } & \text { Prostate-specific antigen } \\ \text { RR } & \text { Relative risk } \\ \text { SD } & \text { Standard deviation } \\ \text { SIR } & \text { Standardized incidence ratio } \\ \text { SMR } & \text { Standardized mortality ratio } \\ \text { TCDD } & 2,3,7,8 \text {-Tetrachlorodibenzo- } p \text {-dioxin } \\ \text { TCP } & \text { Trichlorophenol } \\ \text { TEQ } & \text { Toxic equivalency quotient } \\ \text { VA } & \text { Veterans Administration }\end{array}$

\section{Introduction}

Prostate cancer is the most common non-skin malignancy in U.S. men and the second most common cancer in men globally [1]. Despite extensive clinical and epidemiological research, the causes of prostate cancer remain elusive. Several environmental agents have been proposed to contribute to prostate carcinogenesis, including nutritional factors such as lycopene [2], tobacco smoking [3], and synthetic endocrine-disrupting chemicals [4]. In particular, exposure to 2,3,7,8-tetrachlorodibenzo-p-dioxin (TCDD) has been proposed as a possible cause of prostate cancer [5]. In 1997 and 2012, the International Agency for Research on Cancer (IARC) classified TCDD as an established human carcinogen (IARC group 1) [6, 7]. According to the IARC evaluation, the strongest evidence of an increased risk of cancer in humans is for all cancers combined, while "a positive association has been observed" for soft-tissue sarcoma, non-Hodgkin lymphoma, and lung cancer [7]. The classification of TCDD as a group 1 carcinogen is based in large part on mechanistic data showing tumor promotion through modification of cell replication and apoptosis mediated through the aryl hydrocarbon $(\mathrm{Ah})$ receptor and related signaling pathways and responses, which are conserved across species [6, 7].

Results regarding the association between TCDD exposure and risk of prostate cancer were presented from only three epidemiologic studies reviewed in the earlier IARC evaluation in 1997 [6]; none of these detected a significant increase in prostate cancer incidence or mortality among workers potentially exposed to TCDD [8-10]. The 2012 IARC review, which addressed new information published since the 1997 review as part of a broad update on all group 1 carcinogens, did not mention prostate cancer as an endpoint considered in relation to TCDD [7]. Other national and international agencies that have reviewed the epidemiologic evidence on TCDD and cancer, including some that classified TCDD as "carcinogenic to humans" [11], "at least 'likely to be carcinogenic to humans", [12], or "known to be a human carcinogen" [13], have likewise largely been silent on prostate cancer [11,12,14-16]. Only one of these reports [15] cited any results for prostate cancer, noting that this outcome was not increased above expectation in a pooled international cohort of workers exposed to phenoxy herbicides and chlorophenols contaminated with TCDD [17]. Thus, although epidemiologic studies of the association between TCDD and risk of all cancers and certain sitespecific cancers have been critically reviewed, albeit with conflicting conclusions [18-22], the relationship of TCDD with prostate cancer risk has not yet been well characterized.

Since 1991, the U.S. Institute of Medicine (IOM) has been congressionally mandated to conduct a comprehensive evaluation, updated biennially, of scientific and medical information related to health outcomes associated with Agent Orange and other herbicides used for defoliation and crop destruction during the Vietnam War between 1962 and 1971 [23]. Agent Orange is a defoliant made from equal parts of the phenoxy herbicides 2,4-dichlorophenoxyacetic acid (2,4-D) and 2,4,5-trichlorophenoxyacetic acid (2,4,5-T), the latter of which is contaminated with TCDD as a byproduct of the manufacturing process. Since its initial report in 1994, the IOM committee has repeatedly concluded that there is "limited/suggestive evidence of an association" between herbicides and prostate cancer-that is, that "[e]vidence is suggestive of an association between herbicides and the outcome but is limited because chance, bias, and confounding could not be ruled out with confidence" [23-32].

Understanding the association between TCDD and prostate cancer is important for risk assessment and regulatory decision-making, and is also of public health relevance given that low-dose exposure to TCDD is ubiquitous and prostate cancer is one of the most common malignancies worldwide. Furthermore, recent articles focusing on the relationship between Agent Orange exposure and prostate cancer risk have attracted attention to this issue $[33,34]$. Therefore, this article aims to provide a detailed review of the epidemiologic evidence on Agent Orange/ TCDD and prostate cancer.

\section{Epidemiology of prostate cancer}

More than 1,100,000 new cases of prostate cancer and 300,000 prostate cancer deaths occur each year worldwide [1]. The disease primarily affects older men, with a median age at diagnosis around age 70 years. Incidence rates vary by more than 30 -fold internationally, with the highest rates found in Australia and New Zealand, northern and western Europe, and North America, and the lowest rates found in 
southern and eastern Asia and North Africa [1]. Much of the excess incidence in economically developed regions, along with the rapid rise in prostate cancer incidence in the early 1990s, is attributed to the widespread practice of prostate-specific antigen (PSA) testing to detect asymptomatic tumors, many of which are clinically indolent and would not otherwise become clinically apparent $[35,36]$. The high proportion of such latent disease makes prostate cancer particularly difficult to study epidemiologically. That is, any factor that affects diagnostic intensity and particularly PSA testing will inevitably affect observed prostate cancer incidence, making it difficult to distinguish between factors that influence disease development and those that influence disease detection.

The general epidemiology of prostate cancer has been reviewed in other publications [37-41]. The only established risk factors for prostate cancer are older age, family history of the disease (which confers a twofold to fourfold increased risk in first-degree relatives), certain genetic variants, and race, with higher risk among men of black/ sub-Saharan African origin than men of white/European origin, and lowest risk among those of Asian origin. Other reviews cited in this section are focused on specific potential risk factors for prostate cancer. A few rare genetic mutations, including variants in the tumor suppressor gene $B R C A 2$, the DNA repair genes PALB2, BRIP1, CHEK2, and NBS1, and the transcription factor gene $H O X B 13$, appear to confer a "moderate" excess risk of prostate cancer, and 76 common variants that confer a "small" excess risk have been identified by genome-wide association studies thus far, together explaining approximately $30 \%$ of the familial risk of prostate cancer [42].

Diet has been extensively studied with respect to prostate cancer risk, with largely inconsistent findings other than inverse associations with lycopene and selenium and a positive association with calcium-although even these associations are not generally accepted as causal [2]. If heavy alcohol consumption or tobacco smoking increases prostate cancer risk-a question that is not settled-the excess risk is probably below $30 \%[3,43]$. The role of energy balance, including physical activity, adiposity, and levels of insulin and insulin-like growth factors, in prostate cancer development has also been widely studied, with suggestive but ultimately inconclusive results [2, 44]. A farming occupation appears to be associated with increased prostate cancer risk [45], although results are heterogeneous across studies, and the underlying explanations for this association are unclear given inconsistent associations with specific pesticides [46]. Higher circulating androgen levels may be associated with increased prostate cancer risk, but this apparently complex relationship is not yet understood, and circulating testosterone levels measured in epidemiologic studies may not reflect locally bioavailable levels [47]. Infections have been inconsistently associated with prostate cancer risk [48], including variable findings for sexually transmitted infections, depending on the particular agent and method of detection [49]. Associations with additional causes and biomarkers of inflammation also imply an etiologic role of chronic intraprostatic inflammation in prostate carcinogenesis [50]. No clear association has been demonstrated between ionizing radiation [51], vasectomy [52], or sexual behavior [53] and prostate cancer risk. Uncontrolled confounding by these unestablished risk factors is not likely to be a major source of bias. Instead, potential differences in diagnostic intensity are of greater concern in most epidemiologic studies of prostate cancer risk [54-56].

\section{Methods}

Studies included in this review were selected in a manner similar to that previously described by Boffetta et al. [21] in a review on TCDD and cancer. Specifically, this review focuses on two sets of studies. The first set comprises studies that evaluated prostate cancer incidence or mortality among Vietnam veterans who were involved in the spraying or other handling of Agent Orange, or who reported having been exposed to Agent Orange. Studies of Vietnam veterans without information on Agent Orange/ TCDD exposure are also discussed briefly to provide context for the interpretation of studies with such exposure information. The second set comprises studies of prostate cancer incidence or mortality among workers involved in the production or use of herbicides potentially contaminated by TCDD. We also evaluated studies of groups exposed via industrial accidents to herbicides or intermediates potentially contaminated with TCDD.

We did not review studies of workers exposed to herbicides not contaminated by TCDD, agents contaminated by polychlorinated dibenzo-para-dioxins other than TCDD, or unspecified or poorly specified combinations of pesticides or herbicides. We also excluded studies of occupational groups with potential but unmeasured exposure to TCDD, such as farmers, forestry workers, pulp and paper workers, chloralkali workers, waste incinerator workers, steel mill workers, and fishermen, because no epidemiologic studies of these groups have aimed specifically at estimating the health effects of TCDD as distinct from other potentially hazardous occupational exposures. Furthermore, average TCDD exposure levels in these groups of workers have been shown or are expected to be relatively low [6]. We also excluded ecologic studies that lack individual-level assessment of exposures and outcomes. Studies of PSA levels in the absence of malignancy (e.g., [57]) or after prostate cancer diagnosis (e.g., [58]) were not considered. 
Relevant studies were identified from the IARC Monographs [6, 7], the IOM reports [23-32], and searches of the PubMed database using keywords such as "dioxin," "TCDD," "Agent Orange," "Vietnam," "herbicides," "cancer," "malignancy," "tumor," “adenocarcinoma," "mortality," "morbidity," and "prostate." We also identified additional studies from reference lists of included articles.

\section{Review of epidemiologic studies}

The results of epidemiologic studies of veterans with estimated exposure to Agent Orange/TCDD are provided in Table 1. The results of epidemiologic studies of Vietnam veterans without quantitative or qualitative estimates of Agent Orange/TCDD exposure are provided in Table 2. The results of epidemiologic studies of manufacturers and sprayers of herbicides potentially contaminated with TCDD are provided in Table 3, and the results of epidemiologic studies of the Seveso, Italy, industrial accident involving TCDD are provided in Table 4. All relevant results are provided in the tables; for readability, only selected illustrative results are provided in the text below.

To provide a visual overview of the results of all studies that reported relative risk $(\mathrm{RR})$ estimates for prostate cancer incidence, prevalence, or mortality in association with Agent Orange/TCDD exposure or surrogates for exposure, forest plots are provided in supplementary online figures. Figure S1 shows the results of epidemiologic studies of veterans with estimated exposure to Agent Orange/TCDD, Figure S2 shows the results of epidemiologic studies of Vietnam veterans without estimated exposure to Agent Orange/TCDD, and Figure S3 shows the results of epidemiologic studies of manufacturers and sprayers of herbicides potentially contaminated with TCDD and studies of the Seveso, Italy, industrial accident. To avoid skewing the data by selectively displaying some results but not others, all potentially relevant RR estimates for overall prostate cancer are shown. Results are not shown for clinical subgroups of prostate cancer. Summary RRs are not calculated to avoid presenting a single non-representative RR from each study, obscuring information on potential exposureresponse trends, inappropriately equating disparate exposures such as measured serum TCDD levels and selfreported Agent Orange exposure, and overstating the homogeneity and statistical precision of results [59, 60].

It is important to emphasize that this graphic display of results does not take study quality into account, and it does not more heavily weight studies that used more valid measures of TCDD exposure. Therefore, the results shown in the figures must be interpreted in light of the study descriptions presented in the text and tables.
Studies of veterans with estimated Agent Orange/ TCDD exposure

\section{Air Force Health Study}

The Air Force Health Study is a prospective matched cohort study with up to 20 years of follow-up on 1,261 veterans of Operation Ranch Hand, the U.S. Air Force program that conducted aerial spraying of herbicides, including Agent Orange, in South Vietnam from 1962 through 1971 [61]. Due to their direct handling of herbicides, Operation Ranch Hand veterans (hereafter referred to as Ranch Hands) had the greatest potential for exposure to Agent Orange/TCDD during the Vietnam War. The unexposed comparison group in this study comprised 19,101 personnel assigned to aerial cargo missions in Southeast Asia during the same time period. Up to 10 comparison subjects (a combined total of 10,133) were initially matched to each Ranch Hand on date of birth, race, rank, and military occupation during their duty in Southeast Asia. Ranch Hands and one living comparison subject from each matched set, with replacement of non-participating comparison subjects, were invited to participate in periodic physical examinations and questionnaires. TCDD levels measured at the 1987 examination established that average serum TCDD levels were higher in Ranch Hands than comparison subjects within all strata of military occupation and overall (Table 5).

The Air Force Health Study included two components: a mortality study and a morbidity study. The mortality study found no significant difference in prostate cancer mortality between Ranch Hands and comparison subjects as of 1993, although few prostate cancer deaths were observed [standardized mortality ratio $(\mathrm{SMR})=3.18[0.39-11.5]^{1} ; 2$ deaths [62] (Table 1; Figure S1). With follow-up through 2000, prostate cancer mortality did not differ significantly between Ranch Hands and the general U.S. male population $(\mathrm{SMR}=0.70$ [0.12-2.33]; 2 deaths) or between comparison subjects and the general U.S. male population (SMR $=0.77$ [0.20-2.09]; 3 deaths) [63].

In the morbidity study, health conditions were identified in Ranch Hands and matched comparison subjects through physical examinations in 1982 (baseline), 1985, 1987, 1992, 1997, and 2002 (including digital rectal examination in all years and PSA testing beginning in 1992), questionnaire responses that were validated by review of medical records (which were also used to identify unreported diagnoses, as possible), and death certificates [61].

\footnotetext{
1 Throughout this paper, relative risk point estimates are followed by $95 \%$ confidence intervals unless otherwise stated. Where confidence intervals were not reported by the authors, Fisher's exact $95 \%$ confidence intervals were calculated.
} 


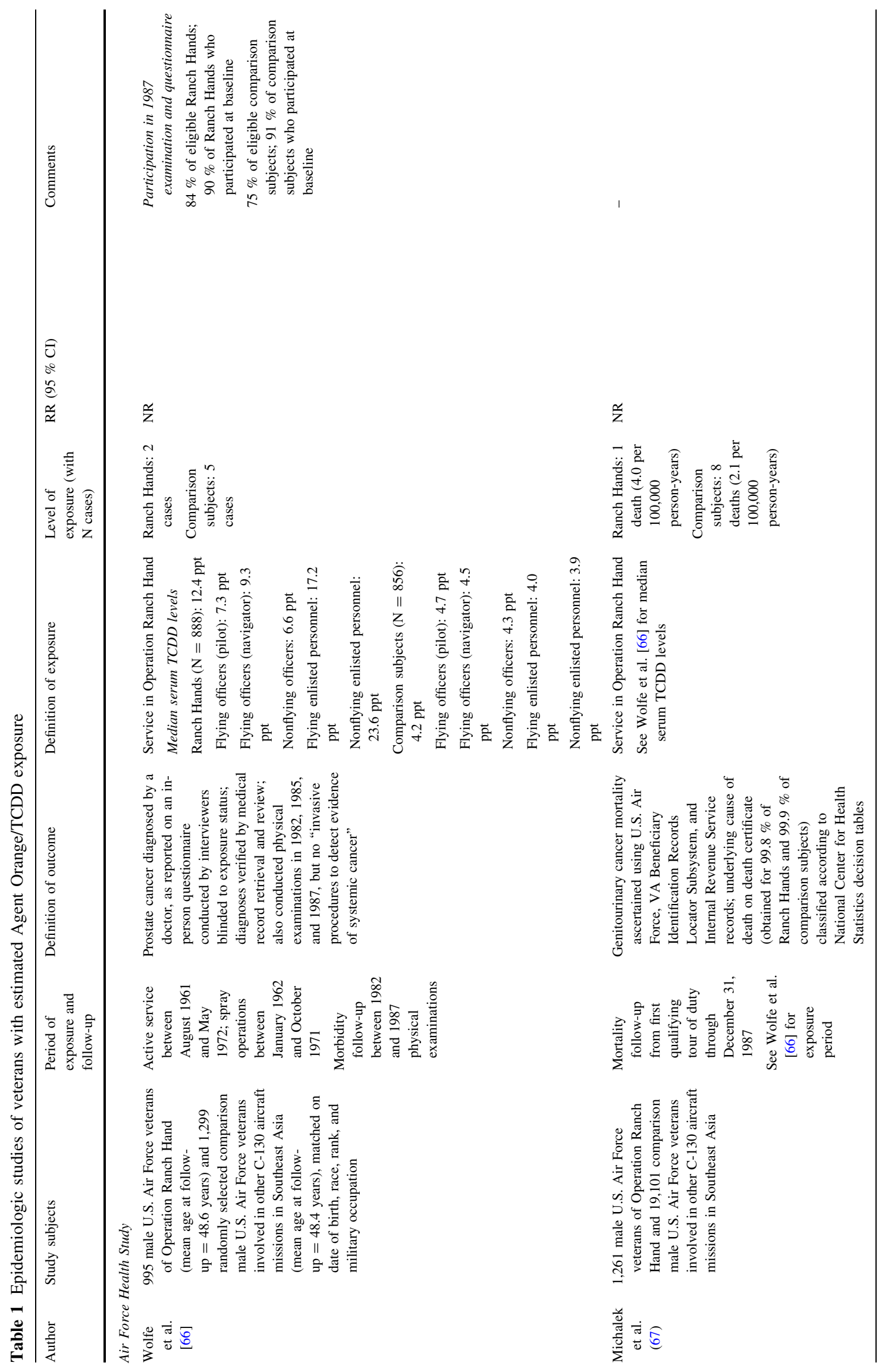




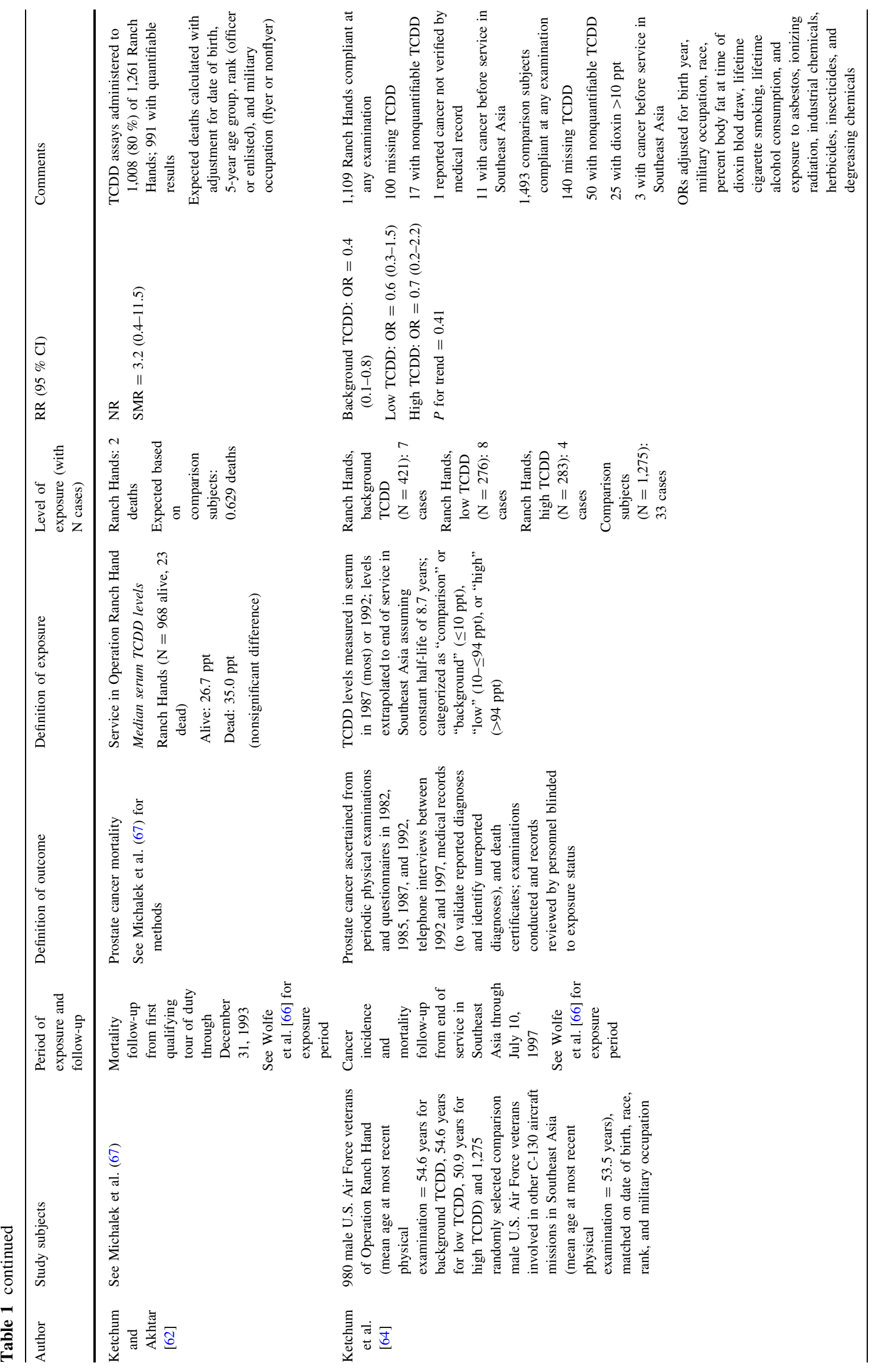




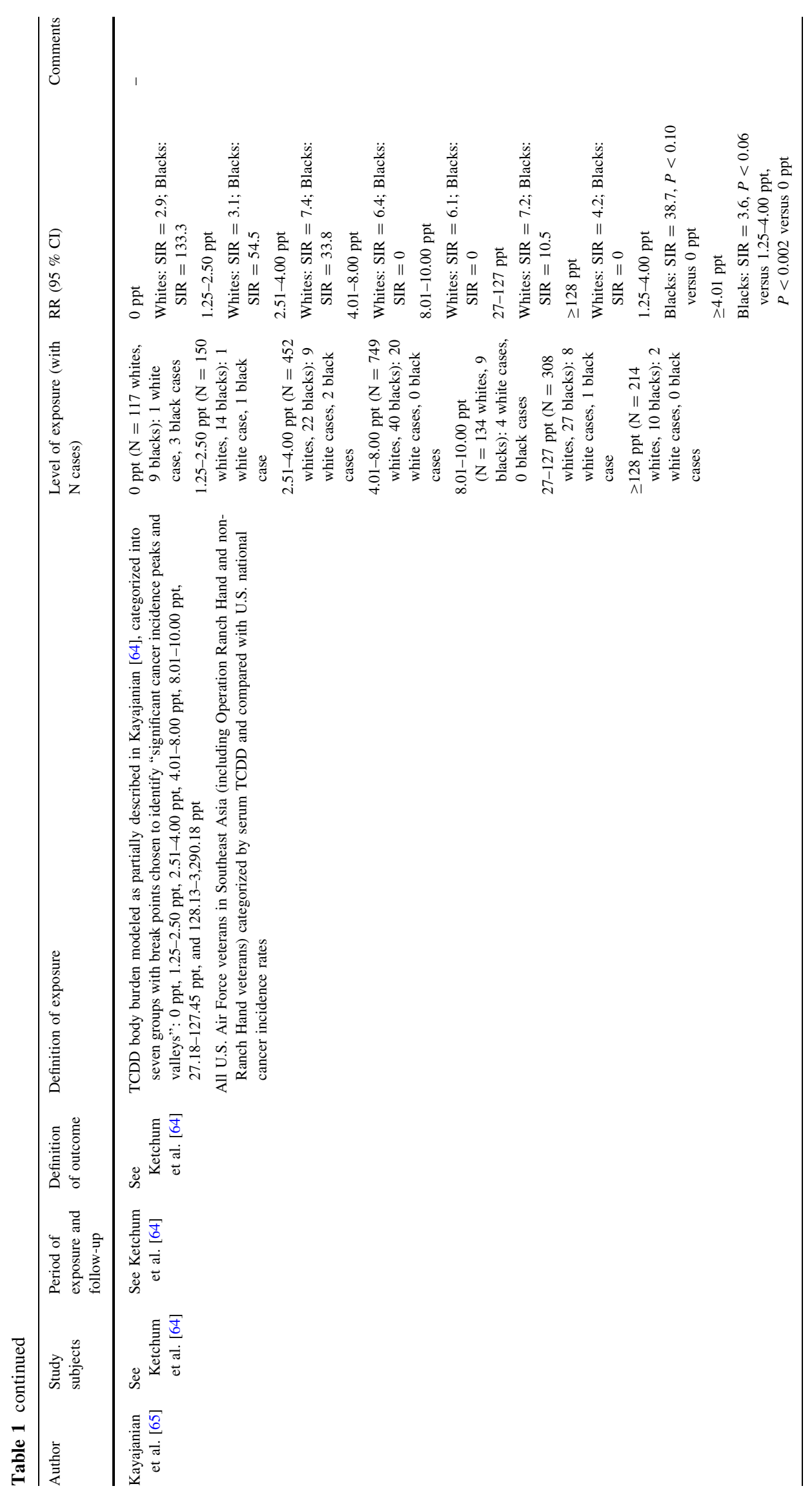




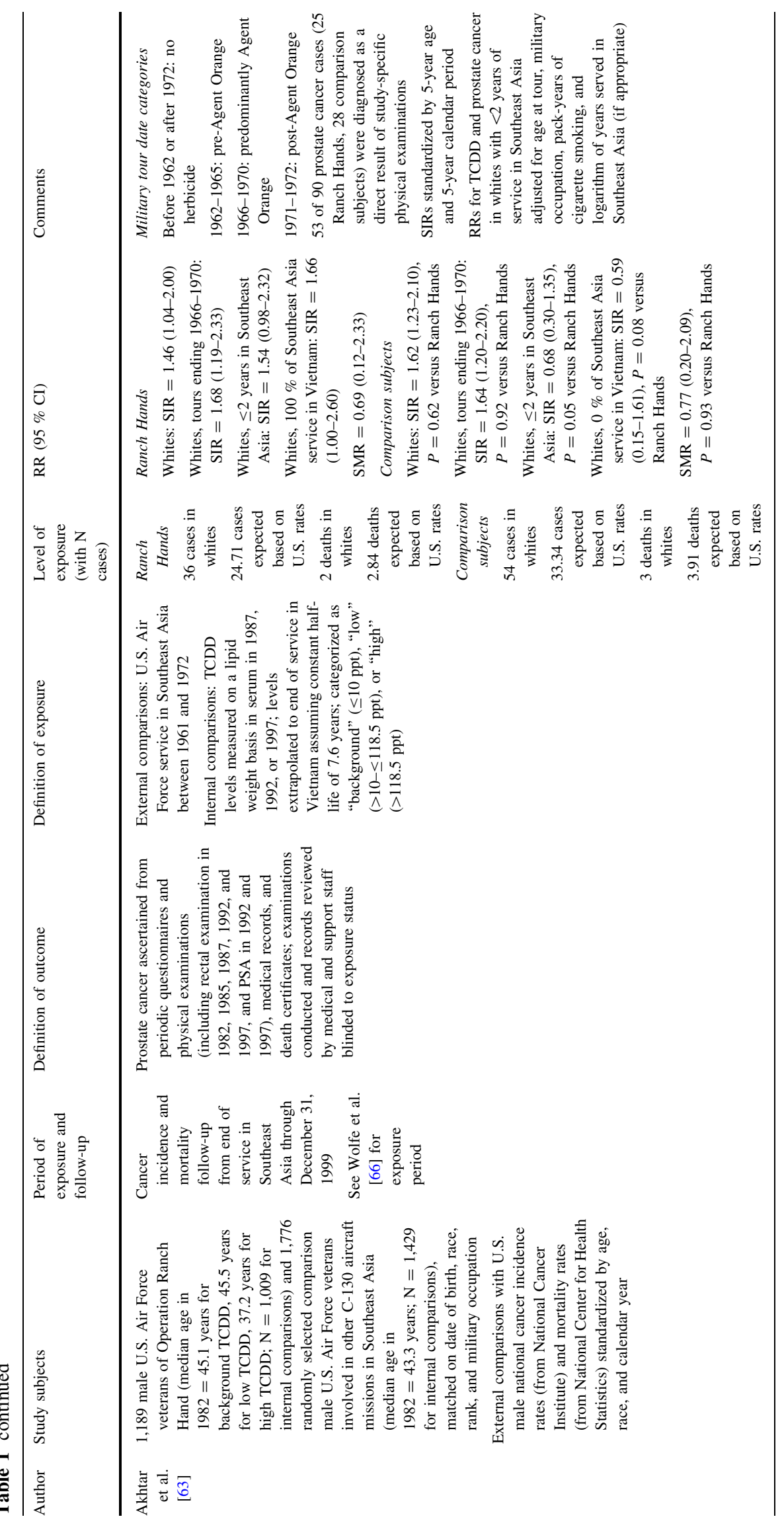




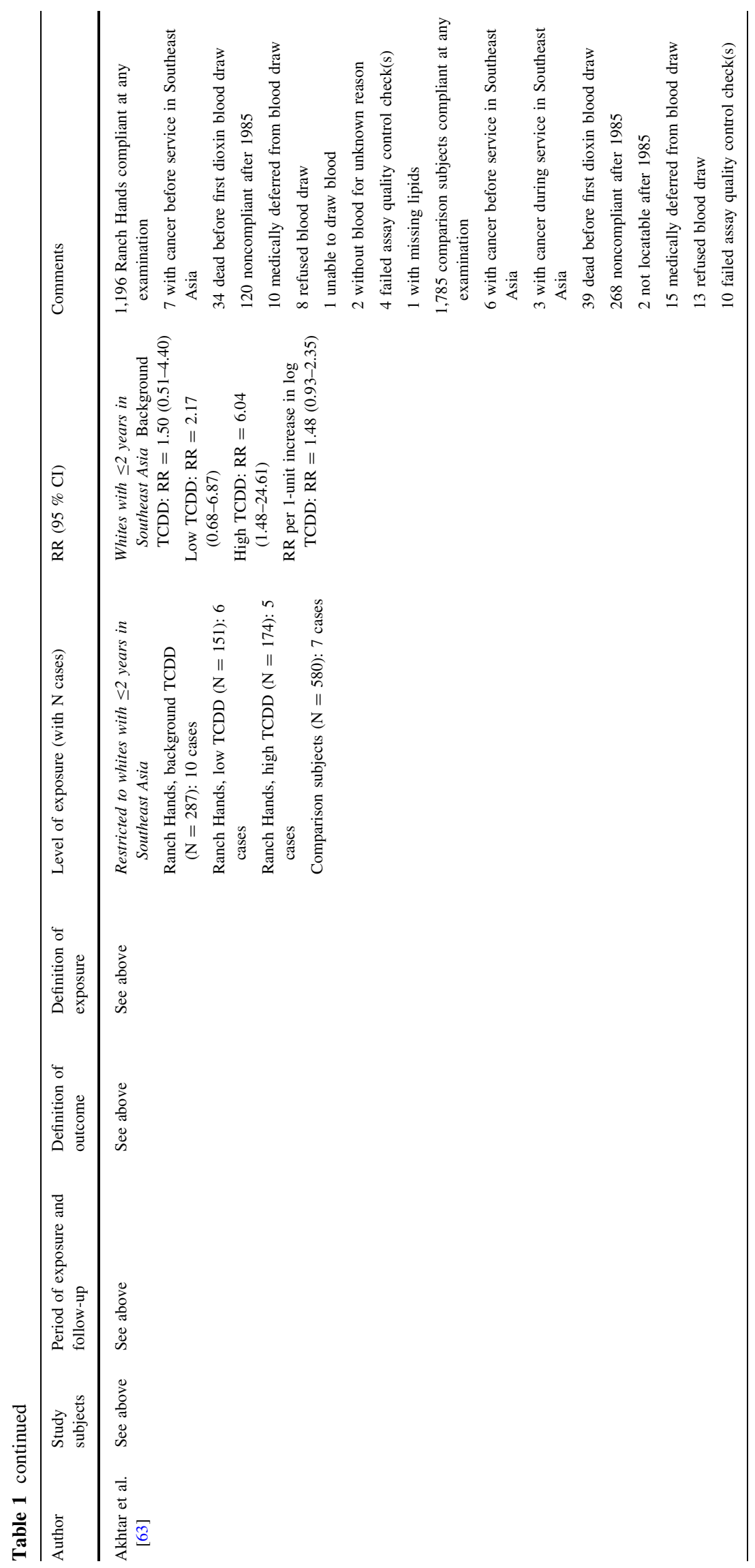




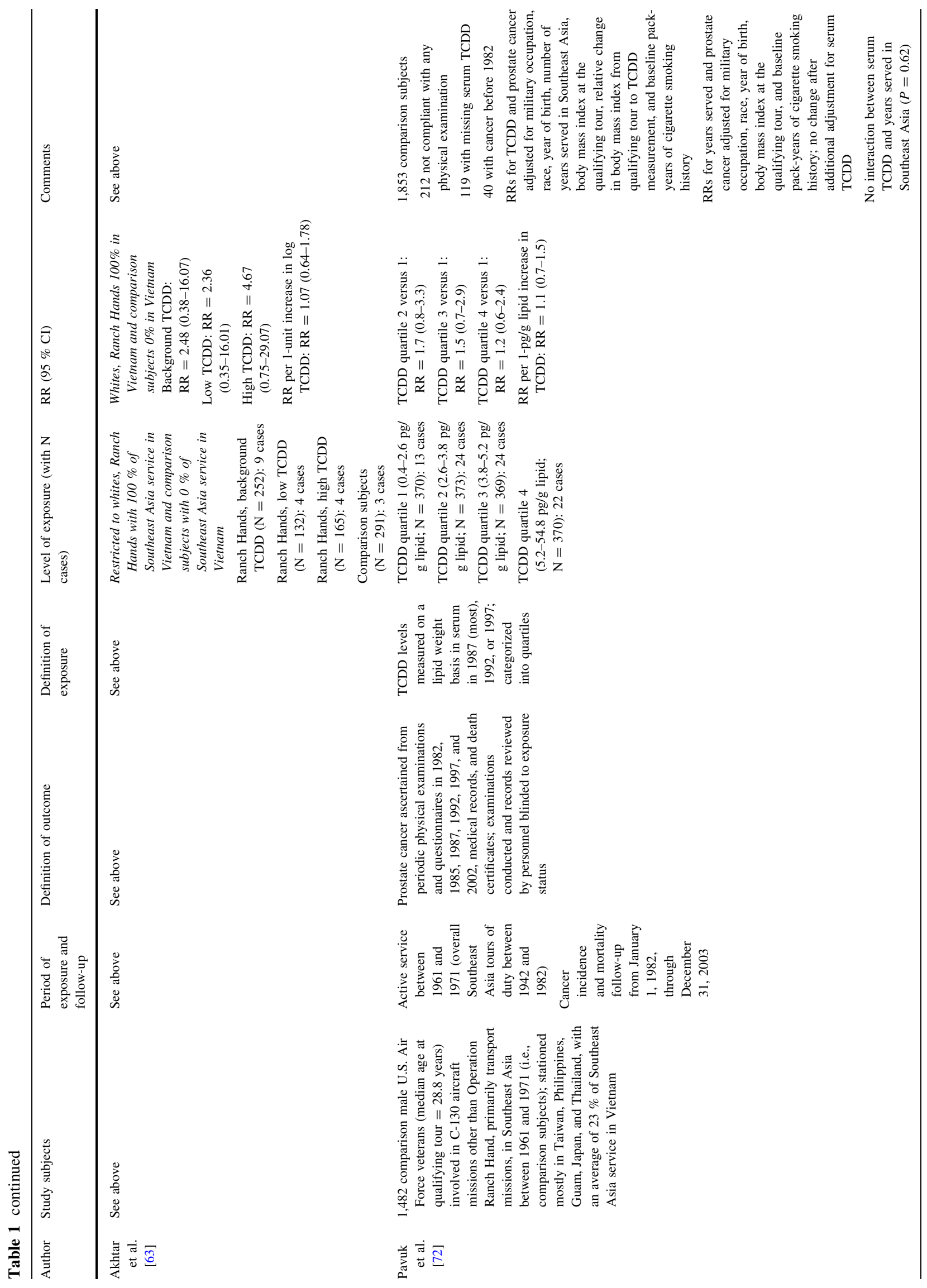




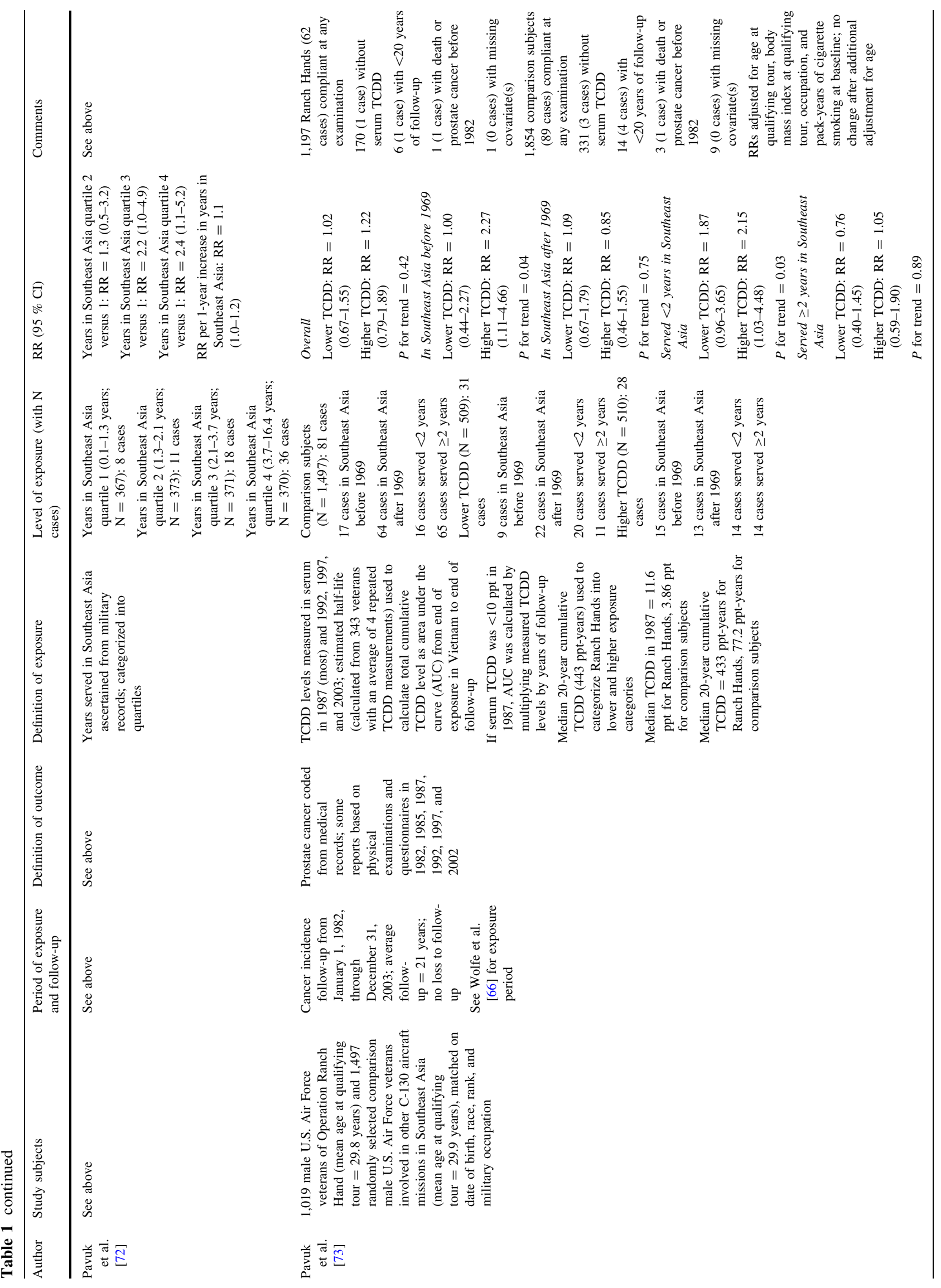




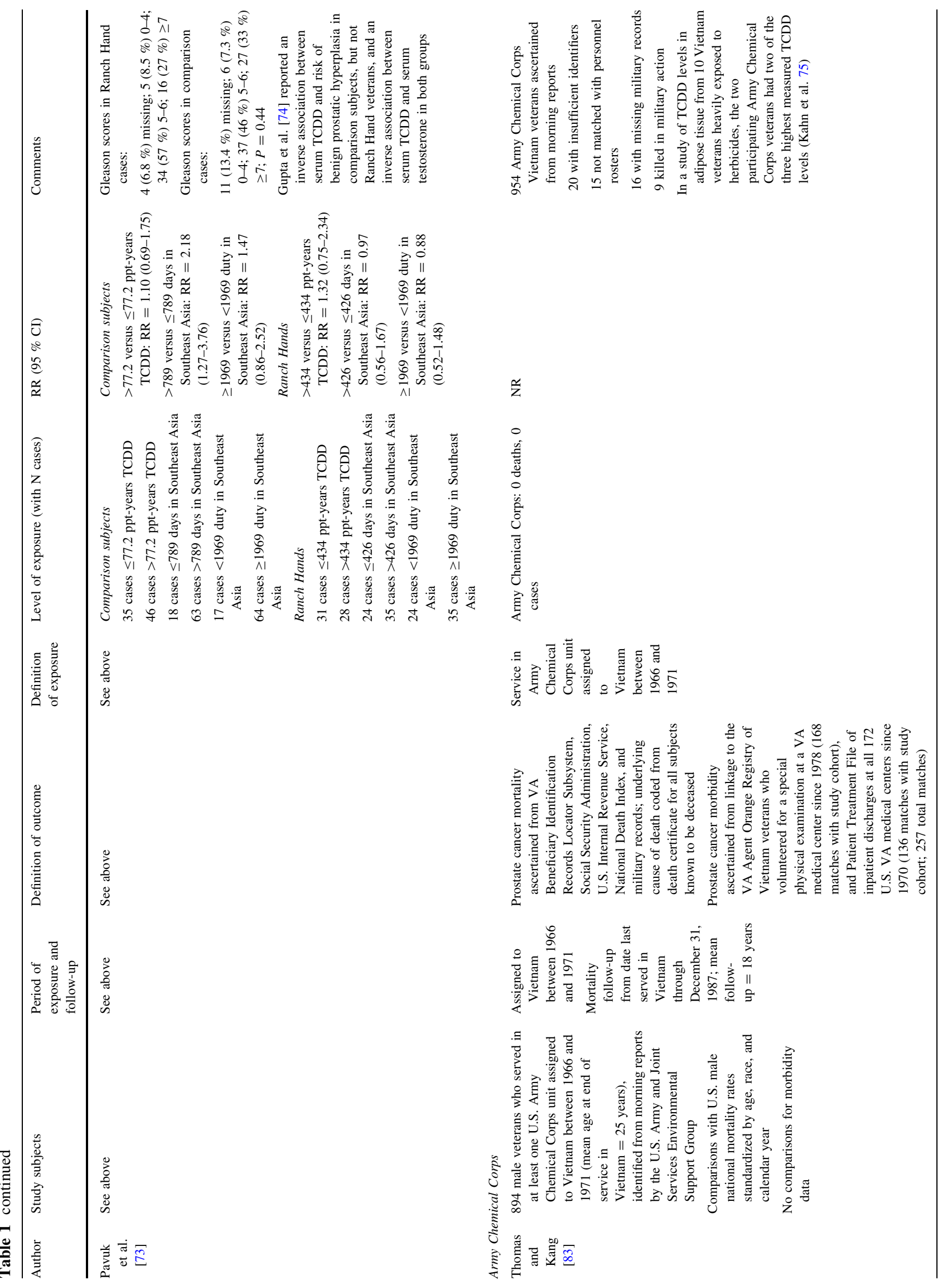




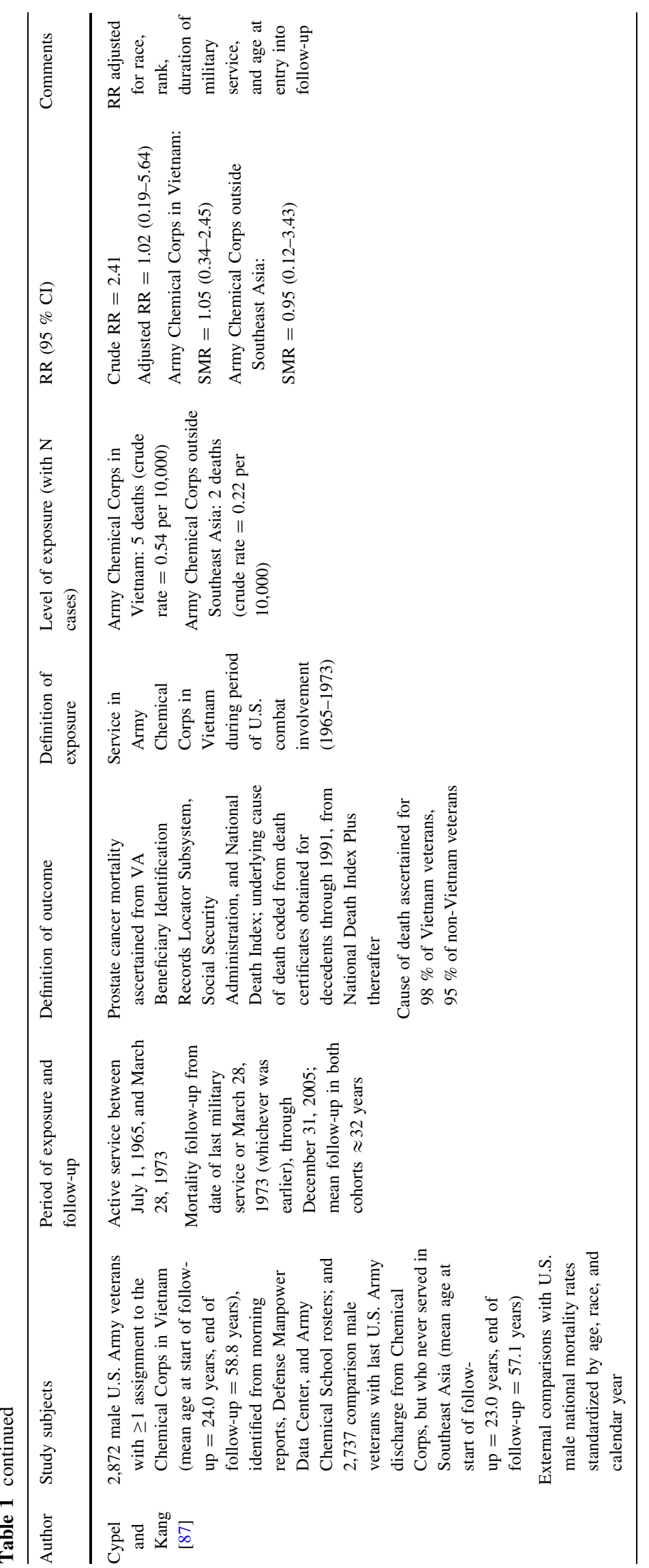




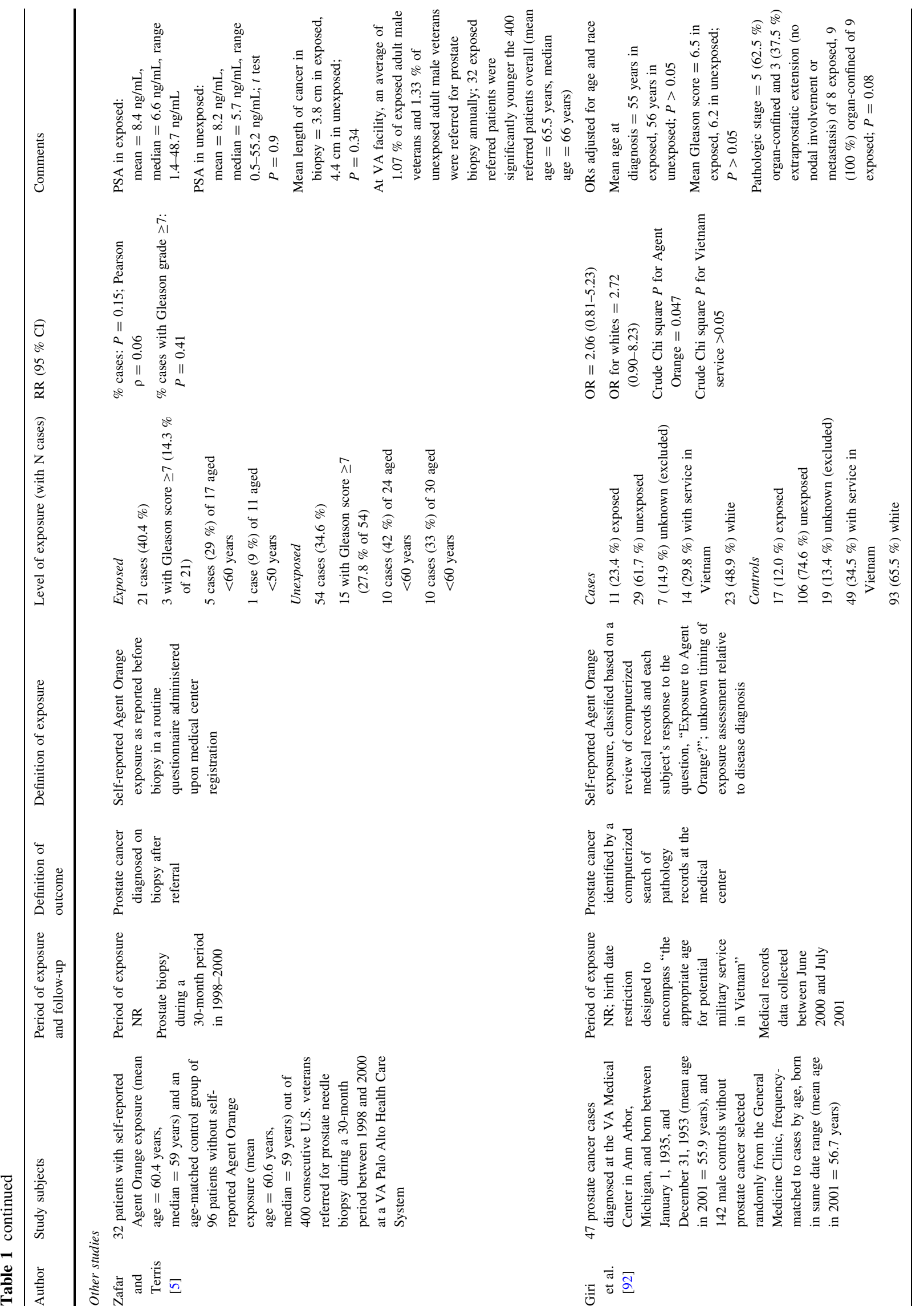




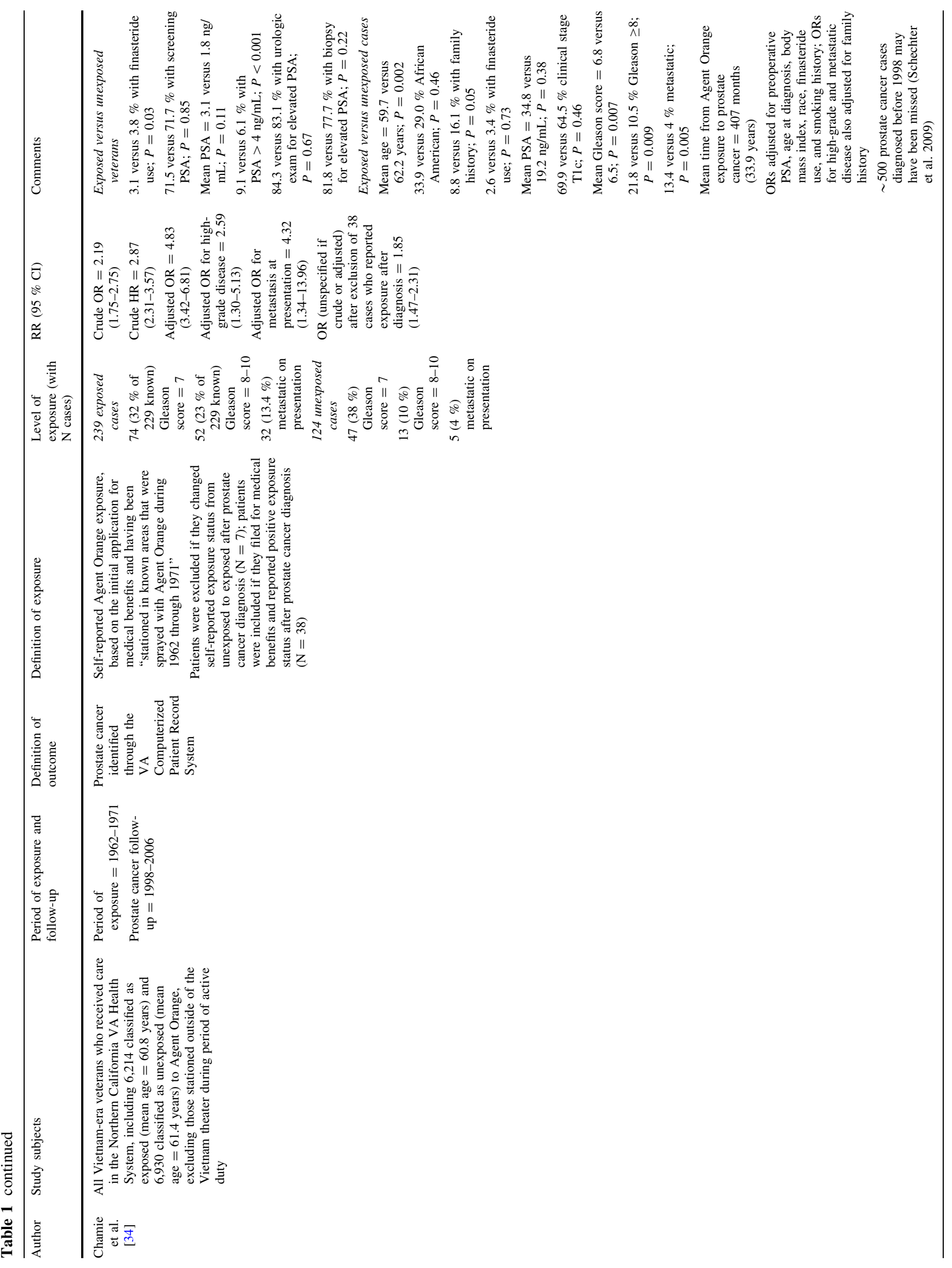




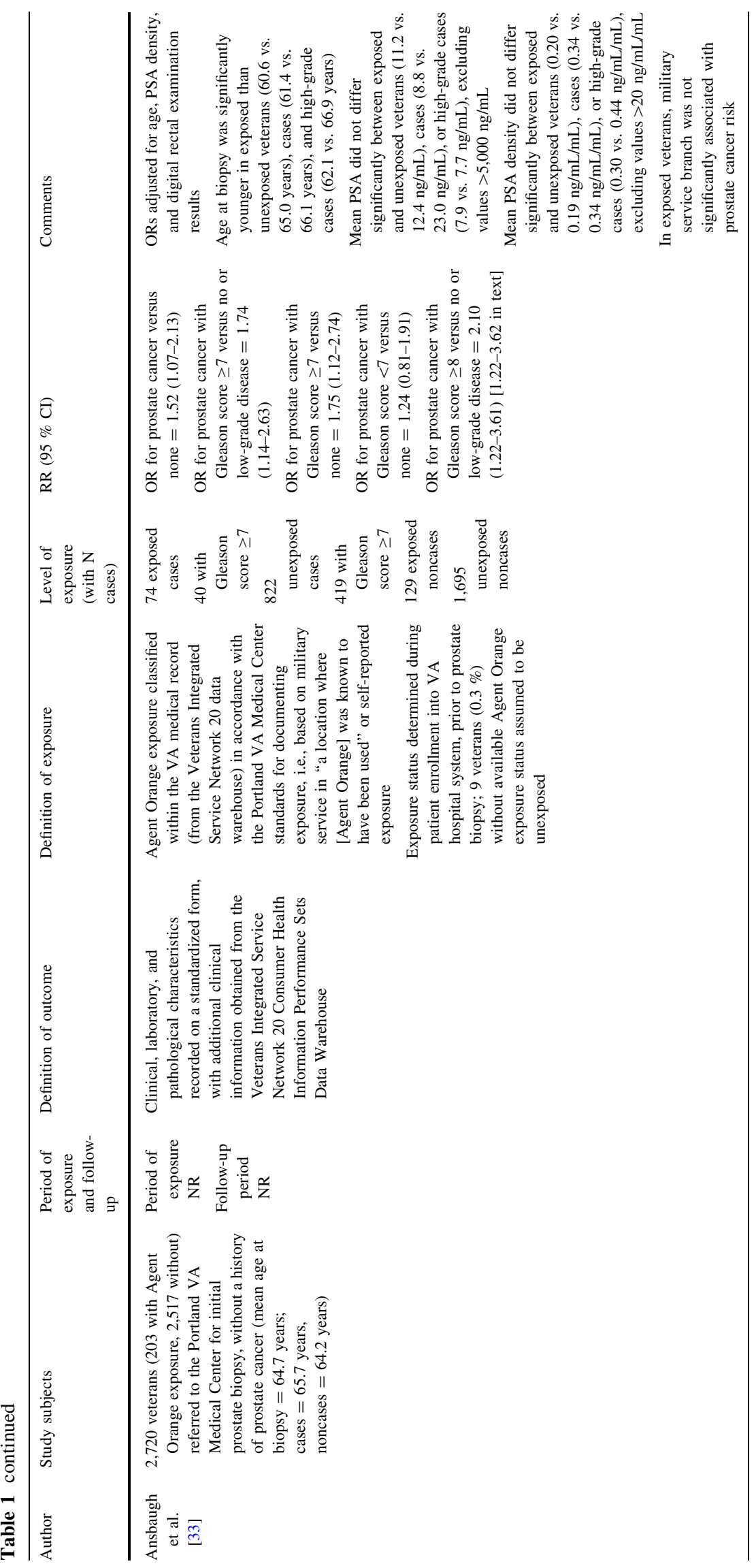




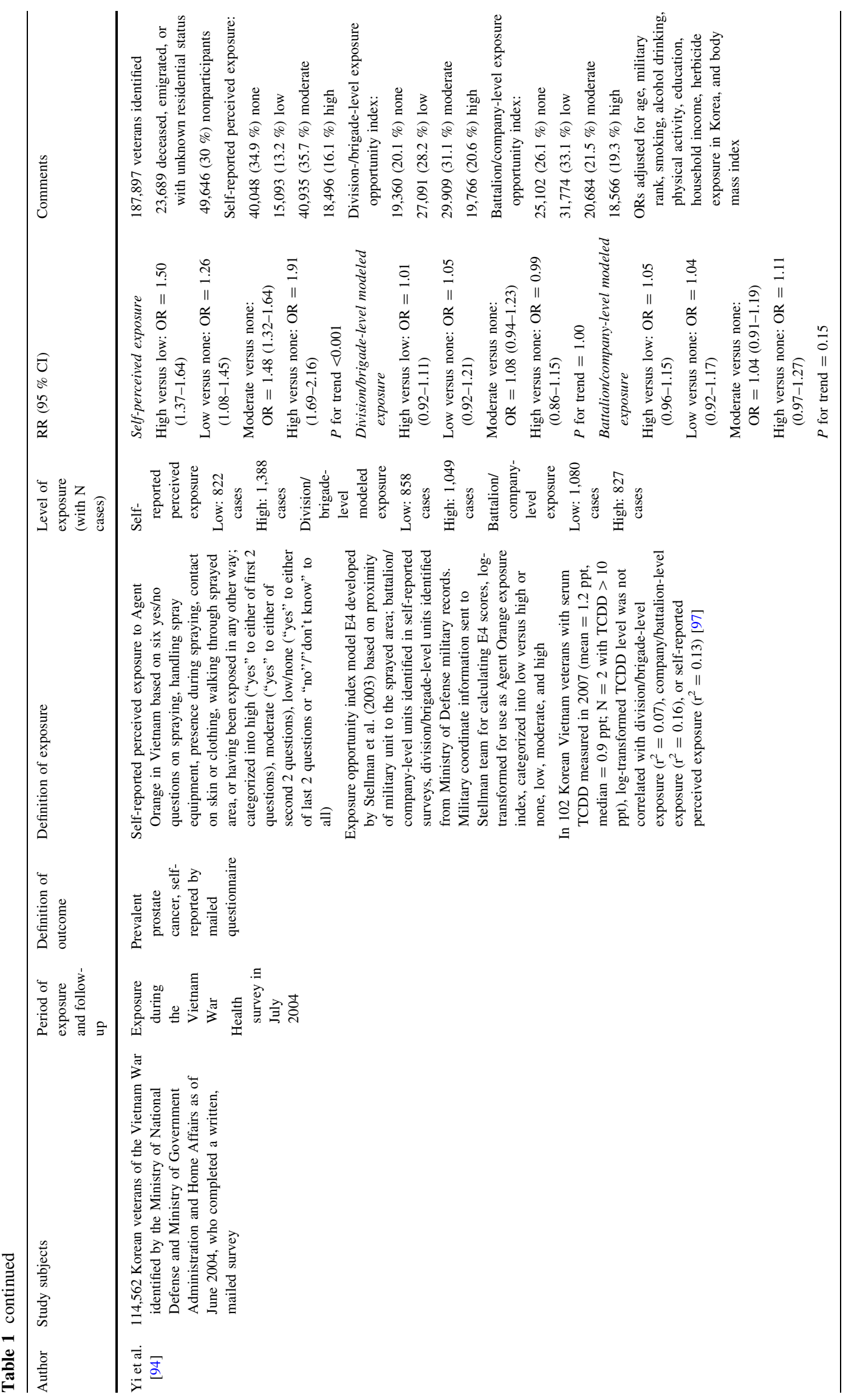




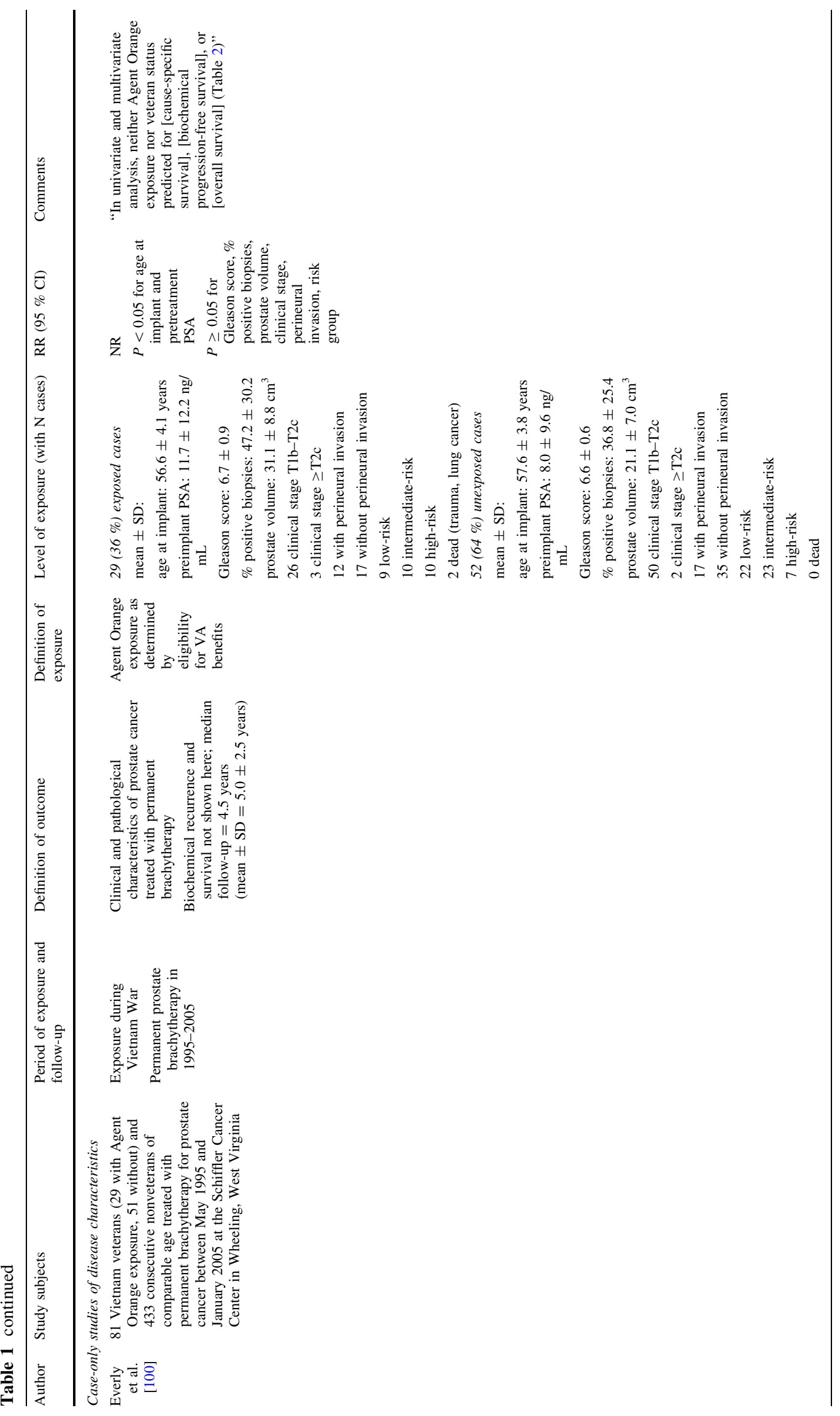




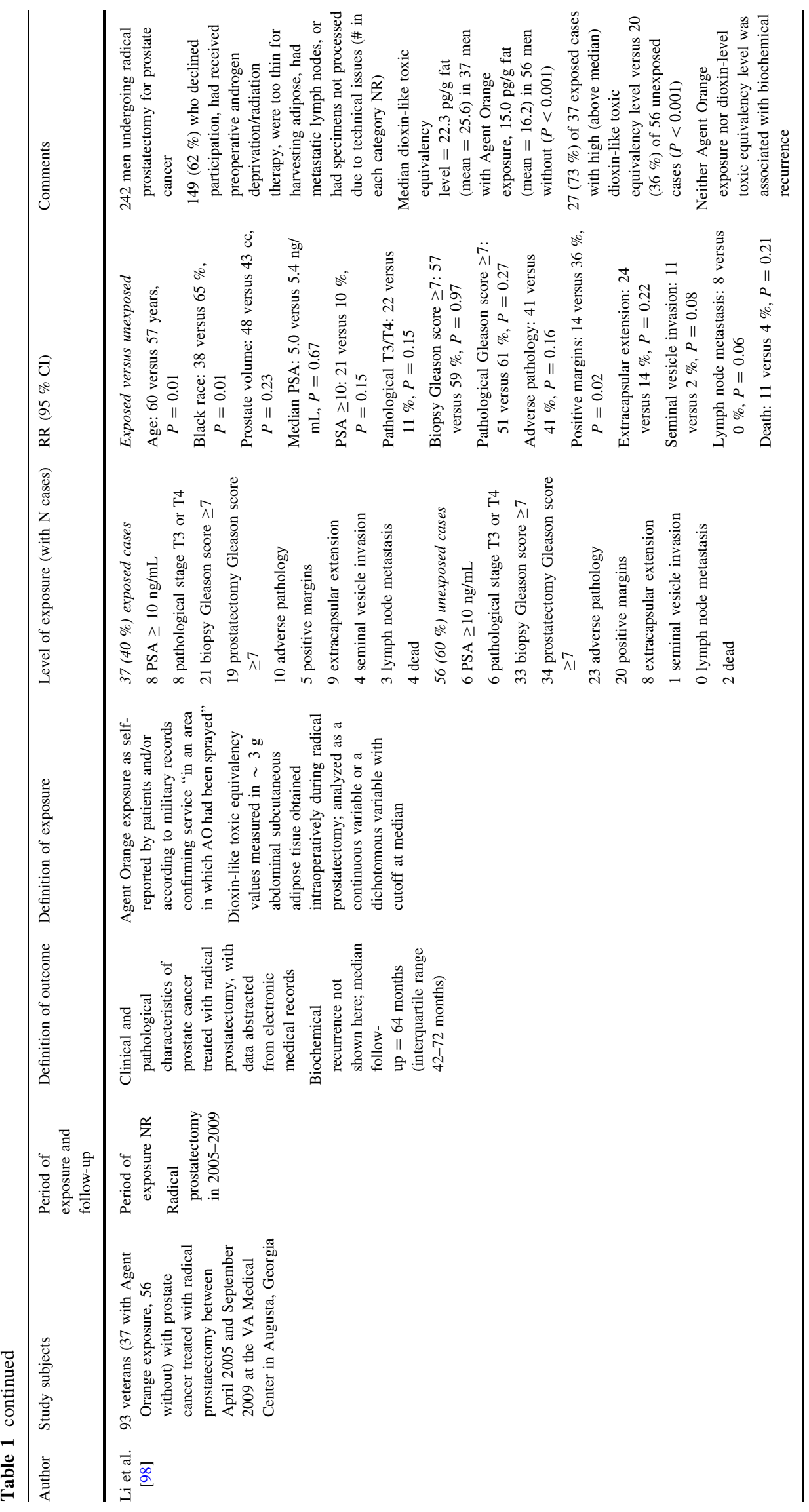




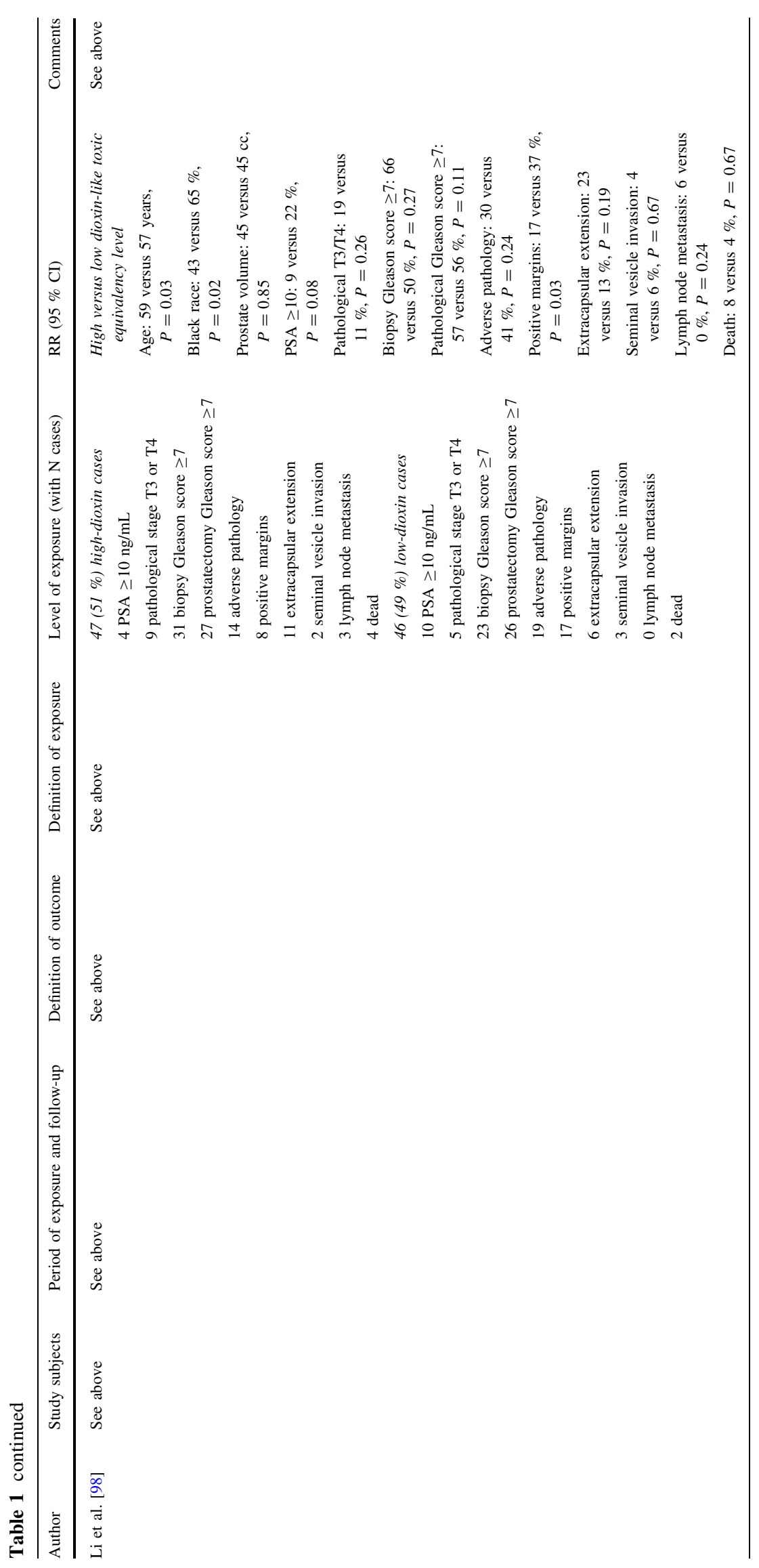




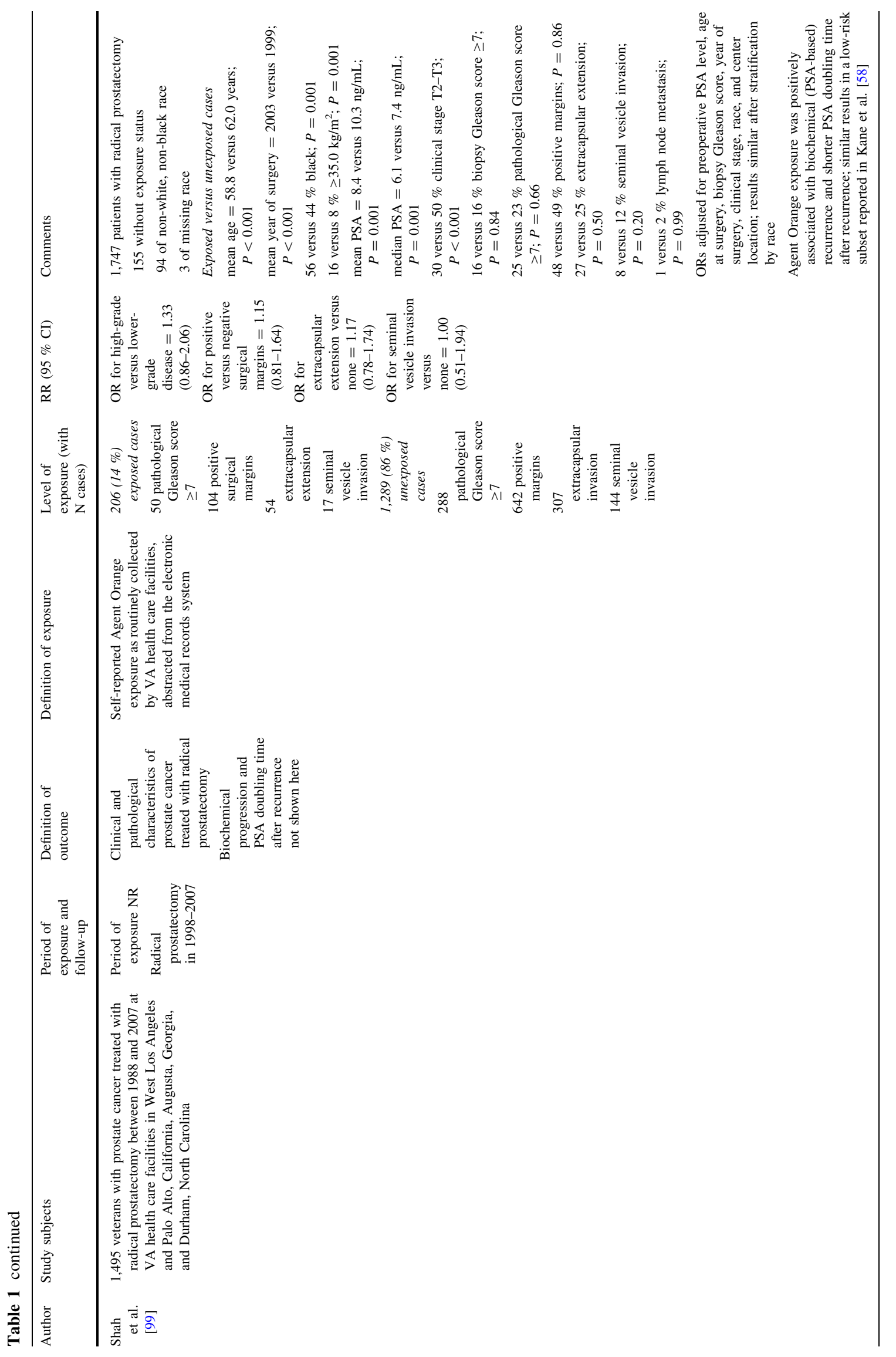




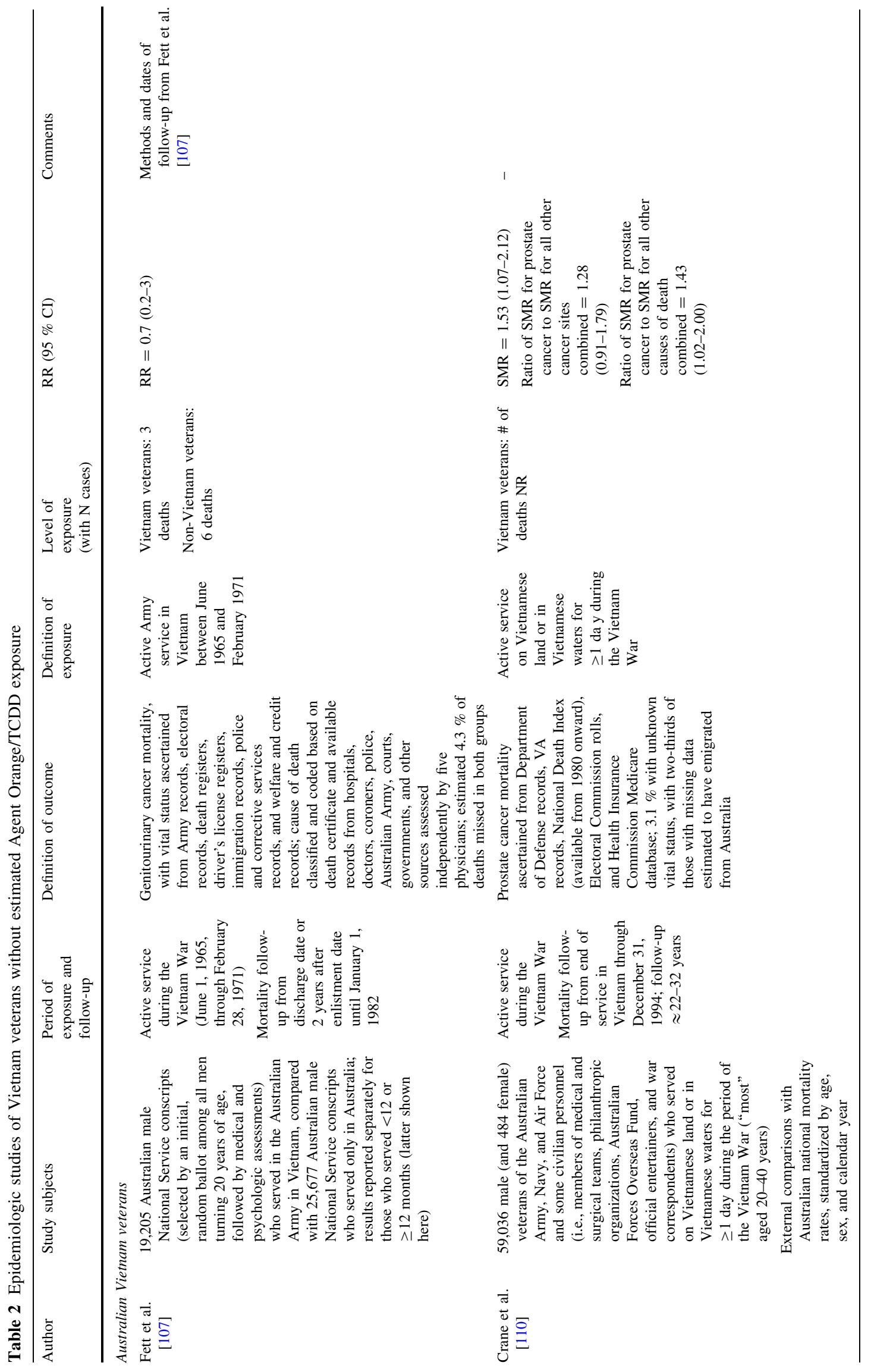




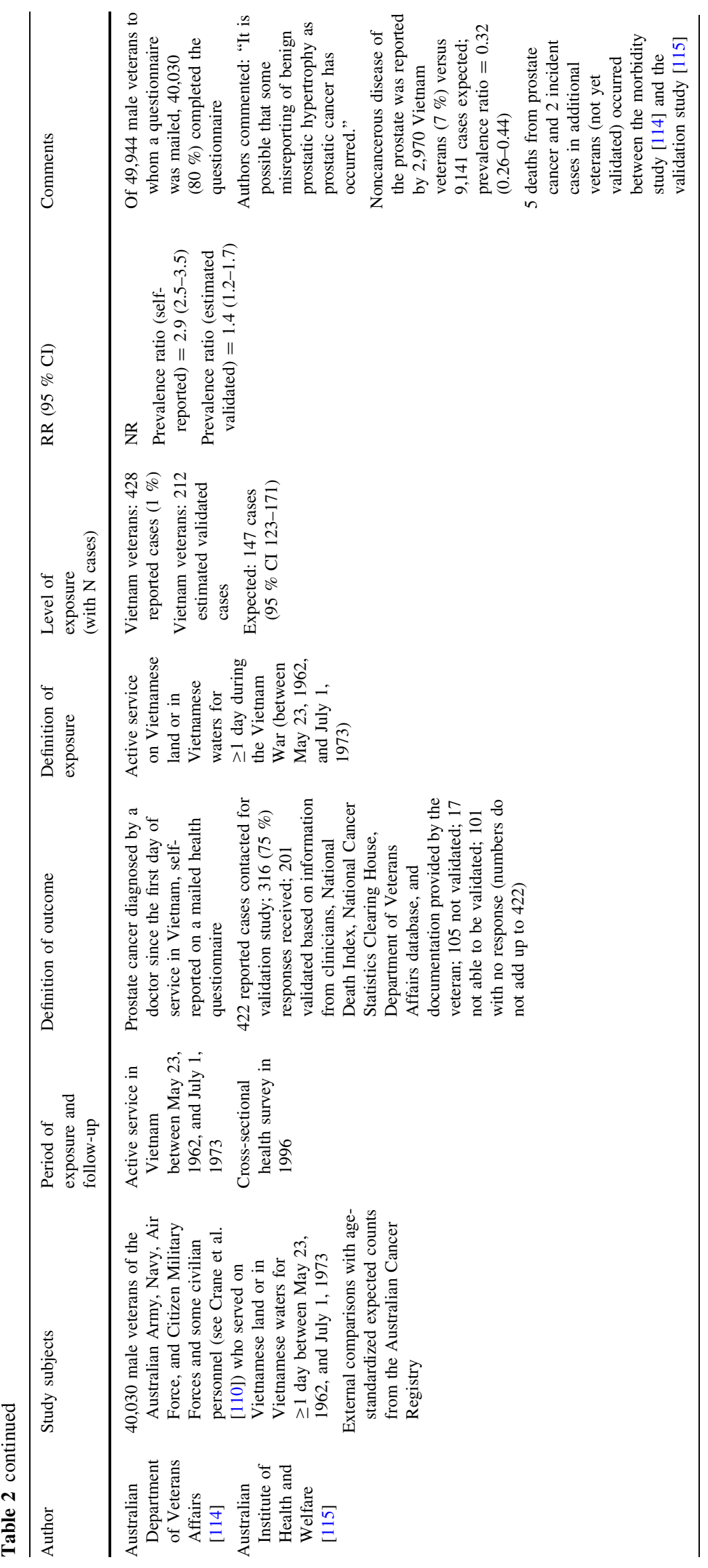




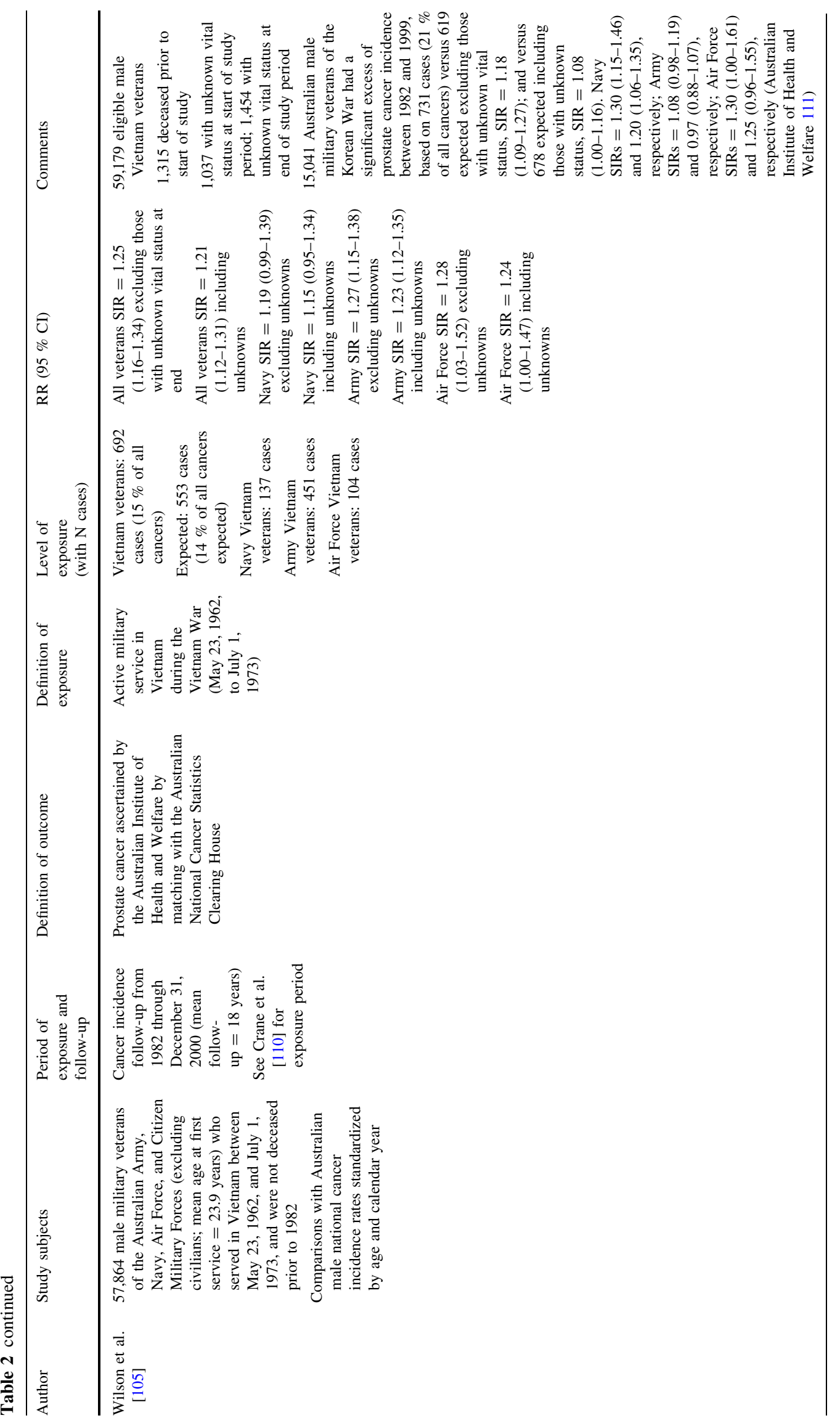




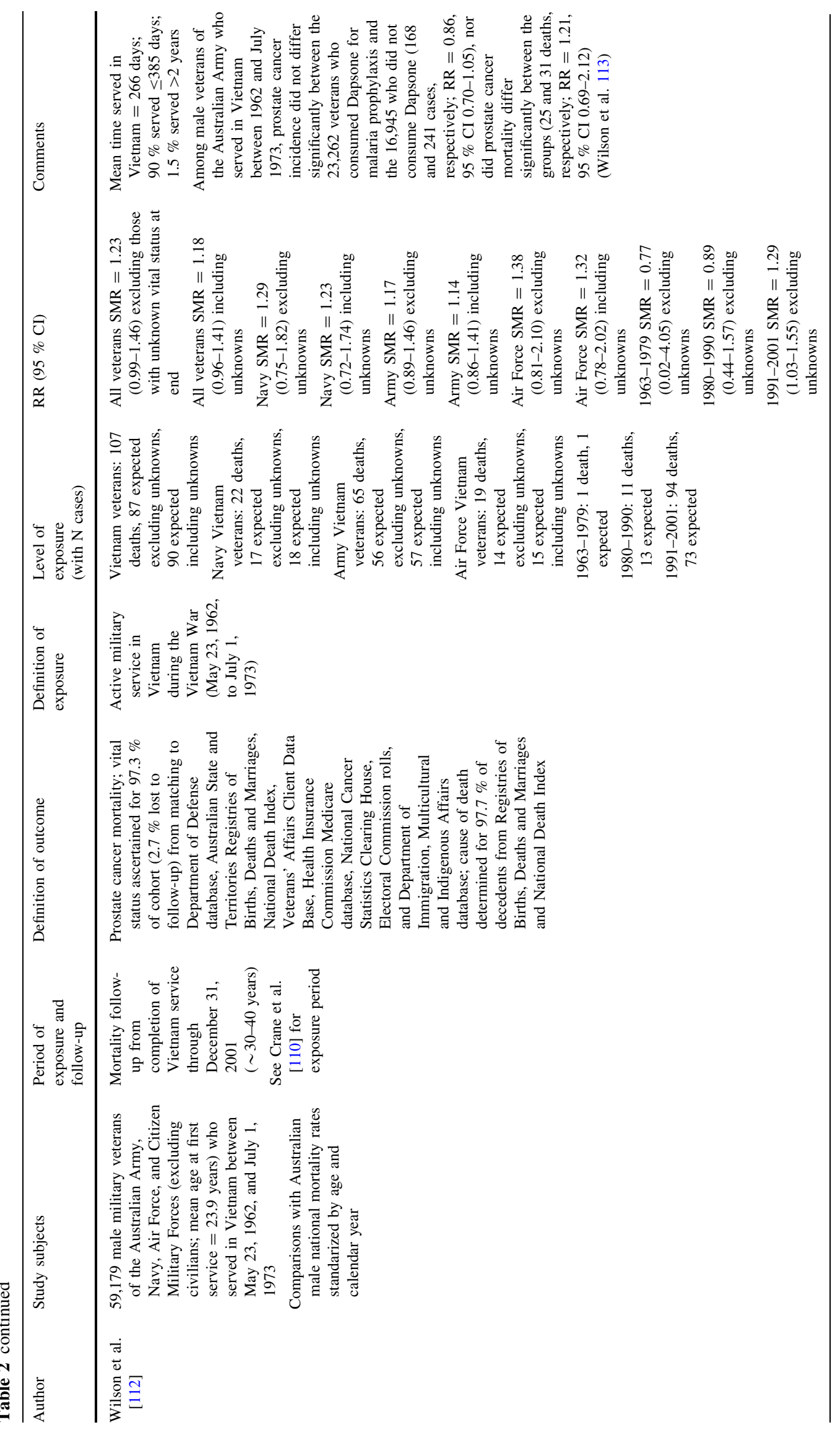




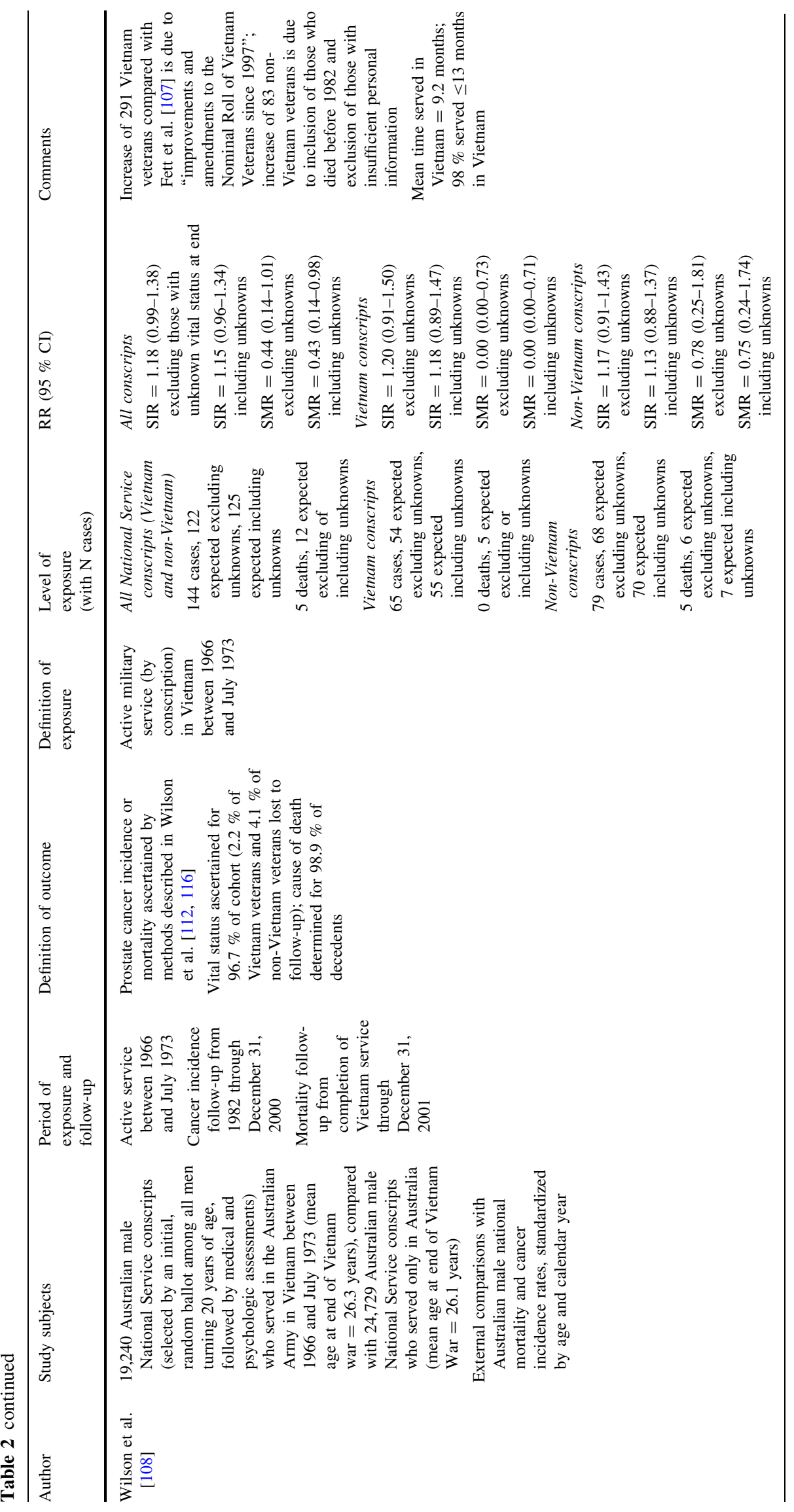




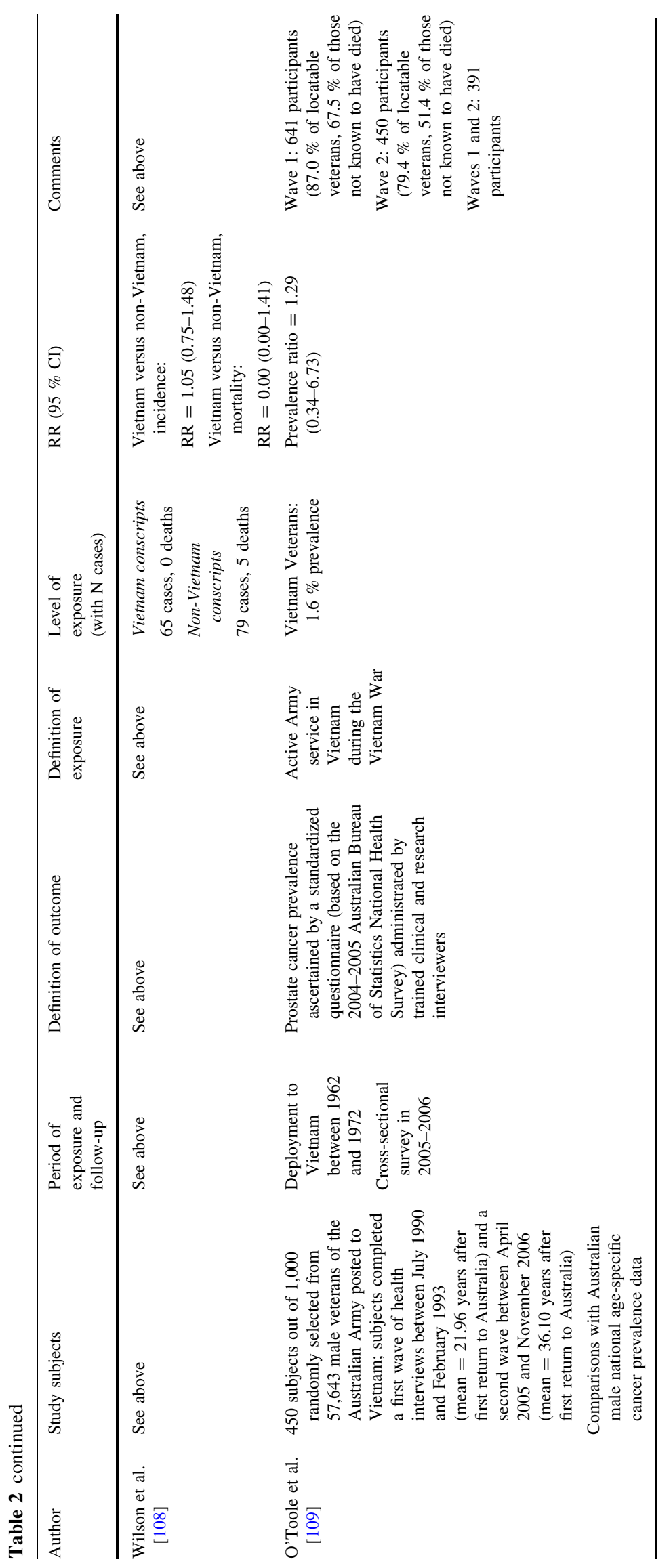




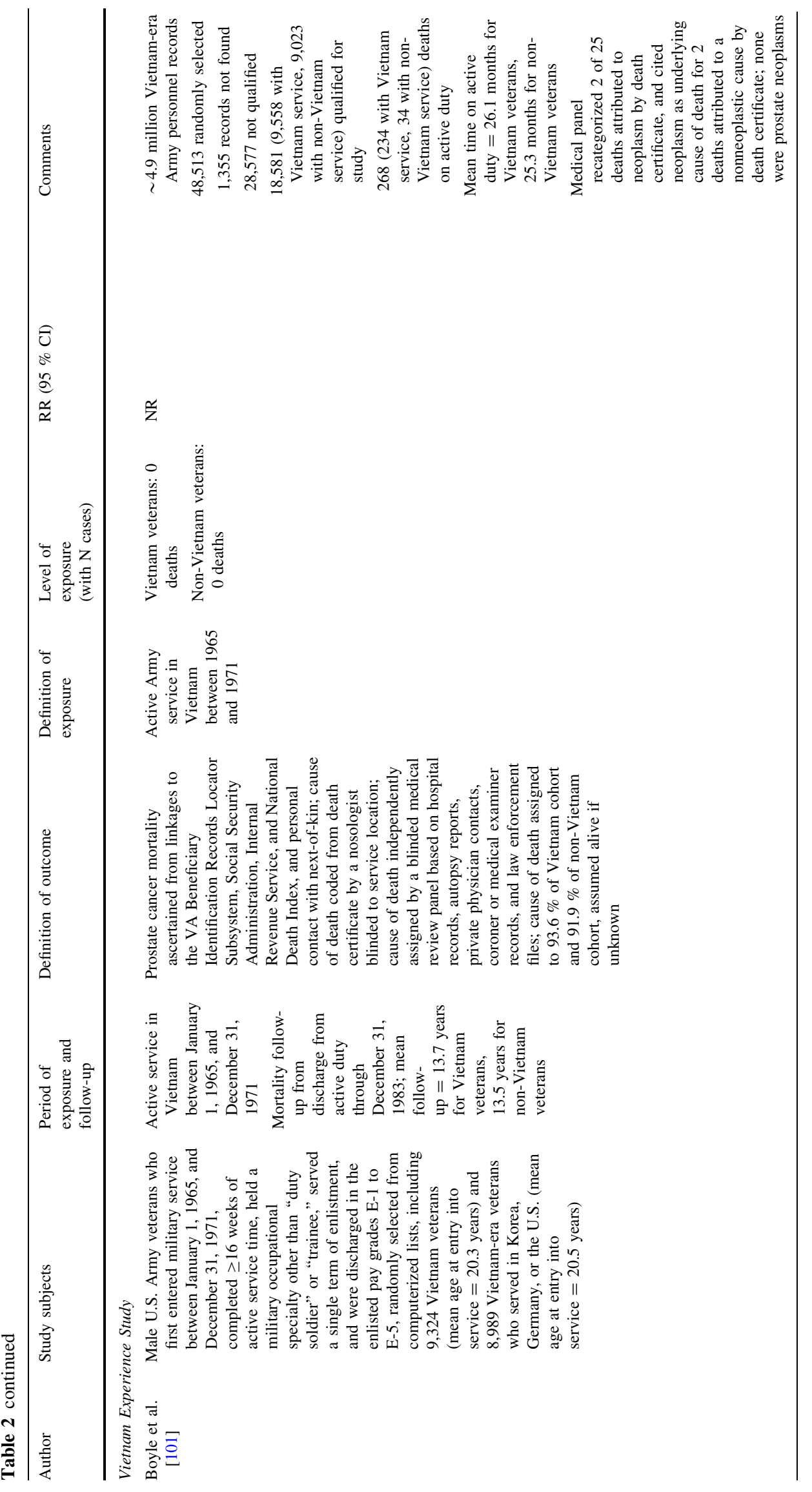




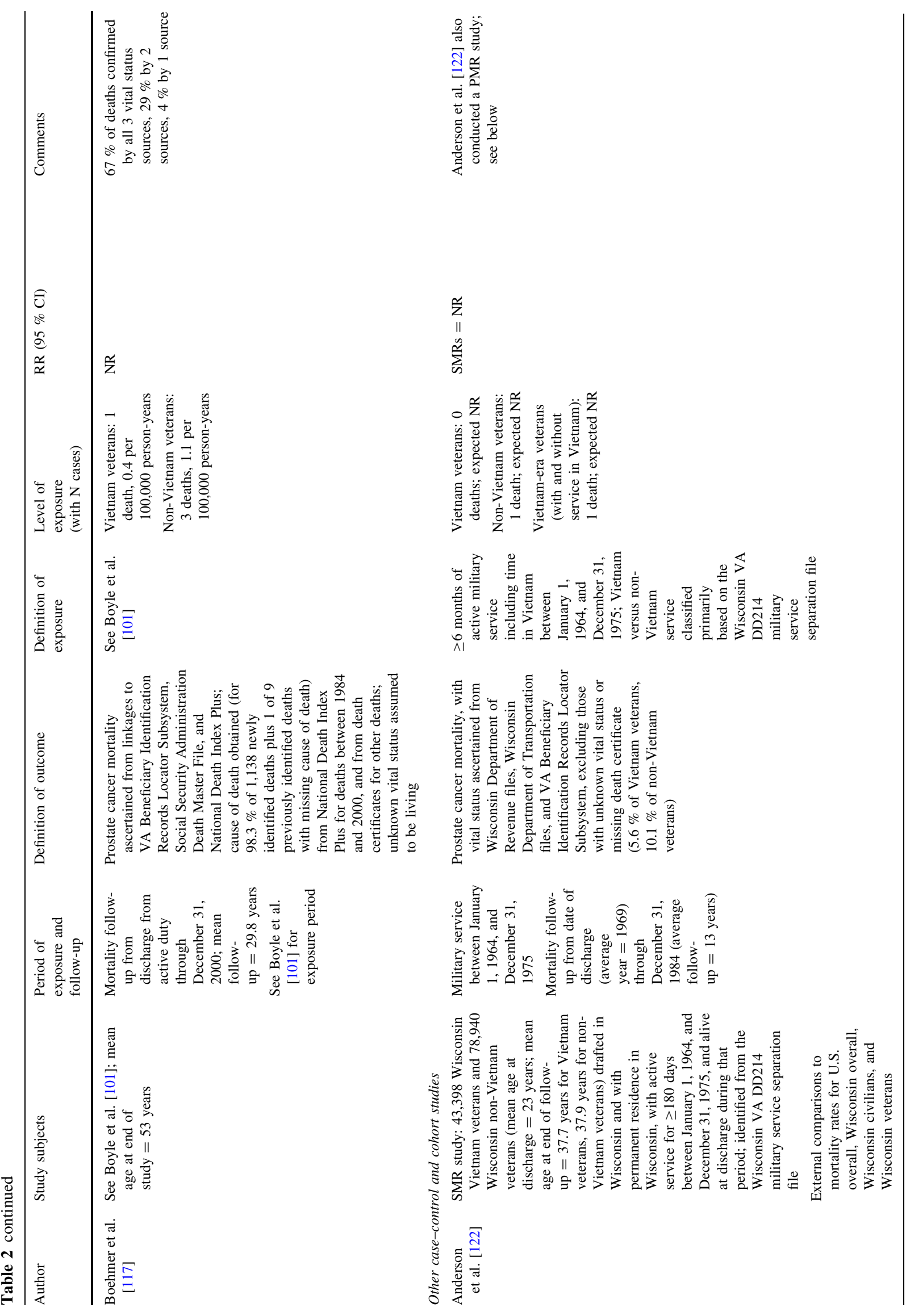




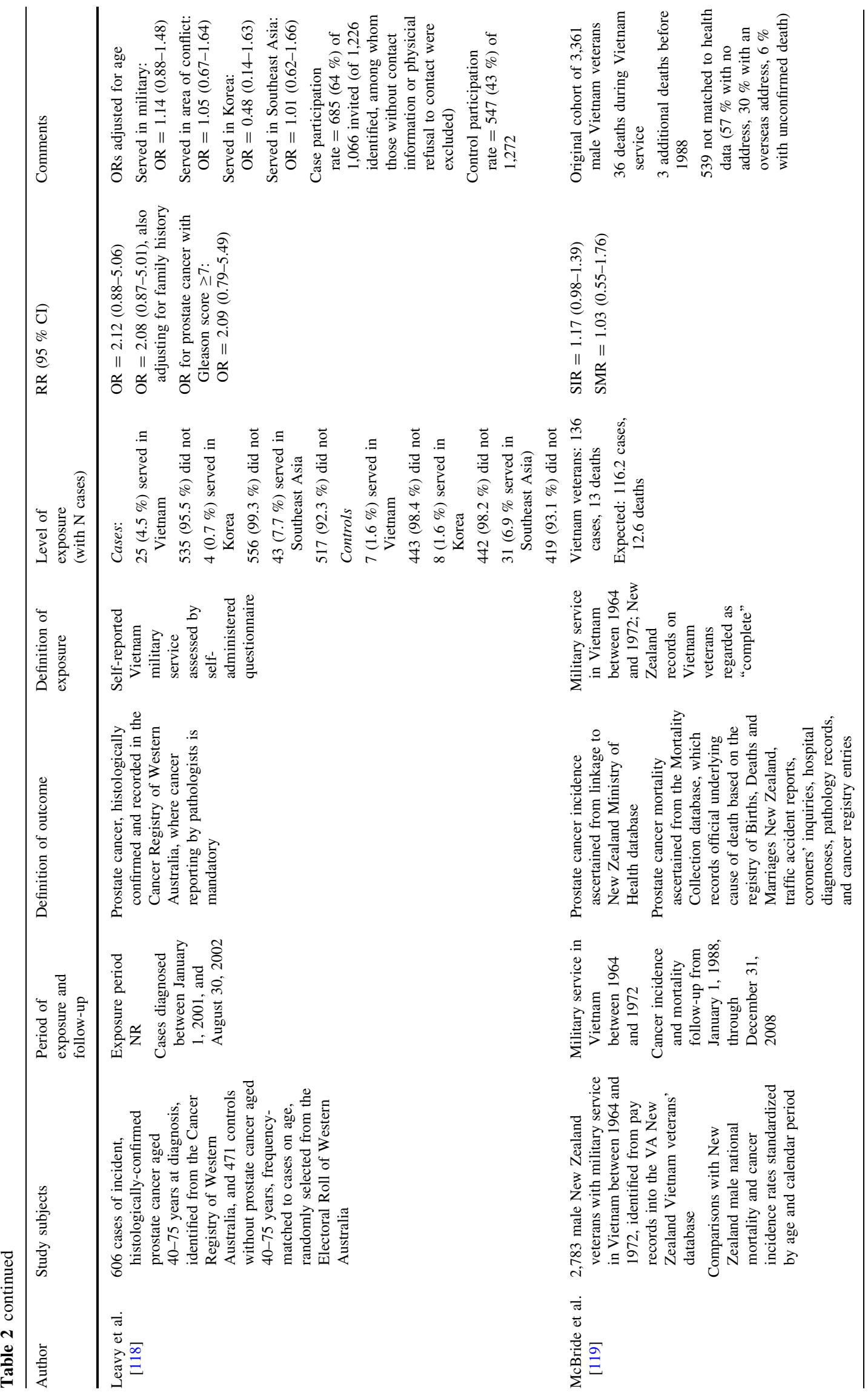




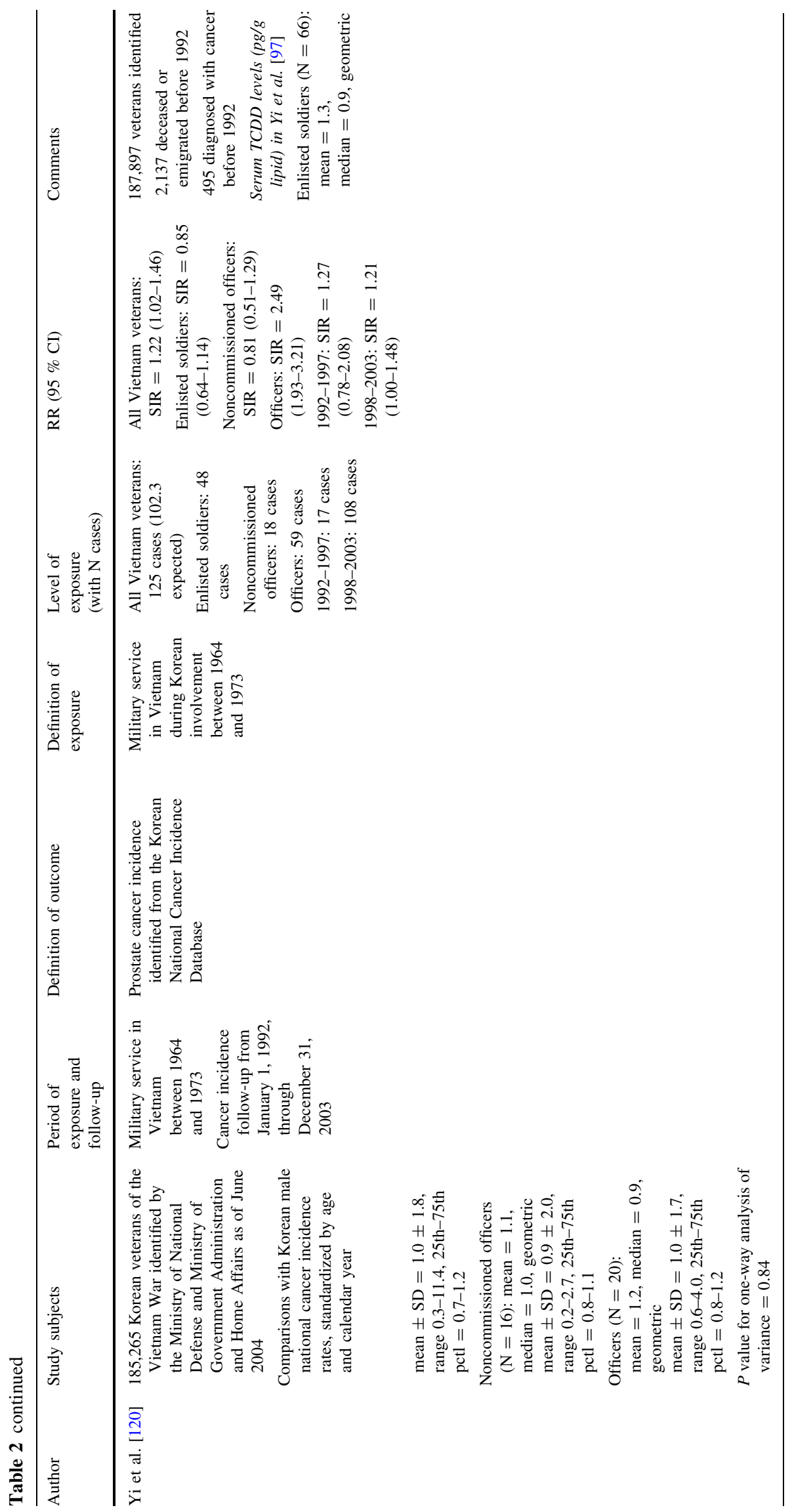




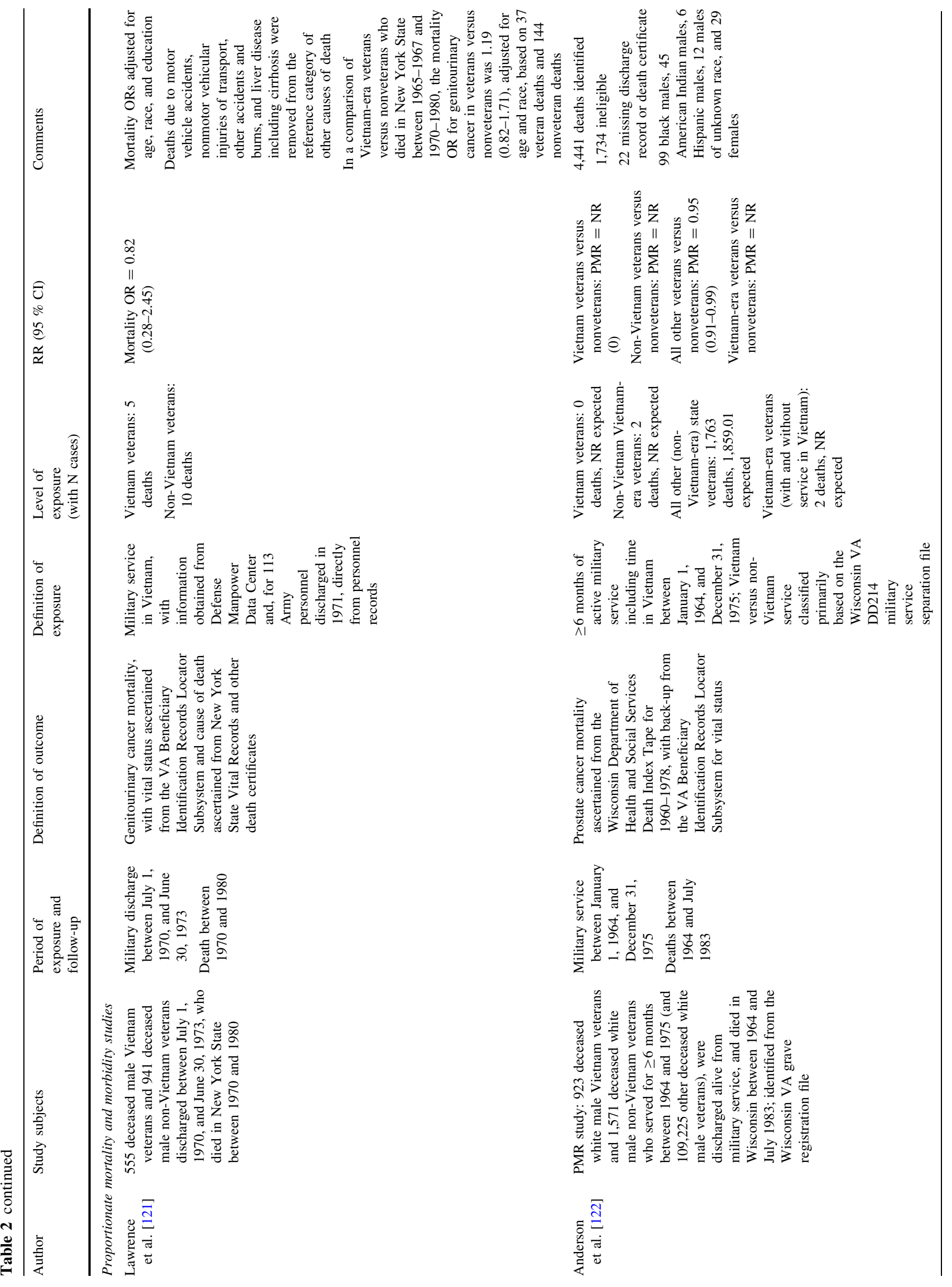




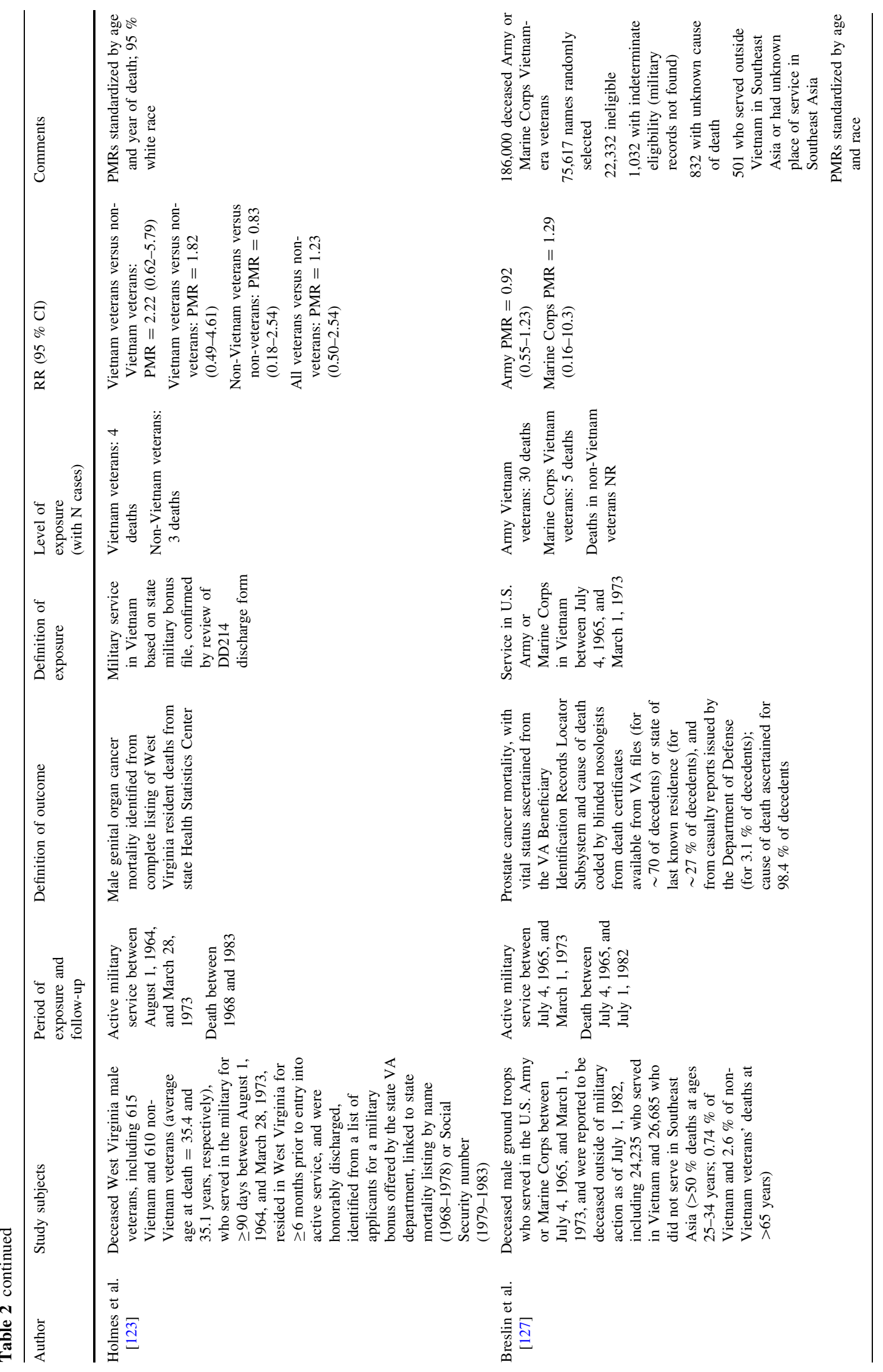




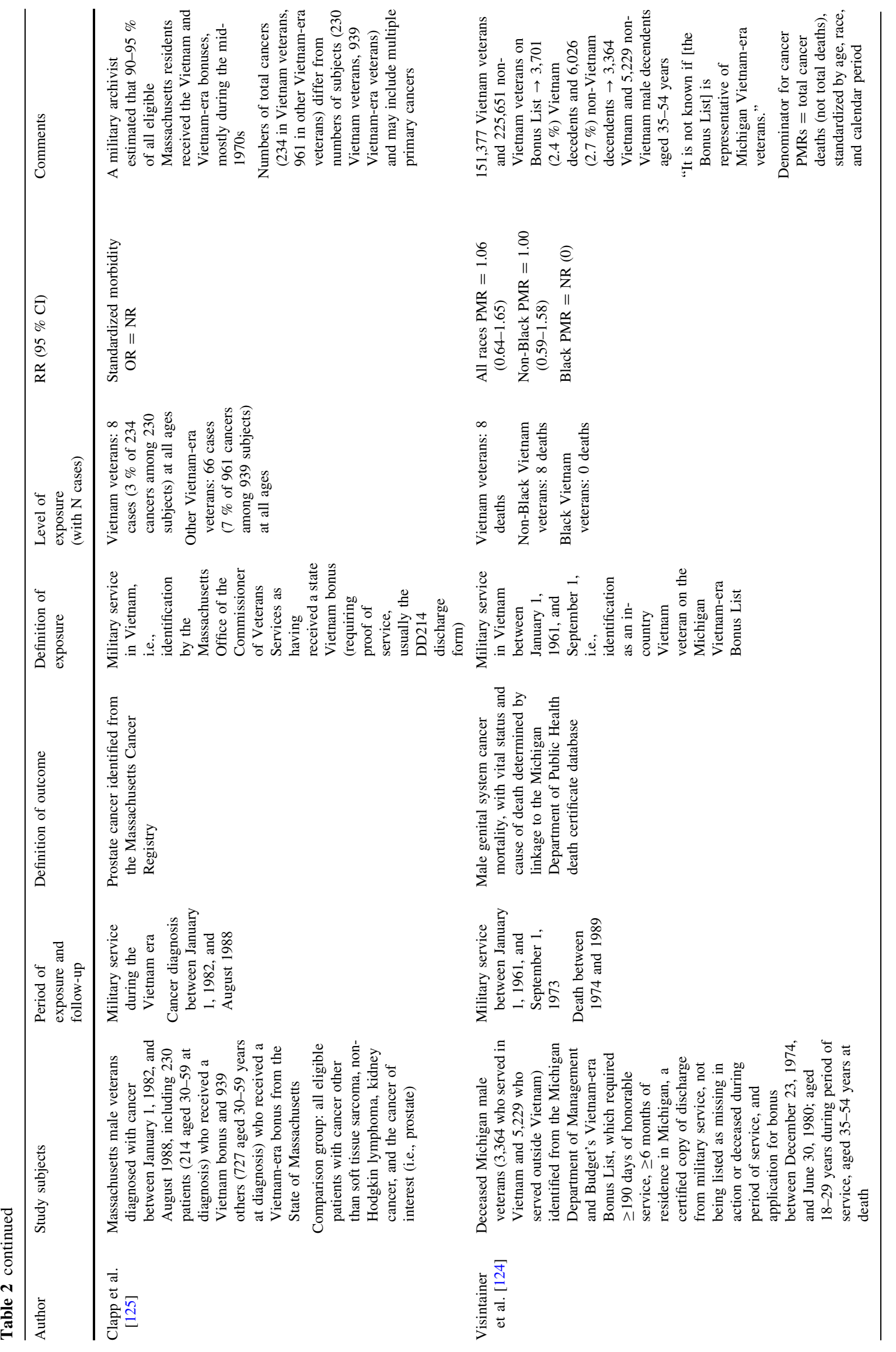




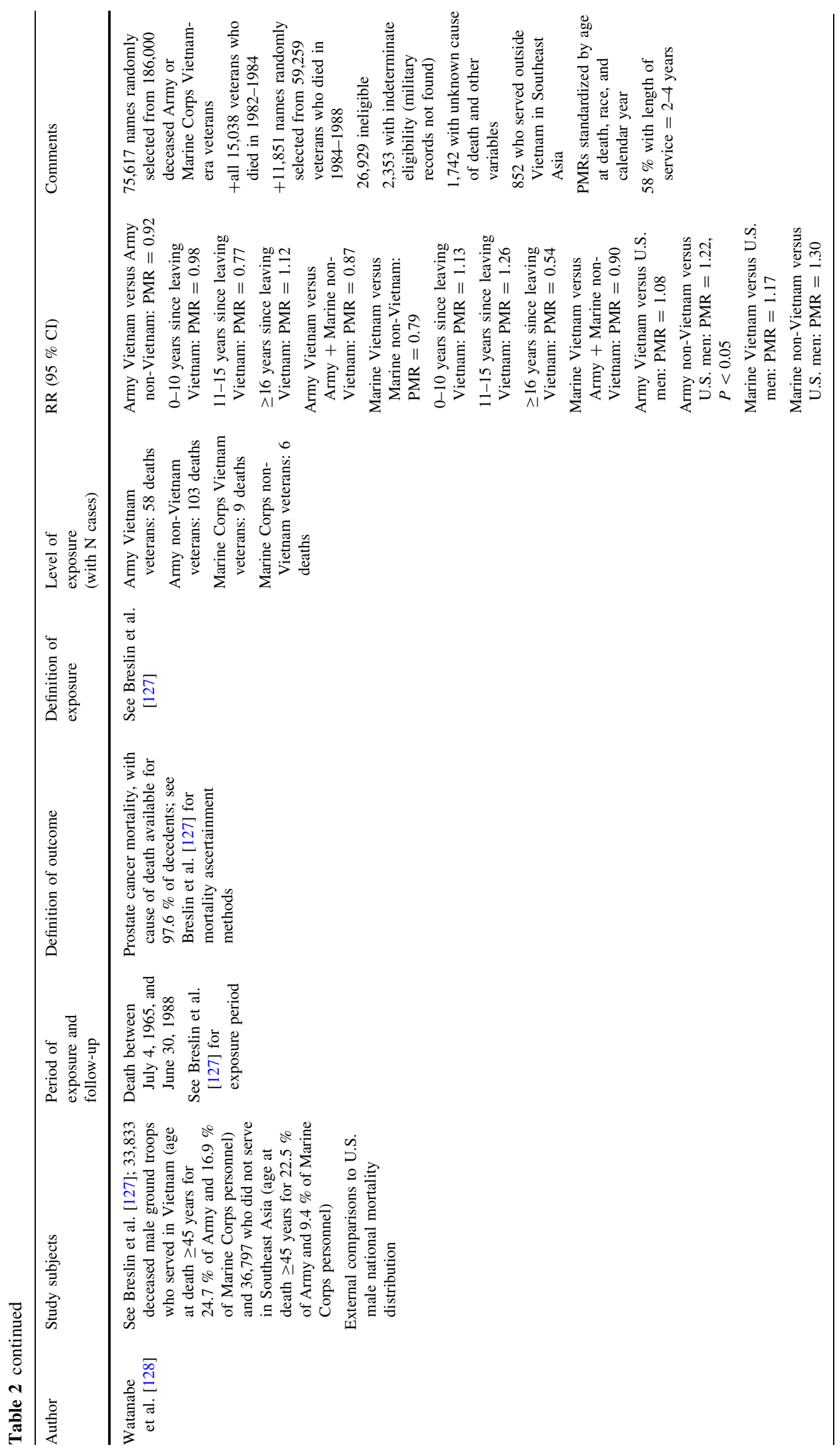




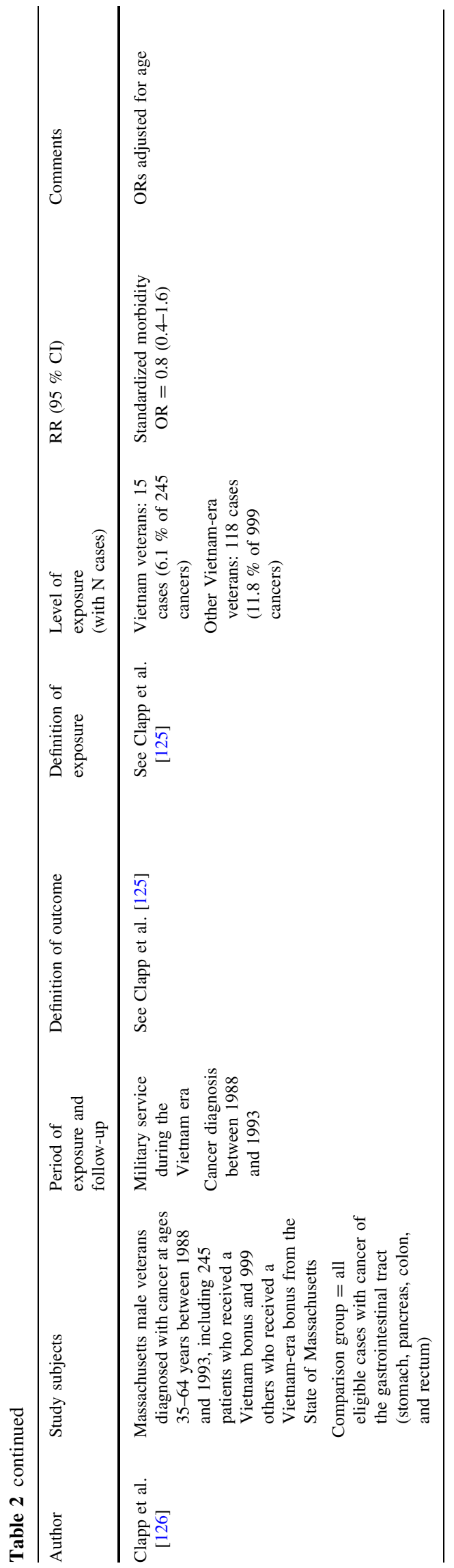

In a 1999 study, Ranch Hands were classified according to serum TCDD levels measured in 1987 (for most subjects) or 1992, extrapolated to the end of military service in Southeast Asia under the assumption of a constant half-life of 8.7 years, and categorized as "background" ( $\leq 10 \mathrm{ppt})$, "low" (10- $\leq 94$ ppt), or "high" ( $>94$ ppt) [64]. As of 1997, the adjusted odds ratio (OR) for prostate cancer in Ranch Hands versus comparison subjects (33 cases) was 0.4 $(0.1-0.8 ; 7$ cases) in those with background serum TCDD levels, $0.6(0.3-1.5 ; 8$ cases $)$ in those with low serum TCDD levels, and $0.7(0.2-2.2 ; 4$ cases $)$ in those with high serum TCDD levels, with no apparent dose-response trend $(P=0.41)$ (Table 1; Figure S1).

In a reanalysis of this dataset, Kayajanian [65] reclassified TCDD exposure according to a body burden model and-in a departure from the original study designcompared observed prostate cancer incidence in all Air Force Health Study participants (including Ranch Hands and comparison subjects) against expected counts based on U.S. national cancer incidence rates. Among white men, the standardized incidence ratio (SIR) was consistently elevated but did not change significantly with higher estimated TCDD body burden, whereas among black men, the SIR was elevated but decreased significantly with higher estimated TCDD body burden $(P<0.006,<0.004$, and $<0.002$ for various comparisons between higher and lower exposure categories) (Table 1; Figure S1).

The Air Force Health Study was not designed to compare Ranch Hands or comparison subjects with an external group outside of Southeast Asia because the objective of the study was "to determine the effects of exposure to TCDD and not of service in Southeast Asia" [66]. Nevertheless, in a 2004 study, the study investigators deviated from the original study design by comparing cancer incidence in Ranch Hands and comparison subjects with that expected in the U.S. general population [63]. Deviation from the original protocol is inappropriate if the a posteriori analysis is more likely to be biased and especially if it is conducted in an effort to detect significant results. In this case, due to greater health care access among veterans [68], comparisons of veterans with the general population were more susceptible to upward bias due to differences in diagnostic intensity than comparisons between Ranch Hands and designated comparison subjects. Bias due to a "healthy serviceman" effect is not a major concern, given the long latency period and advanced average age at onset of prostate cancer [69]. All results reported for prostate cancer in this study were for white men only.

Prostate cancer incidence as of 1999 was significantly higher than expected among both Ranch Hands (SIR $=1.46$ [1.04-2.00]; 36 cases) and comparison subjects (SIR $=1.62$ [1.23-2.10]; 54 cases), but no significant difference was detected between the SIRs for Ranch Hands 


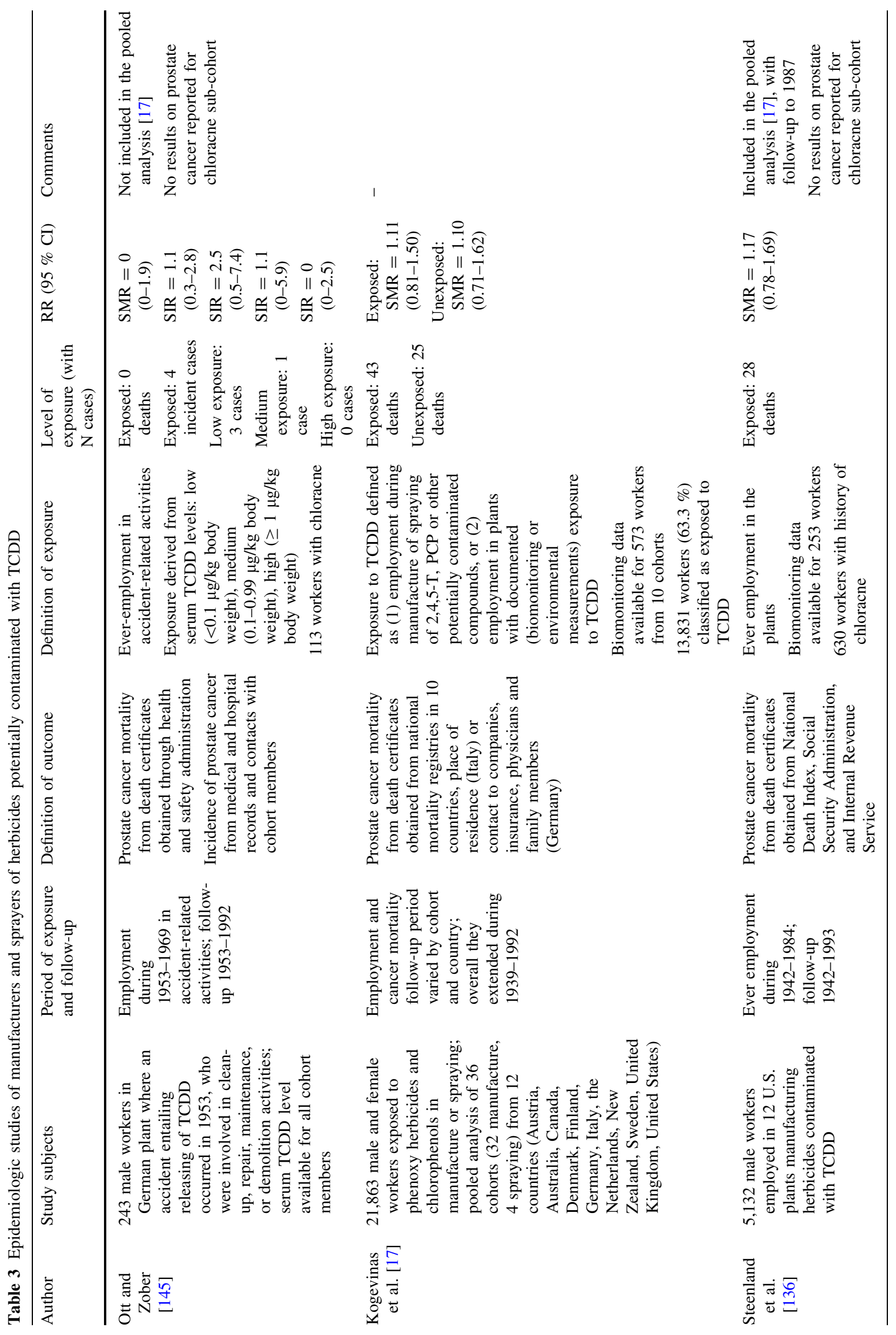




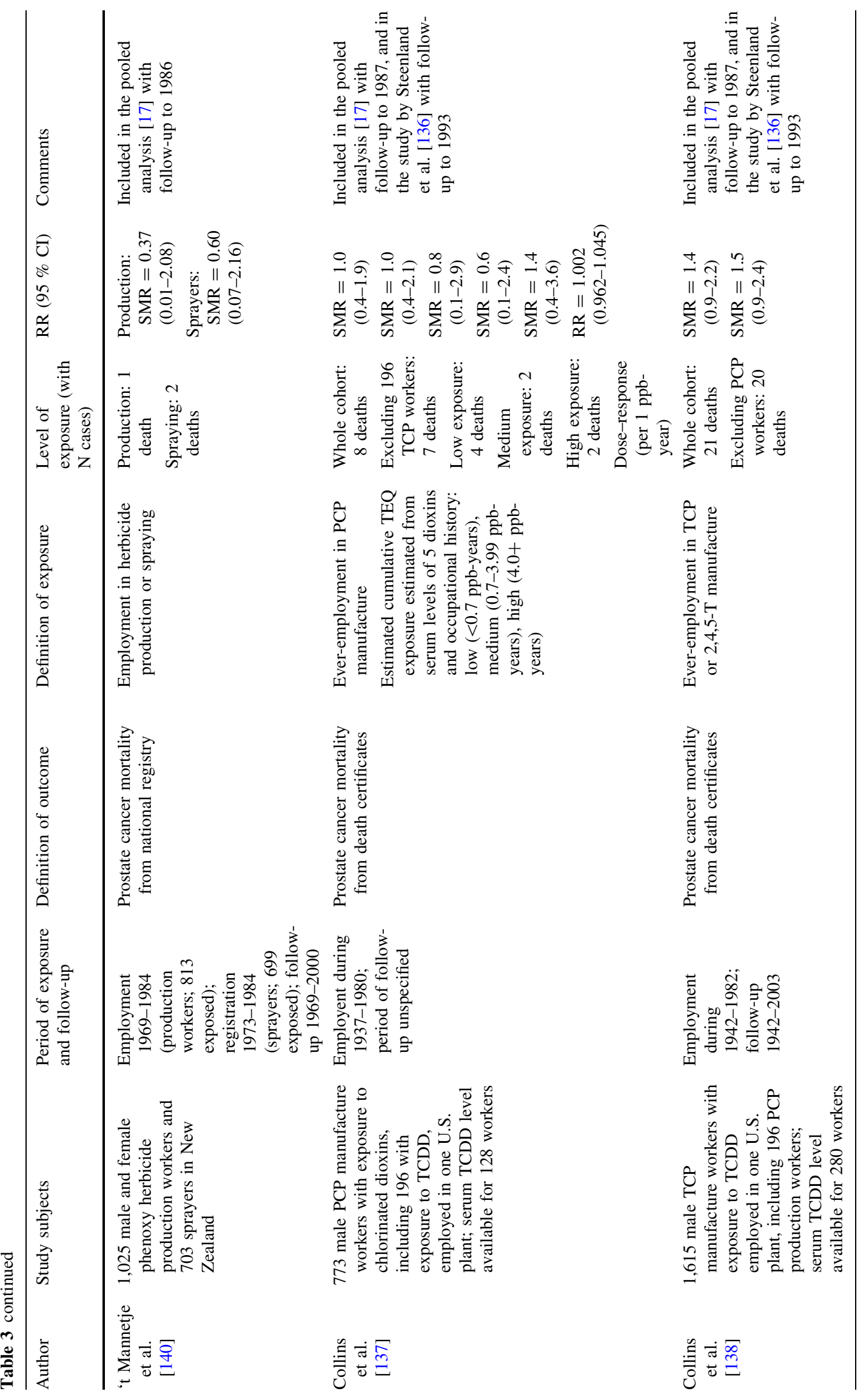




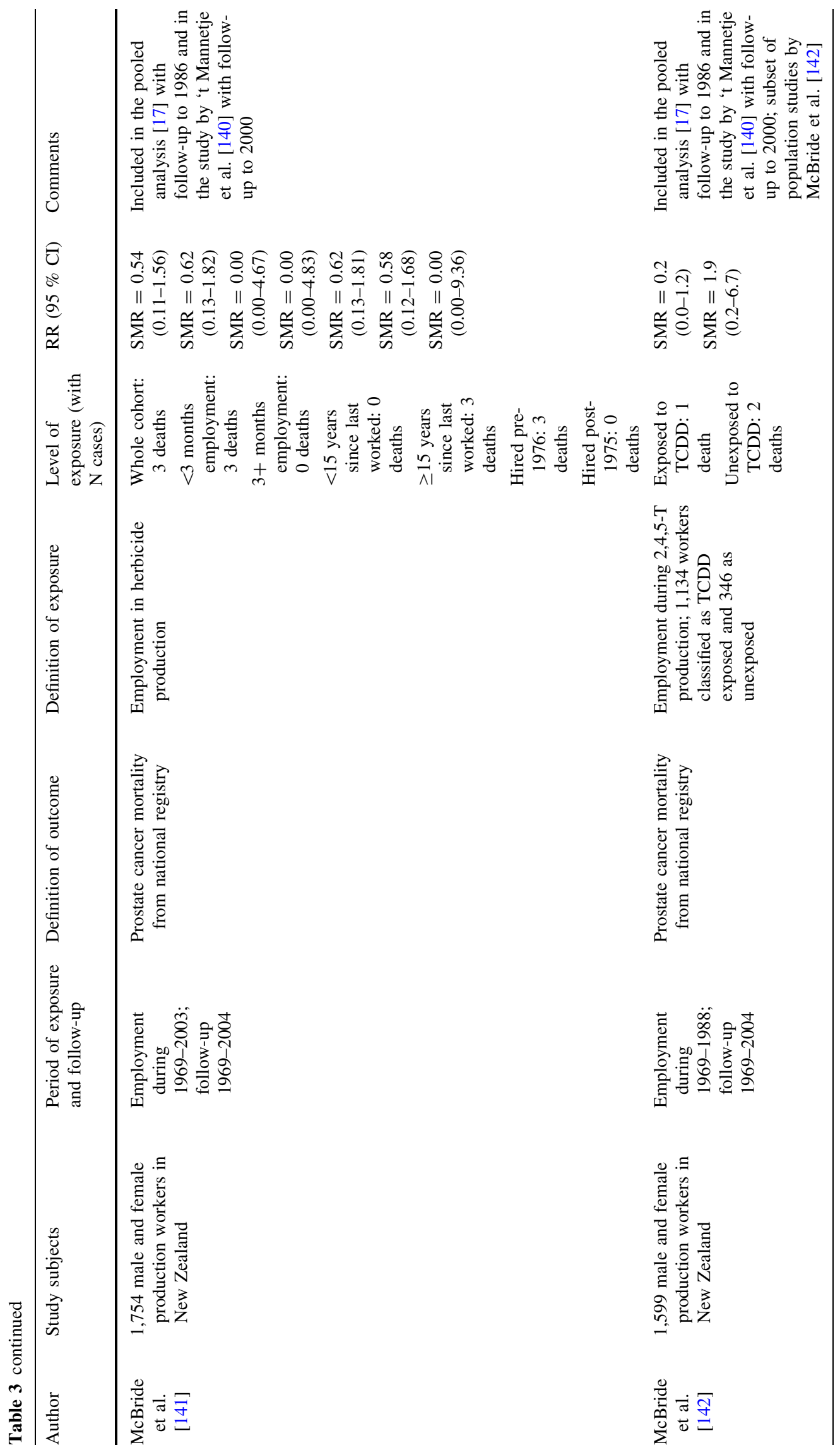




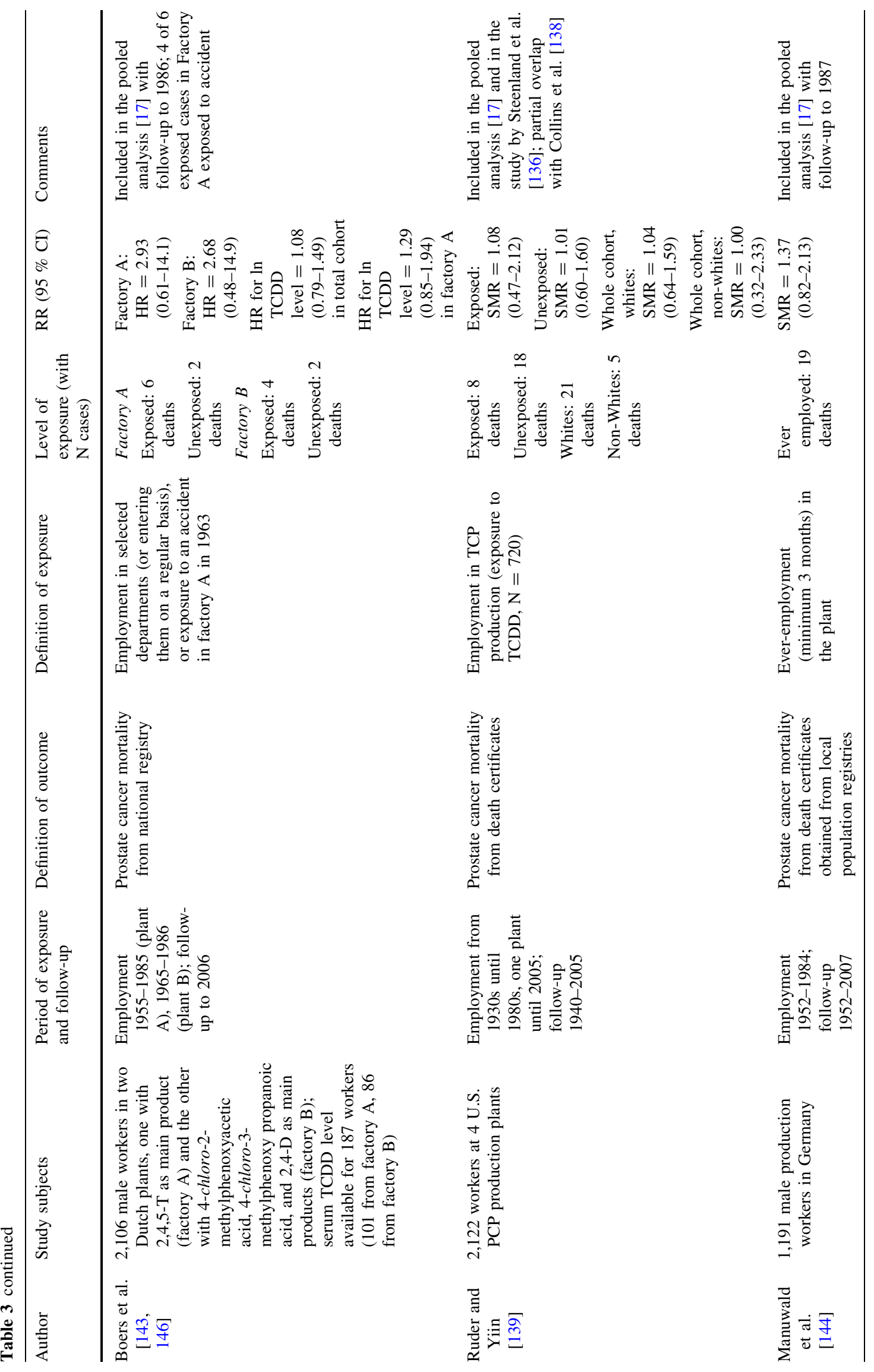




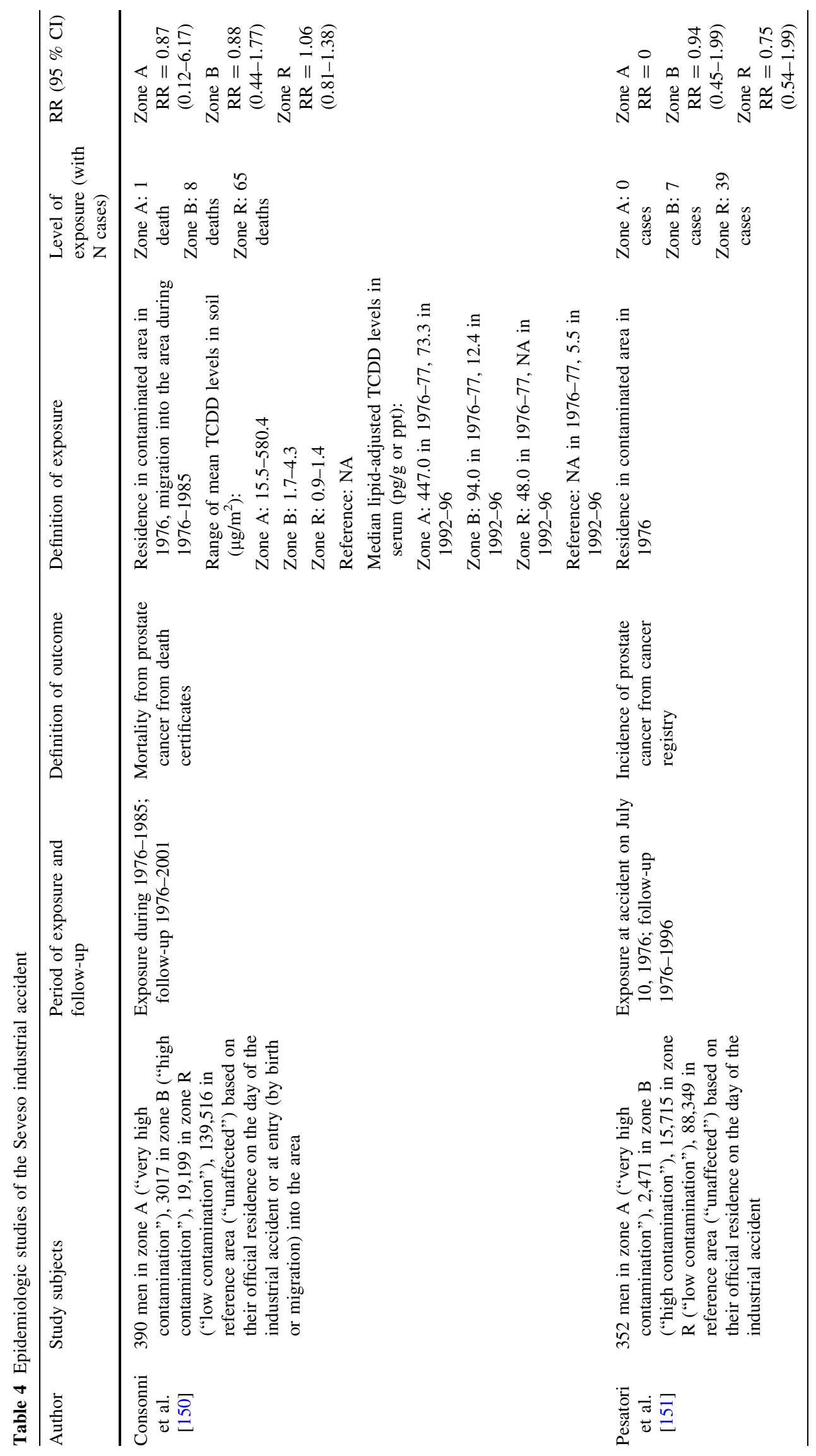


Table 5 Serum 2,3,7,8-tetrachlorodibenzo-p-dioxin levels in Air Force Health Study participants in 1987 (reproduced from Wolfe et al. [66])

\begin{tabular}{|c|c|c|c|c|c|c|}
\hline \multirow[t]{2}{*}{ Stratum } & \multicolumn{3}{|c|}{ Ranch Hands } & \multicolumn{3}{|c|}{ Comparison subjects } \\
\hline & $\mathrm{N}$ & Median (ppt) & Range (ppt) & $\mathrm{N}$ & Median (ppt) & Range (ppt) \\
\hline Flying officers (pilot) & 247 & 7.3 & $0.0-42.6$ & 239 & 4.7 & $0.0-18.5$ \\
\hline Flying officers (navigator) & 63 & 9.3 & $1.1-35.9$ & 53 & 4.5 & $2.2-7.9$ \\
\hline Nonflying officers & 19 & 6.6 & $3.1-24.9$ & 11 & 4.3 & $0.0-6.0$ \\
\hline Flying enlisted personnel & 152 & 17.2 & $0.0-195.5$ & 137 & 4.0 & $0.0-12.7$ \\
\hline Nonflying enlisted personnel & 407 & 23.6 & $0.0-617.7$ & 416 & 3.9 & $0.0-54.8$ \\
\hline All personnel & 888 & 12.4 & $0.0-617.7$ & 856 & 4.2 & $0.0-54.8$ \\
\hline
\end{tabular}

and comparison subjects $\left(P_{\text {heterogeneity }}=0.62\right)$ (Table 1 ; Figure S1) [63]. Prostate cancer mortality was not significantly increased above expectation in either study group; thus, the incidence finding was consistent with confounding by diagnostic intensity. Borderline significant differences in prostate cancer incidence between Ranch Hands and comparison subjects were detected only in subgroup analyses that compared Ranch Hands who spent $100 \%$ of their Southeast Asia service in Vietnam $(\mathrm{SIR}=1.66$ [1.00-2.60]) with comparison subjects who spent $0 \%$ of their Southeast Asia service in Vietnam $(\mathrm{SIR}=0.59$ $\left.[0.15-1.61] ; P_{\text {heterogeneity }}=0.08\right)$, or that were restricted to veterans who spent a maximum of 2 years in Southeast Asia (SIR for Ranch Hands = 1.54 [0.98-2.32]; SIR for comparison subjects $\left.=0.68 ; \quad P_{\text {heterogeneity }}=0.05\right)$. The former association may have been influenced by differences in diagnostic intensity if health care usage was greater among Vietnam than non-Vietnam veterans, as suggested by some data [70]. Again, this comparison marked a departure from the original Air Force Health Study design and was more likely to be confounded than contrasts between Ranch Hands and the original comparison subjects. The latter association, which was based on $68 \%$ of Ranch Hands and $47 \%$ of comparison subjects, could have been due to selection bias resulting from conditioning on a characteristic [71]—-shorter duration of military service - that was more frequent among Ranch Hands and that could have been associated with greater health care usage if, for example, servicemen served for a shorter time due to health problems requiring medical attention. The finding of a positive association restricted to this subgroup is also counterintuitive, since shorter duration of service among Ranch Hands should have decreased cumulative Agent Orange exposure.

In internal cohort analyses, serum TCDD levels were extrapolated to the end of service in Vietnam assuming a constant half-life of 7.6 years, and categorized as "background" ( $\leq 10 \mathrm{ppt})$, "low" ( $>10-\leq 118.5 \mathrm{ppt})$, or "high" ( $>118.5 \mathrm{ppt}$ ) [63]. After restriction to veterans who spent at most two years in Southeast Asia, the adjusted RR of prostate cancer in Ranch Hands versus comparison subjects increased with higher serum TCDD levels and was significantly elevated for those with high serum TCDD $(\mathrm{RR}=6.04$ [1.48-24.61]; 5 cases) (Table 1). However, log-transformed serum TCDD level itself was not significantly associated with prostate cancer risk in this subgroup $(\mathrm{RR}=1.48$ [0.93-2.35]). In another analysis restricted to Ranch Hands who spent $100 \%$ of their Southeast Asia service in Vietnam versus comparison subjects who spent $0 \%$ of their Southeast Asia service in Vietnam, the RR for high serum TCDD was 4.67 (0.75-29.07; 4 cases), with an RR of 1.07 (0.64-1.78) per unit increase in log-transformed serum TCDD level.

The authors noted that 53 of the 90 prostate cancer cases (25 of 36 [69\%] among Ranch Hands and 28 of 54 [52\%] among comparison subjects) were "diagnosed as a direct result of the examinations" scheduled for the study, and that "these data are consistent with the hypothesis that the increased SIR for ... prostate cancer might be at least partially explained by the medical examinations that these men received" [63]. These case numbers were sufficient to account for the excess prostate cancer incidence observed among Ranch Hands versus the general population (36 cases observed vs. 24.71 expected) and among comparison subjects versus the general population (54 cases observed vs. 33.34 expected). The results of the internal analyses in selected subgroups were potentially biased and difficult to interpret due to the reasons described above. Due to insufficient information, it is unclear whether discrepancies in prostate cancer detection by the physical examination were sufficient to account for the observed differences between subgroups.

Pavuk et al. [72] undertook an analysis of serum TCDD levels measured in 1987 (mostly), 1992, or 1997 and cancer risk among the comparison subjects only, and found no significant association between serum TCDD quartile and prostate cancer incidence, with no apparent doseresponse trend $(P=0.72$ ) (Table 1 ; Figure $\mathrm{S} 1)$. However, risk of prostate cancer increased with longer duration of military service in Southeast Asia, with significant excesses 
among those who served for $2.1-3.7$ years $(R R=2.2$ $[1.0-4.9] ; \quad 28$ cases) or $3.7-16.4$ years $\quad(R R=2.4$ [1.1-5.2]; 36 cases) versus $0.8-1.3$ years (8 cases; $\left.P_{\text {trend }}=0.003\right)$. These findings suggest that exposures in Southeast Asia other than Agent Orange, or factors associated with longer duration of military service, may be responsible for observed associations with prostate cancer. The correlation between serum TCDD levels and time served in Southeast Asia was not reported, but it appeared to be modest, based on a table showing quartiles of serum TCDD by quartiles of years in Southeast Asia.

Finally, in the most recent analysis of prostate cancer incidence in the Air Force Health Study, estimated 20-year cumulative TCDD level was not significantly associated with prostate cancer risk [73]. The adjusted RR for low cumulative TCDD in Ranch Hands (dichotomized at the median of 443 ppt-years) versus comparison subjects was $1.02(0.67-1.55 ; 31$ cases), and that for high cumulative TCDD in Ranch Hands was $1.22(0.79-1.89 ; 28$ cases $)$ $\left(P_{\text {trend }}=0.42\right)($ Table 1 ; Figure S1). A positive association was detected among those who completed their last tour of duty in Southeast Asia before 1969 (RR for high cumulative TCDD $=2.27[1.11-4.66] ; 15$ cases; $\left.P_{\text {trend }}=0.04\right)$ and among those who served for less than two years (RR for high cumulative $\quad$ TCDD $=2.15 \quad[1.03-4.48] ; \quad 14$ cases; $\left.P_{\text {trend }}=0.03\right)$. When Ranch Hands and comparison subjects were analyzed separately, high versus low cumulative TCDD was not significantly associated with prostate cancer risk in either group. Time served in Southeast Asia and last year of duty also were not significantly associated with prostate cancer risk among Ranch Hands, but longer time served in Southeast Asia (dichotomized at 789 days) was significantly associated with increased risk among comparison subjects ( $\mathrm{RR}=2.18$ [1.27-3.76]; 63 cases). Of note, the distribution of Gleason score (disease grade indicating likelihood of tumor spread) did not differ significantly between the 62 Ranch Hand prostate cancer cases and the 89 comparison subject cases $(P=0.44)$. This finding suggests that the two groups were equally affected by the detection of low-grade disease by means of PSA testing.

Taken together, results from the Air Force Health Study demonstrate no clear association between TCDD exposure and prostate cancer risk. The higher risk in both Ranch Hands and comparison subjects relative to the U.S. general population, combined with the lack of a difference between Ranch Hands and comparison subjects, as well as the absence of a significant difference in prostate cancer mortality between study subjects and the general population, suggests that increased prostate cancer screening among study participants compared with the general population may be responsible for much or all of the observed excess incidence. The positive associations within certain subgroups selected based on shorter duration of military service or geographic location exclusively in or outside of Vietnam were not well justified in advance, and were potentially biased or due to chance if numerous subgroups were tested.

Methodological strengths and limitations of the Air Force Health Study have been thoroughly discussed (e.g., [23, 32, 76-81]). Overall, exposure assessment is a major strength of this study. The Air Force Health Study is the only study of Vietnam veterans to have obtained serum TCDD measurements for all subjects included in doseresponse analyses, thereby enabling identification of the most highly-exposed subjects. These measurements demonstrated that Ranch Hands were sufficiently exposed to TCDD that serum levels were detectable more than 15 years after their last service in Vietnam. Moreover, their TCDD levels exceeded those among U.S. Army Chemical Corps veterans (discussed below) and U.S. Army ground combat troops who served in heavily sprayed areas of Vietnam (among whom serum TCDD levels were indistinguishable from troops with no service in Vietnam or even the general public [82]). Although the estimates of past TCDD exposure could have been based on some incorrect assumptions, the substantial difference in average serum TCDD concentrations between Ranch Hands and comparison subjects indicates that the impact on estimated associations was probably modest. Thus, the persistently elevated serum TCDD levels in the majority of Ranch Hands make this group the primary bellwether for the health effects of Agent Orange/TCDD.

Another key strength of this study is the inclusion of a comparison group of veterans matched on age, race, rank, and military occupation and controlling for military service involving aircraft missions in Southeast Asia, thereby making the groups equivalent in terms of "combat-induced physiologic, psychophysiologic, and other related morbidity and mortality disorders," as well as "the effects of alcohol consumption, the use of chemoprophylactic and/or illicit drugs, and the acquisition of tropical diseases associated with life in [Southeast Asia]" [83]. Notably, this strength was nullified in external comparisons of Ranch Hands with the general population, as conducted by Akhtar et al. [63]. With the exception of those analyses, given the unique advantages of the Air Force Health Study, its results provide compelling evidence against a strong causal relationship between Agent Orange/TCDD and prostate cancer, although the number of cases may be insufficient to detect statistically significant differences in the range of RRs and SIRs reported.

\section{Army Chemical Corps study}

Members of 22 U.S. Army Chemical Corps units assigned to South Vietnam between 1966 and 1971 were responsible for the storage, handling, mixing, application, and equipment maintenance of tear gas, burning agents, and herbicides, 
including Agent Orange [84]. Due to these job responsibilities, Army Chemical Corps personnel in Vietnam were assumed to have had, on average, much higher levels of Agent Orange exposure than other veterans (excluding Ranch Hands). Among Army Chemical Corps veterans, serum TCDD levels were highest in those who were stationed in Vietnam and reported having sprayed herbicides (mean $=4.3$ ppt lipid-corrected, range 0.5-85.8), followed by herbicide sprayers not stationed in Vietnam (3.1, 0.8-9.6), non-sprayers stationed in Vietnam (2.70, $0.6-27.7)$, and non-sprayers not stationed in Vietnam (2.1, 0.4-12.5) [85]. Levels of six other dioxin congeners did not differ significantly between Vietnam sprayers and nonVietnam non-sprayers [86]. In an initial cohort of 894 Army Chemical Corps members assigned to Vietnam, no prostate cancer deaths had occurred as of the end of 1987 (expected number of deaths not stated, but probably near zero), and no incident prostate cancers were identified from the U.S. Department of Veterans Affairs (VA) Agent Orange Registry (which collects information on veterans who claim Agent Orange exposure and undergo a special physical examination at a VA medical center) as of 1988 or VA inpatient discharges as of 1986 [83].

Subsequently the cohort was expanded to include 2,872 male U.S. Army veterans with at least one assignment to the Chemical Corps in Vietnam, and a comparison group of 2,737 male U.S. Army veterans last discharged from the Chemical Corps but never assigned to Southeast Asia [87]. Through 2005, five deaths from prostate cancer had occurred in Vietnam Chemical Corps members versus two in comparison subjects, resulting in an adjusted RR of 1.02 (0.19-5.64) (Table 1; Figure S1). Compared with the general U.S. population, the SMR for prostate cancer was 1.05 (0.34-2.45) among Chemical Corps members who served in Vietnam and 0.95 (0.12-3.43) among those who served outside Southeast Asia.

Despite its small size and lack of quantitative exposure estimates in Vietnam Chemical Corps members, this study is strengthened by its focus on Vietnam veterans with known military exposure to herbicides, its long and highly complete follow-up, and its use of a comparable group of veterans without military service in Southeast Asia (and, consequently, little chance of exposure to Agent Orange). Due to high survival rates, prostate cancer mortality is not a close proxy for incidence, but associations with prostate cancer mortality are less susceptible to diagnostic bias. Overall, these findings suggest little to no excess of prostate cancer mortality in Army Chemical Corps veterans who served in Vietnam, relative to their peers and U.S. males in general.

\section{Other studies}

Other epidemiological studies of prostate cancer have relied in part on self-reported exposure to Agent Orange, which has been shown not to be a valid indicator of serum TCDD levels [81]. Many of these studies also used the VA's presumptive definition of Agent Orange exposure, which classifies veterans as exposed if they served for any length of time in Vietnam (including brief visits ashore and service on inland waterways) between January 9, 1962, and May 7, 1975, or in or near the Korean demilitarized zone anytime between April 1, 1968, and August 31, 1971 [88]. This definition of exposure is inconsistent with considerable evidence that ground troops in Vietnam were not appreciably exposed to Agent Orange [89]. Therefore, a major concern in such studies is exposure misclassification, which may differ between prostate cancer cases and noncases if cases are more likely to report past exposure or to undergo a VA Agent Orange Registry health exam, or if veterans designated as exposed are more likely to undergo prostate cancer screening and/or diagnostic work-up. Importantly, such misclassification should not be assumed to be non-differential, and even exactly non-differential misclassification can often lead to overestimated RRs [90, 91]. Overall, given the unreliability of self-reported and geography-based Agent Orange exposure, the results of these studies cannot be interpreted as valid estimates of the association between Agent Orange/TCDD exposure and prostate cancer risk.

Of 400 consecutive veterans referred for prostate needle biopsy at the Palo Alto, California, VA medical center in 1998-2000, 32 (8 \%) self-reported on a standard registration questionnaire that they had been exposed to Agent Orange [5]. The 32 exposed patients were age-matched to a comparison group of 96 unexposed subjects selected from the remaining 368 veterans who did not report Agent Orange exposure, and prostate cancer incidence and related characteristics were compared between the groups. Military service in Vietnam was not required for eligibility. No significant difference was detected in the proportion of exposed patients (40.4\%) versus unexposed patients (34.6\%) who were subsequently diagnosed with prostate cancer $(P=0.15)$, nor did the proportion of cases with Gleason score $\geq 7$ differ significantly by exposure status (Table 1). Mean PSA levels, overall frequency of referral for prostate biopsy, and mean length of cancer in biopsy also did not vary between the exposed and unexposed groups, whereas exposed patients were, on average, 5 years younger at referral for prostate biopsy than the overall group of 400 referred patients $(P=0.01)$, suggesting potential differences in diagnostic intensity by exposure status. On the other hand, authors reported that an average of $1.07 \%$ of exposed patients at their facility were referred annually for prostate biopsy, compared with $1.33 \%$ of unexposed patients, potentially resulting in modest underestimation of the association due to diagnostic bias. Probable exposure misclassification could have biased estimates 
in either direction, and the number of subjects was modest. Overall, this study provides no support for an increased risk of overall or high-grade prostate cancer in veterans who self-report exposure to Agent Orange.

In a VA hospital-based case-control study set in Ann Arbor, Michigan, investigators compared self-reported Agent Orange exposure, as recorded in the computerized medical record, between 47 prostate cancer cases diagnosed in 2000-2001 and born between 1935 and 1953 (to "encompass men who were the appropriate age for potential military service in Vietnam") and 142 age-matched controls selected randomly from the hospital's general medicine clinic [92]. The proportion of cases (29.8\%) and controls $(34.5 \%)$ who reported military service in Vietnam did not differ significantly. However, the proportion who reported Agent Orange exposure was nonsignificantly higher among cases $(23.4 \%)$ than controls $(12.0 \%) \quad$ (adjusted $\mathrm{OR}=2.06 \quad[0.81-5.23]) \quad$ (Table 1; Figure S1). The proportion of non-Vietnam veterans who reported Agent Orange exposure was not stated. Mean age at diagnosis, Gleason score, and pathologic stage did not differ significantly between prostate cancer cases with and without Agent Orange exposure. Whether Agent Orange exposure was self-reported before or after prostate cancer diagnosis was unknown, raising the possibility of differential exposure misclassification due to recall bias. The authors also raised the possibility of selection bias due to exclusion of subjects with missing data, and noted the small number of subjects. Thus, this methodologically weak study offers no reliable evidence of any association between self-reported Agent Orange exposure and prostate cancer risk in veterans.

Another VA study based in northern California evaluated prostate cancer incidence ascertained from electronic medical records between 1998 and 2006 among 6,214 Vietnam veterans who were classified as exposed to Agent Orange (239 cases) and 6,930 Vietnam veterans classified as unexposed (124 cases) [34]. Exposure status was based on self-reported Agent Orange exposure on the initial application for medical benefits and having been stationed in "known areas that were sprayed with Agent Orange during 1962 through 1971" (i.e., 27-36 years prior to case ascertainment). The definition of "known areas" was not further elaborated, making it unclear whether, for example, the entire country of Vietnam was considered to be an area sprayed with Agent Orange. Seven veterans who initially claimed no exposure to Agent Orange but changed their self-reported exposure status after developing prostate cancer were excluded, whereas 38 patients who first reported Agent Orange exposure after prostate cancer diagnosis were retained in the analysis; the remaining 231 cases who reported Agent Orange exposure apparently did so before prostate cancer diagnosis. The timing of exposure ascertainment relative to prostate cancer diagnosis or study entry was unclear for the remaining study subjects.

The frequency of PSA screening, the proportion of patients evaluated by a urologist for elevated PSA, and the proportion who subsequently underwent biopsy did not differ significantly by exposure status (Table 1) [34]. Risk of prostate cancer was significantly higher among exposed than unexposed veterans (adjusted OR $=4.83$ [3.42-6.81]) (Figure S1). Adjusted ORs were also significantly elevated for high-grade prostate cancer $(\mathrm{OR}=2.59[1.30-5.13])$ and metastatic prostate cancer at diagnosis $(\mathrm{OR}=4.32$ [1.34-13.96]). After excluding the 38 patients who reported Agent Orange exposure after prostate cancer diagnosis, the association was substantially attenuated but still statistically significant $(\mathrm{OR}=1.85[1.47-2.31])$. Among the prostate cancer cases, those classified as exposed to Agent Orange, compared with those classified as unexposed, were significantly younger at diagnosis, had a higher mean Gleason score, had a higher proportion of high-grade disease, were more likely to present with metastasis, and were less likely to have a family history of prostate cancer, but did not differ significantly in clinical stage or PSA level. It is somewhat surprising that the prevalence of PSA testing and early-stage prostate cancer did not differ by exposure status, given that veterans with self-reported exposure were invited to undergo PSA testing and digital rectal examination; therefore, one might expect that exposed veterans would be more likely to undergo these procedures than the non-exposed. As expressed by Air Force Health Study investigators [93], the "serious misclassification of Agent Orange/TCDD exposure" in the study by Chamie et al. [34] "undermines the validity of their conclusions." Moreover, the implausibly large estimated RRs suggest a chance finding, potential selection bias, differential exposure misclassification, or other sources of bias, although possible bias was difficult to evaluate due to the ambiguous description of study methods.

Among 2,720 veterans referred to the Portland, Oregon, VA Medical Center for initial prostate biopsy and without a history of prostate cancer, 203 were classified as exposed to Agent Orange based on self-report at the time of hospital enrollment (before prostate biopsy) or military service in "a location where [Agent Orange] was known to have been used," and the remaining 2,517 were classified as unexposed [33]. Subjects were not restricted to Vietnam or Vietnam-era veterans. Prostate cancer was diagnosed in 74 (36\%) exposed veterans, including $40(20 \%)$ with Gleason score $\geq 7$, and in $822(33 \%)$ unexposed veterans, including $419(17 \%)$ with Gleason score $\geq 7$.

Despite these relatively small differences by exposure status, the adjusted OR for prostate cancer (vs. no prostate cancer) in exposed versus unexposed veterans was 1.52 (1.07-2.13) (Table 1; Figure S1) [33]. Comparing high- 
grade (Gleason score $\geq 7$ ) disease with none, the adjusted OR was 1.75 (1.12-2.74), whereas that for low-grade disease was $1.24(0.81-1.91)$. However, military service branch was not significantly associated with prostate cancer risk among veterans classified as exposed to Agent Orange (results not shown by authors). Veterans with reported Agent Orange exposure were significantly younger at biopsy than unexposed veterans, and age at diagnosis was also younger and mean PSA (but not PSA density) was lower in exposed than unexposed cases, suggesting greater diagnostic intensity among exposed subjects. Yet, the stronger association of Agent Orange exposure with high-grade than low-grade disease runs counter to the anticipated effect of diagnostic bias. The high potential for exposure misclassification based on selfreport and the VA's presumptive definition of Agent Orange exposure renders the results difficult to interpret. Thus, this study does not offer reliable evidence of a significant positive association between actual exposure to Agent Orange and risk of high-grade prostate cancer.

A cross-sectional postal survey of 114,562 Korean veterans of the Vietnam War (70\% of 164,208 contacted) was conducted in 2004 to evaluate associations between Agent Orange exposure and self-reported disease outcomes [94]. Agent Orange exposure was assessed based on self-report (categorized as no, low, moderate, or high) and based on the proximity of the military unit (battalion or company based on self-reported survey data; division or brigade based on Ministry of Defense records) to sprayed areas, using the exposure opportunity index model E4 developed by Stellman et al. [95].

Self-perceived exposure to Agent Orange was associated with an increased prevalence of prostate cancer (OR for high vs. no exposure $=1.91$ [1.69-2.16]) (Table 1; Figure S1) [94]. However, modeled exposure to Agent Orange was not significantly associated with prostate cancer, either at the division/brigade level or at the more detailed battalion/company level (OR for low exposure vs. none $=1.04 \quad[0.92-1.17] ; \quad$ moderate exposure vs. none $=1.04[0.91-1.19] ;$ high exposure vs. none $=1.11$ [0.97-1.27]; $P_{\text {trend }}=0.15$ ). The combination of selfreported exposure and self-reported disease is highly susceptible to information bias. The validity and reliability of the exposure opportunity index model have also been questioned on the basis of widely heterogeneous exposure estimates [96]. Moreover, serum TCDD levels in 102 Korean Vietnam veterans in 2007 were poorly correlated with either perceived self-reported exposure $\left(r^{2}=0.129\right)$ or proximity-based exposure $\left(\mathrm{r}^{2}=0.073\right.$ with division/ brigade-level exposure; $r^{2}=0.159$ with battalion/company-level exposure), nor with military unit $(P=0.67$ for support vs. combat unit as a predictor of serum TCDD concentration) [97], and average TCDD levels (mean $=1.2 \mathrm{ppt}$, median $=0.9 \mathrm{ppt})$ were lower than in U.S. Vietnam-era veterans stationed in the continental U.S. or Germany (mean $=4.1 \mathrm{ppt}$ ) [81]. Thus, the interpretation of perceived and modeled Agent Orange exposure in this study is unclear, and the results do not support an association between actual Agent Orange exposure and prostate cancer in Korean Vietnam veterans.

Three other studies of prostate cancer in veterans compared patient and disease characteristics between prostate cancer patients with and without reported Agent Orange exposure (Table 1) [98-100]. These studies do not address the association between Agent Orange exposure and prostate cancer risk. However, they can provide information on differences in diagnostic intensity between exposed and unexposed veterans (although not between veterans and the general population), and address the hypothesis raised by Ansbaugh et al. [33] and Chamie et al. [34] that Agent Orange exposure is associated with higher-grade disease.

At a West Virginia cancer center between 1995 and 2005, 29 Vietnam veterans with Agent Orange exposure determined by eligibility for VA benefits and 52 Vietnam veterans without Agent Orange exposure underwent permanent brachytherapy for prostate cancer [100]. Those with Agent Orange exposure were significantly younger at the time of implantation and had significantly higher pretreatment PSA, but did not differ significantly in terms of Gleason score, percent positive biopsies, prostate volume, clinical stage, perineural invasion, or risk group (based on a combination of PSA, Gleason score, and stage), indicating no significant difference in diagnostic intensity or disease characteristics by VA-designated Agent Orange status.

Among 1,495 veterans at four VA medical centers who underwent radical prostatectomy for prostate cancer in 1988-2007, including 206 classified in the electronic medical record as having been exposed to Agent Orange and 1,289 classified as unexposed, exposed patients were significantly more likely to be younger at the time of radical prostatectomy, have lower-stage disease, and have a lower preoperative PSA level [99]. However, no significant group differences were observed in the distribution of biopsy or pathological Gleason score, the prevalence of lymph node metastasis, or the odds of having high-grade disease, positive surgical margins, or seminal vesicle invasion. These results may suggest heightened surveillance for prostate cancer among veterans reporting Agent Orange exposure, but no significant difference in Gleason score or other disease characteristics.

Among 93 veterans at the Augusta, Georgia, VA medical center who underwent radical prostatectomy for prostate cancer in 2005-2009, those classified in the electronic medical records (based on self-report and military records confirming military service "in an area in which [Agent 
Orange] had been sprayed") as exposed were older at the time of radical prostatectomy than those classified as unexposed, and were less likely to have positive surgical margins, but did not differ significantly in terms of preoperative PSA level, prostate volume, biopsy or prostatectomy Gleason score, tumor pathological stage, extracapsular extension, seminal vesicle invasion, lymph node metastasis, or subsequent mortality (with a median follow-up of 64 months) [98]. Results were similar when patients were classified as having high or low dioxin-like toxic equivalency values measured in subcutaneous adipose tissue. Although the findings regarding age at prostatectomy, preoperative PSA level, and tumor stage differ from those of Shah et al. [99], with less evidence of disparate diagnostic intensity, they again suggest no significant relationship between self-reported/geography-based Agent Orange exposure and clinical disease characteristics.

In summary, three VA hospital-based studies in the U.S. $[33,34,92]$ and a cross-sectional study of prostate cancer prevalence in Korea [94] reported a significant positive association between self-reported or geography-based Agent Orange exposure and prostate cancer, whereas one VA-based study did not [5]. Also, two studies found a significant positive association between self-reported or geography-based Agent Orange exposure and risk of highgrade prostate cancer [33, 34], whereas five did not [5, 92, 98-100]. Only the Korean investigators attempted to validate self-reported Agent Orange exposure by comparison with serum TCDD levels, and they found no correlation between the two [97]. The same lack of association between serum TCDD levels and self-reported or proximity-based estimated Agent Orange exposure has been demonstrated in U.S. veterans [81]. In light of the high probability of severe exposure misclassification, these studies cannot reliably be interpreted as unbiased analyses of associations with actual Agent Orange exposure. Combined with concerns about potential recall bias, selection/ diagnostic bias, and other methodological problems, the unknown interpretation of self-reported Agent Orange exposure renders these studies essentially uninformative with regard to the question of a causal effect of Agent Orange or TCDD on prostate cancer.

Studies of Vietnam veterans without estimated Agent Orange/TCDD exposure

In its Veterans and Agent Orange updates, the IOM Committee takes into consideration studies of Vietnam veterans that lack estimates of exposure to Agent Orange/ TCDD or restriction to a subgroup of veterans known to have had high potential for Agent Orange exposure [2332]. As stated in the most recent (2012) update, Vietnam veterans "are assumed to have had a higher probability of exposure to the [chemicals of interest] than people who did not serve in Vietnam, whether or not their individual exposures are characterized beyond the mere fact that they were deployed to Vietnam" [23]. However, comparisons of all Vietnam veterans with veterans who served outside of Southeast Asia must be interpreted with caution due to the high potential for misclassification of Agent Orange exposure, as well as possible differences in diagnostic intensity. As noted by the U.S. Centers for Disease Control and Prevention (CDC), differences between Vietnam and non-Vietnam veterans could include "psychological stresses of war, possible exposure to various infectious diseases prevalent in Vietnam, possible misuse of drugs and alcohol, and possible exposure to the defoliant Agent Orange, as well as many unknown exposures" [101]. Such exposures might contribute to increased health care usage and, hence, diagnostic intensity among Vietnam veterans [102104]. Comparisons with general populations are especially susceptible to this type of bias due to the generally greater health care access and/or usage among veterans than nonveterans $[68,105]$. Thus, associations with military service in Vietnam cannot reliably be attributed to exposure to Agent Orange/TCDD, and such studies are only briefly discussed here because they are not informative about causal associations between Agent Orange/TCDD exposure and prostate cancer risk.

The Government of Australia conducted a series of retrospective cohort studies comparing Australian veterans of the Vietnam War with either conscripts who served only in Australia or the general population of Australia. Australian military personnel in Vietnam were mostly stationed in Phuoc Tuy Province, which was not heavily sprayed with Agent Orange; thus, the average exposure of Australian troops to Agent Orange was probably low, if any [106]. Analyses that compared approximately 19,000 Australian male National Service conscripts who served in Vietnam with approximately 25,000 who served only in Australia found no significant difference in genitourinary cancer mortality $(\mathrm{RR}=0.7[0.2-3])$ [107], prostate cancer incidence $(\mathrm{RR}=1.05[0.75-1.48])$ [109], or prostate cancer mortality $(\mathrm{RR}=0.00[0.00-1.41] ; 0$ vs. 5 deaths $)$ between the groups (Table 2; Figure S2).

Other epidemiologic studies of Australian veterans of the Vietnam War were based on comparisons between Vietnam veterans and the general Australian population, rather than veterans stationed elsewhere. Although most (but not all [109]) of these analyses found significant elevations in prostate cancer mortality [110, 112], prevalence $[114,115]$, and incidence [116] among Australian Vietnam veterans (Table 2; Figure S2), the excess cannot reliably be attributed to any specific difference, including Agent Orange or any other exposure, between veterans and nonveterans. 
The U.S. CDC designed the Vietnam Experience Study to evaluate the health consequences of military service in Vietnam, where "Vietnam Experience" was used as "a generic term for a wide range of health-influencing exposures operating among those who served in the military in Vietnam" [101]. The authors noted that "[t]hese factors are unmeasured in this study; therefore, it is not possible to examine directly their relation to mortality." Postservice mortality was compared between 9,324 Vietnam veterans and 8,989 non-Vietnam veterans who served in Korea, Germany, or the U.S. during the Vietnam era. As of the end of 1983, no deaths from prostate cancer had occurred among either Vietnam or non-Vietnam veterans (Table 2) [101]. With additional follow-up through 2000, one death from prostate cancer had occurred among Vietnam veterans (mortality rate $=0.4$ per 100,000 person-years), compared with three deaths among non-Vietnam veterans (1.1 per 100,000 person-years) [117].

Notably, the CDC designed another study specifically to evaluate the potential health effects of Agent Orange exposure. However, this study was stopped after the exposure assessment phase because serum TCDD levels measured in 1987 did not differ between veterans who were stationed in the most heavily sprayed area of Vietnam (III Corps) and veterans who served in Germany or the U.S. during the same years [81]. Therefore, the authors concluded that "most U.S. Army ground troops who served in Vietnam were not heavily exposed to TCDD, except perhaps men whose jobs involved handling herbicides" [81], and that investigation of the potential health effects of Agent Orange exposure in Vietnam veterans overall was infeasible.

A case-control study of 606 prostate cancer cases (61\% participation) and 471 age-matched controls randomly selected from electoral rolls (43\% participation) in Western Australia found a non-significant increase in prostate cancer risk in association between self-reported military service in Vietnam (age-adjusted OR $=2.12$ [0.88-5.06]) [118]. The estimated association with Vietnam service was similar after adjusting for family history of prostate cancer or restriction to patients with Gleason score $\geq 7$ (Table 2; Figure S2). Potential exposure to Agent Orange was not assessed, but as stated by others [106], was likely to have been low or nonexistent among Australian troops in Vietnam.

A retrospective cohort study of 2,783 (out of 3,322 eligible) male New Zealand veterans who served in Vietnam found no significant increase in prostate cancer incidence $(\mathrm{SIR}=1.17$ [0.98-1.39]) or mortality (SMR $=1.03$ [0.55-1.76]) in comparison with the general New Zealand population (Table 2; Figure S2) [119]. The majority of New Zealand troops served alongside the Australian Army in Phuoc Tuy Province [119], where Agent Orange spraying was limited [106].

Another retrospective cohort study of 185,265 male Korean veterans of the Vietnam War detected a significant excess of prostate cancer incidence $\quad(\mathrm{SIR}=1.22$ [1.02-1.46]) among all Vietnam veterans combined, compared with the general male population of Korea (Table 2; Figure S2) [120]. This excess was restricted to officers $(\mathrm{SIR}=2.49$ [1.93-3.21]), whereas enlisted soldiers and non-commissioned officers had a non-significant deficit of prostate cancer incidence (SIRs $=0.85$ [0.64-1.14] and 0.81 [0.51-1.29], respectively). Given that serum TCDD levels did not vary by military rank [97], the prostate cancer excess in officers cannot reliably be attributed to differences in Agent Orange exposure.

Proportionate mortality studies, which compare the percentage of all deaths from a specified cause between an exposed group of interest and an unexposed or general population group, can give rise to misleading conclusions about risk associations if they are used to compare groups with different distributions of causes of death unrelated to the exposure under study. Therefore, they do not provide useful information about the association between Agent Orange/TCDD exposure and prostate cancer risk, and they are listed here only for the sake of completeness. No published proportionate mortality or morbidity studies of U.S. Vietnam versus non-Vietnam veterans, including those in New York State [121], Wisconsin [122], West Virginia [123], Michigan [124], Massachusetts [125, 126], and the U.S. Army and Marine Corps [127, 128], found a significant excess of prostate cancer incidence or mortality among Vietnam veterans (Table 2; Figure S2).

In summary, studies in Australia, New Zealand, and Korea found that prostate cancer incidence, mortality, and/ or prevalence were higher in Vietnam veterans than in the general population [110-116, 118-120], but comparisons between Vietnam and non-Vietnam veterans in Australia [107, 109] and the U.S. [101, 117, 121, 122, 124-128] found no such excess. Thus, the collective findings suggest that military service specifically in Vietnam does not confer an increased risk of prostate cancer beyond that associated with military service in general. These studies are limited by a lack of detailed exposure assessment, poor control for confounding by medical surveillance and other factors, possible selection bias, and a low probability of direct or indirect exposure to Agent Orange. Therefore, these studies-most of which found no significant association between Vietnam military service and prostate cancer-do not provide informative results regarding the potential causal effect of Agent Orange/TCDD on prostate cancer.

Studies of manufacturers and sprayers of herbicides potentially contaminated with TCDD

The most informative industry-based studies of occupational exposure to TCDD concern two groups of workers: chemical workers involved in the production of potentially 
contaminated herbicides (2,4,5-T, trichlorophenol, and pentachlorophenol), and sprayers of the same herbicides (mainly 2,4,5-T). The review of the results on prostate cancer risk among herbicide manufacturers and sprayers is complicated by the fact that several partially overlapping study groups have been included in various reports. Several studies conducted in Europe and Oceania (most of which had been reported separately) were combined in a pooled analysis coordinated by IARC [129]; similarly, several USbased studies (also reported separately) were combined in a pooled analysis coordinated by the National Institute for Occupational Safety and Health (NIOSH) [135]. The results of the two pooled analyses were then reported in a combined publication, which comprised four additional German cohorts that also had been reported separately [17]. An update of the NIOSH pooled study was subsequently reported [136], as well as updated analyses of some of the individual plants. Similarly, updated analyses were reported for several of the studies included in the IARC pooled study and one of the German cohorts.

In our review, we considered the combined publication of the two pooled analyses [17], the NIOSH study update [136], as well as the subsequent individual cohort studies that provided more extensive results in terms of the size of the study group or the duration of follow-up [137-144]. One additional study of herbicide production workers was not included in any pooled analysis and is reviewed separately [145]. The relevant studies are summarized in Table 3, and are described relatively briefly in this section because of their uniformly statistically null results with respect to prostate cancer. Although false-negative findings are a possibility, whether due to insufficient statistical power, exposure misclassification, confounding, other biases, or chance, the consistency of null findings suggests that the absence of association is real.

The combined IARC/NIOSH pooled analysis comprised 21,863 male and female workers exposed to phenoxy herbicides or chlorophenols from 32 cohorts of manufacturing workers from Austria, Denmark, Finland, Germany, Italy, the Netherlands, New Zealand, Sweden, the United Kingdom, and the United States, and four cohorts of sprayers from Australia, Canada, New Zealand, and the United Kingdom (Supplemental Table S1) [17]. The period of employment and mortality follow-up varied among countries; overall, they extended from 1939 to 1992. Exposure to TCDD was defined as employment during manufacture or spraying of 2,4,5-T, pentachlorophenol, or other potentially contaminated compounds, or employment in plants with documented exposure through biomonitoring (data available for 573 workers from 10 cohorts) or environmental measurements. Published mean serum TCDD levels in subsets of workers included in the IARC/NIOSH pooled analysis and controls are shown in Table 6; these data demonstrate that phenoxy herbicide and chlorophenol production workers and sprayers experienced higher TCDD exposure than the population at large.

Overall, 13,831 workers from 28 cohorts $(63.3 \%)$ were classified as exposed to TCDD (73\% manufacturing workers and $27 \%$ sprayers; $63 \%$ from the IARC study and $37 \%$ from the NIOSH study), and 7,553 workers $(34.5 \%)$ were classified as unexposed to TCDD (479 workers from a UK plant [2.2\%] could not be classified as to TCDD exposure). The SMR for prostate cancer was 1.11 (0.81-1.50; 43 deaths) among exposed workers and 1.10 (0.71-1.62; 25 deaths) among unexposed workers (Table 3; Figure S3). Prostate cancer results by duration of employment, time since first employment, or other indirect indicators of exposure were not reported. Similarly, separate results on herbicide manufacturers and sprayers were not reported for prostate cancer. The original IARC pooled analysis comprised 13,482 workers from 20 cohorts of production workers and sprayers exposed to phenoxy herbicides and chlorophenols [129]. A total of 30 deaths from prostate cancer were observed $(\mathrm{SMR}=1.11[0.75-1.58])$; no results were reported according to TCDD exposure. In the original NIOSH pooled analysis, comprising 5,172

Table 6 Mean serum TCDD levels in groups of workers included in the IARC/NIOSH pooled analysis [17] and controls

\begin{tabular}{|c|c|c|c|c|c|}
\hline \multirow[t]{2}{*}{ Country } & \multicolumn{2}{|c|}{ Exposed workers } & \multicolumn{2}{|c|}{ Unexposed controls } & \multirow[t]{2}{*}{ References } \\
\hline & $\mathrm{N}$, type & Mean (ppt) & $\mathrm{N}$, type & Mean (ppt) & \\
\hline Austria & $9 \mathrm{PC}$ & 389 & $17 \mathrm{O}$ & $\sim 14$ & Neuberger et al. (130) \\
\hline Germany & $20 \mathrm{P}$ & $141^{\mathrm{a}}$ & - & - & Flesch-Janys et al. [131] \\
\hline Germany & $20 \mathrm{PC}$ & $402^{\mathrm{a}}$ & - & - & Manz et al. [132] \\
\hline New Zealand & $9 \mathrm{Sp}$ & 53 & $9 \mathrm{O}$ & 6 & Smith et al. [133] \\
\hline Sweden & $5 \mathrm{P}$ & 17 & $5 \mathrm{O}$ & 2 & Littorin et al. [134] \\
\hline United States & $253 \mathrm{P}$ & 233 & $79 \mathrm{~S}$ & 2 & Fingerhut et al. [135] \\
\hline
\end{tabular}

$\mathrm{P}$, production workers; C, chloracne patients; Sp, sprayers; S, workers from same plants as exposed workers; O, workers from other plants than exposed workers

${ }^{\text {a }}$ Modeled TCDD level at the end of employment 
production workers, the SMR for prostate cancer was 1.22 (0.71-1.95; 17 deaths) in the whole cohort and 1.52 (0.70-2.90; 9 deaths) in the group of 1,520 workers with one or more years of employment [135].

A subsequent analysis of the NIOSH pooled study [136] provided results for mortality up to 1993, as compared with 1987 in the combined IARC/NIOSH analysis. This analysis comprised 5,132 workers employed in 12 plants, all of whom were considered exposed to TCDD. The SMR for prostate cancer, based on 28 deaths, was 1.17 (0.78-1.68) (Table 3; Figure S3).

Collins et al. [137, 138] reported two analyses of workers employed in one of the plants included in the NIOSH pooled analysis. The first analysis [137] included 773 male pentachlorophenol manufacture workers exposed to TCDD. The period of follow-up was not specified. Serum TCDD levels were available for 128 workers and were used to model TCDD exposure for the whole study cohort. The SMR for prostate cancer in the whole cohort was 1.0 (0.4-1.9), based on eight deaths (Table 3; Figure S3). When workers were categorized in tertiles according to estimated TCDD exposure, SMRs were $0.8(0.1-2.9)$ for low exposure $(<0.7$ ppt-years; 2 deaths), $0.6(0.1-2.4)$ for medium exposure (0.7-3.99 ppt-years; 2 deaths), and 1.4 (0.4-3.6) for high exposure ( $\geq 4.0$ ppt-years; 4 deaths). The estimated RR of prostate cancer death per ppt-year was 1.002 (0.962-1.045). The second analysis [138] included 1,615 trichlorophenol workers with potential TCDD exposure, including 196 pentachlorophenol workers who presumably were also included in the first analysis. As in the first analysis, TCDD exposure was modeled based on serum levels, which were available for 280 workers. After excluding pentachlorophenol workers, there were 20 deaths from prostate cancer through 2003 (SMR $=1.5$ [0.9-2.4]). The RR of prostate cancer death per ppb-year increase in cumulative estimated TCDD level was 1.013 (0.989-1.038; $P=0.29)$.

A further analysis included 2,122 workers at four pentachlorophenol production plants that were part of the NIOSH pooled study [139]. A subcohort of 720 workers involved in trichlorophenol production was considered exposed to TCDD. In a follow-up through 2005, eight deaths from prostate cancer were observed among the exposed workers $(\mathrm{SMR}=1.03$ [0.45-2.04]), whereas 18 prostate cancer deaths were observed among the unexposed $(\mathrm{SMR}=0.98$ [0.58-1.55]) (Table 3; Figure S3).

't Mannetje et al. [140] extended to 2000 the follow-up of two cohorts from New Zealand included in the IARC pooled analysis (1,025 production workers and 703 sprayers). The SMR for prostate cancer was 0.37 (0.01-2.08; 1 death) among production workers and 0.60 (0.07-2.16; 2 deaths) among sprayers (Table 3; Figure S3). The cohort study of manufacturing workers was expanded by McBride et al. [141, 142]. A first report [141] included 1,754 workers employed in the manufacturing plant between 1969 and 2003, with mortality follow-up through 2004. A total of three deaths from prostate cancer were observed $(\mathrm{SMR}=0.54 \quad[0.11-1.56])$. All three deaths occurred among workers with less than three months of employment $(\mathrm{SMR}$ in this group $=0.62$ [0.13-1.82]; 0.8 expected prostate cancer deaths among workers with longer duration of employment). The second analysis [142] was restricted to 1,599 workers employed between 1969 and 1988, when 2,4,5-T was used and exposure to TCDD was possible, with mortality follow-up through 2004. A total of 1,134 workers were classified as exposed to TCDD, and 465 workers were considered unexposed. Cumulative TCDD levels were estimated based on serum levels available for 346 workers. Three deaths from prostate cancer were observed in this cohort (presumably the same deaths reported in [141]); one death was among exposed workers $(\mathrm{SMR}=0.2[0.0-1.2])$ and two deaths were among unexposed workers (SMR $=1.9$ [0.2-6.7]). Results according to estimated cumulative TCDD exposure were not reported for prostate cancer.

The mortality of 2,106 male production workers employed in two Dutch plants included in the IARC pooled study was updated to 2006 [143]. A total of 539 workers in factory A and 411 workers in factory B were classified as exposed to TCDD based on either their history of employment in selected departments (or having entered them on a regular basis) or exposure to an accident that occurred in 1963 in factory A. The remaining 482 workers in factory A and 626 workers in factory B were classified as unexposed. The RR of prostate cancer for TCDD exposure was $2.93(0.61-14.1)$ in factory A (based on six deaths among the exposed and two deaths among the unexposed) and $2.68(0.48-14.9)$ in factory B (based on four deaths among the exposed and two deaths among the unexposed) (Table 3; Figure S3). Four out of the six exposed cases in factory A were present during the 1963 accident. Boers and colleagues [146] extended this analysis by including estimated TCDD exposure based on plasma measurements available for 187 workers. The RR of prostate cancer per log unit of TCDD (with a 10-year lag) was $1.08(0.79-1.49)$. In this analysis, all workers in factory B were considered unexposed to TCDD, and when the analysis was restricted to factory A, the RR per lagged log unit of TCDD level was $1.29(0.85,1.94)$.

The mortality follow-up of one of the plants from Germany included in the IARC pooled study was extended to 2007 [144]. The cohort included workers ever employed between 1952 and 1984, when the plant was closed. Causes of death of deceased cohort members were coded by a study pathologist; expected deaths were calculated based on regional rates. Among 1,191 male workers, a total of 19 
deaths from prostate cancer were observed (SMR $=1.37$ [0.82-2.13]) (Table 3; Figure S3). Cumulative TCDD exposure was estimated on the basis of serum levels on a subset of workers, but results on prostate cancer were not reported according to estimated TCDD level.

The only group of workers not included in the IARC or the NIOSH pooled analysis is a cohort of 243 male workers who were involved between 1953 and 1969 in clean-up, repair, maintenance, or demolition activities at a German plant where an accident entailing release of TCDD occurred in 1953 [145]. Serum TCDD level was available for all cohort members. Follow-up for mortality and cancer incidence covered the period 1953-1992. No deaths from prostate cancer occurred in the cohort (SMR $=0$ [0-1.9]), while four incident cases were observed $(\mathrm{SIR}=1.1 \quad[0.3-2.8])$ (Table 3; Figure S3). When workers were categorized according to serum TCDD level, the SIR was 2.5 (0.5-7.4; 3 cases) in the low-exposure category $(<0.1 \mu \mathrm{g} / \mathrm{kg}$ body weight), $1.1(0.0-5.9 ; 1$ case) in the medium-exposure category $(0.1-0.99 \mu \mathrm{g} / \mathrm{kg}$ body weight), and 0.0 (0.0-2.5; 0 cases) the high-exposure category ( $\geq 1 \mu \mathrm{g} / \mathrm{kg}$ body weight).

Subsets of workers who developed chloracne, indicating high TCDD exposure, were identified in the NIOSH pooled cohort (630 workers) [136] and in the German accident cohort (113 workers) [145]. However, no results on risk of prostate cancer were reported for these groups of workers.

Two other studies provided limited information on prostate cancer risk associated with potential occupational exposure to TCDD-contaminated herbicides. In the Agricultural Health Study, a cohort of 55,332 male pesticide applicators from Iowa and North Carolina, no association was found between self-reported use of 2,4,5-T (or 2,4-D) and risk of prostate cancer, based on 566 cases after a mean follow-up period of 4.3 years (detailed results not reported) [147]. In a population-based case-control study in Western Australia, self-reported exposure to phenoxy herbicides was not associated with risk of prostate cancer $(\mathrm{OR}=1.00$ [0.61-1.63]; 40 exposed cases) [148].

In summary, although a formal combination of results is complicated by the overlap among reports, studies of manufacturers and sprayers of TCDD-contaminated herbicides consistently indicate no significant increase in risk of prostate cancer. This conclusion comports with that of a meta-analysis of 20 cohort studies of phenoxy herbicide manufacturing workers published through 2003, in which the combined SMR for prostate cancer was $1.16(0.85-1.57)$ [149]. Limitations of the available data include the fact that most studies reported only results for prostate cancer mortality and that the number of workers with high documented exposure is relatively small. Workers with presumably different levels of TCDD exposure were combined for analysis, resulting in some degree of exposure misclassification. Despite these limitations, a substantial proportion of manufacturers and sprayers included in these cohorts did experience considerably higher exposure to TCDD than the general population, as demonstrated by the serum TCDD levels measured in several subsets of workers. Thus, the results of these studies provide solid evidence against a significant positive association between TCDD or herbicides contaminated with TCDD, including 2,4,5-T, and prostate cancer.

Studies of the Seveso industrial accident

Part of the population living in six Italian municipalities was exposed to TCDD as a result of an accident in a trichlorophenol production plant in Seveso in 1976. Several reports on cancer mortality or incidence in this area have been published; the most recent analyses are based on follow-up for cancer mortality through 2001 [150] and cancer incidence through 1996 [151]. The design and results of these studies are summarized in Table 4, and results are shown in Figure S3.

The exposed group was divided among those living in 1976 (or migrating during 1976-1985) in zone A, with the highest exposure (median serum TCDD level in $1976=447.0 \mathrm{ppt})$; zone B, with intermediate exposure (median serum TCDD $=94.0 \mathrm{ppt}$ ); and zone R, with low exposure (median TCDD level $=48.0 \mathrm{ppt}$ ). The reference group comprised the remaining areas of the six municipalities, as well as five surrounding municipalities. Cancer incidence was based on record linkage with the regional population-based cancer registry, and the mortality followup was based on vital status information obtained from the municipalities of residence and on cause of death obtained from the regional statistical office.

The cancer incidence analysis was based on people living in the contaminated area (352 men in area A, 2,471 men in zone B, 15,715 men in zone R, and 88,349 men in the reference zone) [151]. This analysis included zero cases of prostate cancer in zone A (expected cases not reported, but estimated as approximately 1 case, based on the rates in zones $\mathrm{B}$ and $\mathrm{R})$, seven cases in zone $\mathrm{B}(\mathrm{RR}=0.94$ [0.45-1.99]), and 39 cases in zone $R \quad(R R=0.75$ [0.54-1.05]) (Table 4; Figure S3).

The cancer mortality analysis included also those individuals who were born or immigrated into the study area between 1976 and 1985 (390 men in area A, 3017 men in area B, 19,199 men in area R, and 139,516 men in the reference area) [150]. The observed deaths from prostate cancer were one in zone A ( $R R=0.87$ [0.12-6.17]), eight in zone $\mathrm{B}(\mathrm{RR}=0.88[0.44-1.77])$, and 65 in zone $\mathrm{R}$ $(\mathrm{RR}=1.06$ [0.81-1.38]) (Table 4; Figure S3).

In summary, there is no evidence of an increased risk of prostate cancer in the community exposed to the Seveso accident with follow-up extending over 20-25 years. While the number of individuals in the zone with highest exposure 
is relatively small, and exposure was classified with some error based on geographic zone of residence instead of individual serum TCDD level, the results in the combined zones $\mathrm{A}$ and $\mathrm{B}$ are not compatible with a significant association between TCDD exposure and prostate cancer.

A recent meta-analysis of cohort studies of TCDD and prostate cancer calculated a meta-SMR of $1.26(1.00-1.57)$ based on 13 military and occupational cohorts (one of which reported an SIR) and a meta-RR of $1.04(0.84-1.28)$ based on four military and community cohorts [152]. This meta-analysis had a number of important flaws, such as the omission of several relevant articles [17, 137, 142, 144, 146, 151], the selection of results from some exposed subcohorts but not others [140], the equal weighting of RRs or SIRs for subjects with low, medium, or high TCDD exposure within a given cohort $[145,150]$, and the conflation of incidence and mortality data and heterogeneous military, occupational, and environmental exposure levels. Overall, this study offers no additional insight into the relationship between TCDD and prostate cancer risk. This study also demonstrates that metaanalysis may be poorly suited for synthesizing results of observational studies with heterogeneous settings, methods, and exposure levels that require careful interpretation of individual and collective results for causal inference $[59,60]$.

\section{Discussion}

The best available epidemiologic studies of exposure to Agent Orange/TCDD show no significant association with prostate cancer incidence or mortality. Specifically, the only two studies of Vietnam veterans with exposure to Agent Orange confirmed by elevated serum TCDD levelsnamely, the Air Force Health Study and the Army Chemical Corps study-found no significant increase in prostate cancer incidence $[64,73]$ or mortality $[62,84,87]$ in exposed veterans overall. Likewise, occupational cohort studies of industrial exposure to TCDD-contaminated herbicides and studies of the Seveso community cohort-considered by IARC to be the most informative epidemiologic studies for evaluating the carcinogenic effects of TCDD in humansconsistently found no significant association with prostate cancer incidence or mortality [17, 136-145, 150, 151]. RR point estimates in these studies were fairly evenly distributed above, below, and at the null value of 1.0, with no evidence that subgroups with greater exposure experienced a higher risk. The Air Force Health Study main analyses, the Army Chemical Corps study, the occupational cohort studies, and the Seveso cohort study are accorded the greatest weight in evaluation of the overall epidemiologic literature on Agent Orange/TCDD exposure and prostate cancer because these are the only studies in which subjects designated as exposed were confirmed to have elevated serum levels of TCDD.
In his well-known and widely implemented guidelines for the evaluation of potential causal associations, Sir Austin Bradford Hill specified that the guidelines were intended to be applied to "an association between two variables, perfectly clear-cut and beyond what we would care to attribute to the play of chance. What aspects of that association should we especially consider before deciding that the most likely interpretation of it is causation?" [153]. In the absence of such a "clear-cut" association-indeed, in the presence of considerable evidence indicating no association, as in the case of Agent Orange/TCDD and prostate cancer-characteristics such as the strength, consistency, specificity, temporality, exposure-response gradient, plausibility, and coherence of a potential exposuredisease relationship are not strictly applicable. Nonetheless, based on the most informative epidemiologic studies, we can state that the apparent association is not strong, that results across studies are consistent in demonstrating the absence of any increase in prostate cancer risk, and that there is no positive exposure-response gradient.

The null results are also coherent with toxicological data from experimental animal studies. Specifically, although TCDD promotes a variety of tumors in different strains of rats, mice, and hamsters through a non-genotoxic mechanism believed to involve the Ah receptor [11,12, 14-16], benign or malignant tumors of the prostate are not among those observed in excess in experimental animals. 2,4,5- $\mathrm{T}$ itself, in the absence of TCDD, has been found not to increase tumor incidence in experimental rodents [154]. Similarly, 2,4-Dthe other ingredient of Agent Orange-demonstrates no apparent oncogenic effect in experimental animals [155-157]. Thus, animal evidence supports the results of epidemiologic studies showing no significant association between Agent Orange or TCDD exposure and prostate cancer risk.

The only studies that found a significant positive association with prostate cancer were those in which the exposure under evaluation was self-reported or geography-based Agent Orange exposure [33, 34, 92, 94] or Vietnam military service overall in comparison with the general population [63, 110-116, 118-120]; or, in the Air Force Health Study, where the analysis was restricted to veterans with a shorter duration of military service or where Ranch Hands who served exclusively in Vietnam were compared with subjects who served exclusively outside of Vietnam [63]. As discussed earlier, self-reported and proximity-based Agent Orange exposure estimates are not closely correlated with serum TCDD levels $[82,97]$. Therefore, profound exposure misclassification, combined with potential selection bias, largely invalidates the findings of these studies, which cannot contribute useful information about the association between Agent Orange/TCDD exposure and prostate cancer risk. Confounding by diagnostic intensity, particularly PSA testing, is a major concern in studies that compare Vietnam 
veterans with the general population, as well as in the subgroup analyses of the Air Force Health Study, where chance (given probable testing of numerous subgroups) is another important potential explanation for the reported associations. Taken together with the null results of the more reliable studies identified above, the positive findings from these selected studies of veterans are more likely to be spurious than valid.

In conclusion, studies of Vietnam veterans, herbicide manufacturers or sprayers, and community members known to be highly exposed to Agent Orange or TCDD consistently demonstrate the absence of a significant increase in prostate cancer incidence or mortality in these groups. Several biasprone studies of veterans with poorly characterized Agent Orange exposure reported an excess of prostate cancer, but such findings cannot reliably be attributed to an effect of Agent Orange/TCDD rather than confounding or bias. Toxicological findings in animals are also coherent with the absence of a carcinogenic effect of TCDD on the prostate. Overall, the scientific evidence establishes no causal association between exposure to Agent Orange or TCDD and prostate cancer in humans. However, the most rigorously designed studies may lack sufficient power to determine whether RRs of the magnitude generally reported (approximately 0.3-3.0) were statistically significantly different from 1.0. Development of more sensitive biomarkers of past exposure to Agent Orange or TCDD could enable larger studies to rule out a causal association more conclusively.

Conflict of interest Drs. Chang and Mandel are employed by Exponent, Inc., a for-profit corporation that provides engineering and scientific consulting services. All of the authors have consulted with private and government organizations on the health impacts of environmental and occupational exposures, including Agent Orange and TCDD. This independent scientific review was financially supported by the Dow Chemical Company and Monsanto Company. The content of this paper is the sole responsibility of the authors and does not necessarily represent the views or opinions of Dow Chemical Company or Monsanto Company, or any of the employers of the authors. As the study sponsors, Dow Chemical Company and Monsanto Company did not influence the methods or materials used by the authors in conducting their independent review and synthesis of the epidemiological literature or the interpretation of the results, nor were they involved in the preparation or review of the manuscript. The study sponsors did not review or provide feedback on this manuscript prior to its submission.

Open Access This article is distributed under the terms of the Creative Commons Attribution License which permits any use, distribution, and reproduction in any medium, provided the original author(s) and the source are credited.

\section{References}

1. Ferlay J, Soerjomataram I, Ervik M, et al. GLOBOCAN 2012 v1.0, Cancer Incidence and Mortality Worldwide: IARC
CancerBase No. 11 [Internet]. Lyon: International Agency for Research on Cancer (IARC); 2013 http://globocan.iarc.fr. Accessed 13 June 2014.

2. WCRF, AICR. Food, nutrition, physical activity, and the prevention of cancer: a global perspective. Systematic Literature Review Report on Prostate Cancer. Washington, DC: World Cancer Research Fund (WCRF) and American Institute for Cancer Research (AICR); 2007.

3. Huncharek M, Haddock KS, Reid R, Kupelnick B. Smoking as a risk factor for prostate cancer: a meta-analysis of 24 prospective cohort studies. Am J Public Health. 2010;100(4):693-701. doi:10.2105/AJPH.2008.150508.

4. Soto AM, Sonnenschein C. Environmental causes of cancer: endocrine disruptors as carcinogens. Nat Rev Endocrinol. 2010;6(7):363-70. doi:10.1038/nrendo.2010.87.

5. Zafar MB, Terris MK. Prostate cancer detection in veterans with a history of Agent Orange exposure. J Urol. 2001;166(1):100-3.

6. IARC. IARC monographs on the evaluation of carcinogenic risks to humans. Volume 69. Polychlorinated dibenzo-para-dioxins and polychlorinated dibenzofurans. Lyon: International Agency for Research on Cancer (IARC); 1997.

7. IARC. IARC monographs on the evaluation of carcinogenic risks to humans. Volume 100F. A review of human carcinogens: chemical agents and related occupations. Lyon: International Association for Research on Cancer (IARC); 2012.

8. Bueno de Mesquita HB, Doornbos G, Van der Kuip DA, Kogevinas M, Winkelmann R. Occupational exposure to phenoxy herbicides and chlorophenols and cancer mortality in The Netherlands. Am J Ind Med. 1993;23(2):289-300.

9. Riihimaki V, Asp S, Hernberg S. Mortality of 2,4-dichlorophenoxyacetic acid and 2,4,5-trichlorophenoxyacetic acid herbicide applicators in Finland: first report of an ongoing prospective cohort study. Scand J Work Environ Health. 1982;8(1):37-42.

10. Hogstedt C, Westerlund B. Survey of the death causes in forest workers with and without exposure to phenoxyacid chemicals. Lakartidningen. 1980;77(19):1828-31.

11. USEPA. Exposure and human health reassessment of 2,3,7,8tetrachlorodibenzo- $p$-dioxin (TCDD) and related compounds. NAS Review Draft. Washington, DC: United States Environmental Protection Agency (USEPA); 2003.

12. National Research Council. Committee on EPA's exposure and human health reassessment of TCDD and related compounds. Health risks from dioxin and related compounds: evaluation of the EPA reassessment. Washington, DC: National Academies Press; 2006.

13. National Toxicology Program. 12th report on carcinogens (RoC). Washington, DC: National Institute of Environmental Health Sciences; 2011.

14. WHO. Assessment of the health risk of dioxins: re-evaluation of the tolerable daily intake (TDI). WHO Consultation. Geneva: World Health Organization (WHO); May 25-29, 1998.

15. WHO. Safety evaluation of certain food additives and contaminants. Polychlorinated dibenzodioxins, polychlorinated dibenzofurans, and coplanar polychlorinated biphenyls. WHO Food Additives Series 48. Geneva: World Health Organization (WHO); 2002.

16. ATSDR. Toxicological profile for chlorinated dibenzo- $p$-dioxins. Atlanta: Agency for Toxic Substances and Disease Registry (ATSDR)1998.

17. Kogevinas M, Becher H, Benn T, et al. Cancer mortality in workers exposed to phenoxy herbicides, chlorophenols, and dioxins. An expanded and updated international cohort study. Am J Epidemiol. 1997;145(12):1061-75.

18. Cole P, Trichopoulos D, Pastides H, Starr T, Mandel JS. Dioxin and cancer: a critical review. Regul Toxicol Pharmacol (RTP). 2003;38(3):378-88. 
19. Frumkin H. Agent Orange and cancer: an overview for clinicians. CA Cancer J Clin. 2003;53(4):245-55.

20. Steenland K, Bertazzi P, Baccarelli A, Kogevinas M. Dioxin revisited: developments since the 1997 IARC classification of dioxin as a human carcinogen. Environ Health Perspect. 2004;112(13):1265-8.

21. Boffetta P, Mundt KA, Adami HO, Cole P, Mandel JS. TCDD and cancer: a critical review of epidemiologic studies. Crit Rev Toxicol. 2011;41(7):622-36. doi:10.3109/10408444.2011. 560141.

22. Tuomisto J, Tuomisto JT. Is the fear of dioxin cancer more harmful than dioxin? Toxicol Lett. 2012;210(3):338-44. doi:10. 1016/j.toxlet.2012.02.007.

23. Institute of Medicine. Veterans and Agent Orange: Update 2012. Committee to review the health effects in Vietnam Veterans of exposure to herbicides (ninth biennial update) (prepublication copy: uncorrected proofs). Washington, DC: National Academies Press; 2013.

24. Institute of Medicine. Veterans and Agent Orange: health effects of herbicides used in Vietnam. Committee to review the health effects in Vietnam Veterans of exposure to herbicides. Washington, DC: National Academies Press; 1994.

25. Institute of Medicine. Veterans and Agent Orange: update 1996. Committee to review the health effects in Vietnam veterans of exposure to herbicides. Washington, DC: National Academies Press; 1996.

26. Institute of Medicine. Veterans and Agent Orange: update 1998. Committee to review the health effects in Vietnam veterans of exposure to herbicides (second biennial update). Washington, DC: National Academies Press; 1999.

27. Institute of Medicine. Veterans and Agent Orange: update 2000. Committee to review the health effects in Vietnam veterans of exposure to herbicides (third biennial update). Washington, DC: National Academies Press; 2001.

28. Institute of Medicine. Veterans and Agent Orange: update 2002. Committee to review the health effects in Vietnam veterans of exposure to herbicides (fourth biennial update). Washington, DC: National Academies Press; 2003.

29. Institute of Medicine. Veterans and Agent Orange: update 2004. Committee to review the health effects in Vietnam veterans of exposure to herbicides (fifth biennial update). Washington, DC: National Academies Press; 2005.

30. Institute of Medicine. Veterans and Agent Orange: update 2006. Committee to review the health effects in Vietnam veterans of exposure to herbicides (fifth biennial update). Washington, DC: National Academies Press; 2007.

31. Institute of Medicine. Veterans and Agent Orange: update 2008. Committee to review the health effects in Vietnam Veterans of exposure to herbicides (fifth biennial update). Washington, DC: National Academies Press; 2009.

32. Institute of Medicine. Veterans and Agent Orange: update 2010. Committee to review the health effects in Vietnam veterans of exposure to herbicides (eighth biennial update). Washington, DC: National Academies Press; 2011.

33. Ansbaugh N, Shannon J, Mori M, Farris PE, Garzotto M. Agent Orange as a risk factor for high-grade prostate cancer. Cancer. 2013;119(13):2399-404. doi:10.1002/cncr.27941.

34. Chamie K, DeVere White RW, Lee D, Ok JH, Ellison LM. Agent Orange exposure, Vietnam War veterans, and the risk of prostate cancer. Cancer. 2008;113(9):2464-70. doi:10.1002/ cncr.23695.

35. Etzioni R, Penson DF, Legler JM, et al. Overdiagnosis due to prostate-specific antigen screening: lessons from U.S. prostate cancer incidence trends. J Natl Cancer Inst. 2002;94(13):981-90.

36. Kvale R, Auvinen A, Adami HO, et al. Interpreting trends in prostate cancer incidence and mortality in the five Nordic countries. J Natl Cancer Inst. 2007;99(24):1881-7. doi:10.1093/ jnci/djm249.

37. Brawley OW. Prostate cancer epidemiology in the United States. World J Urol. 2012;30(2):195-200. doi:10.1007/s00345012-0824-2.

38. Hsing AW, Chokkalingam AP. Prostate cancer epidemiology. Fron Biosci J Virtual Libr. 2006;11:1388-413.

39. Platz EA, Giovannucci E. Chapter 59. Prostate cancer. In: Schottenfeld D, Fraumeni Jr JF, editors. Cancer epidemiology and prevention. 3rd ed. New York: Oxford University Press; 2006. p. $1128-50$.

40. Mucci LA, Signorello LB, Adami HO. Chapter 20. Prostate cancer. In: Adami HO, Hunter D, Trichopoulos D, editors. Textbook of cancer epidemiology. 2nd ed. New York: Oxford University Press; 2008. p. 517-54.

41. Patel AR, Klein EA. Risk factors for prostate cancer. Nat Clin Pract Urol. 2009;6(2):87-95. doi:10.1038/ncpuro1290.

42. Eeles R, Goh C, Castro E, et al. The genetic epidemiology of prostate cancer and its clinical implications. Nat Rev Urol. 2014;11(1):18-31. doi:10.1038/nrurol.2013.266.

43. Rota M, Scotti L, Turati F, et al. Alcohol consumption and prostate cancer risk: a meta-analysis of the dose-risk relation. Eur J Cancer Prev. 2012;21(4):350-9. doi:10.1097/CEJ. 0b013e32834dbc11.

44. Meyerhardt JA, Ma J, Courneya KS. Energetics in colorectal and prostate cancer. J Clin Oncol. 2010;28(26):4066-73. doi:10. 1200/JCO.2009.26.8797.

45. Ragin C, Davis-Reyes B, Tadesse H, et al. Farming, reported pesticide use, and prostate cancer. Am J Men's Health. 2013;7(2):102-9. doi:10.1177/1557988312458792.

46. Mink PJ, Adami HO, Trichopoulos D, Britton NL, Mandel JS. Pesticides and prostate cancer: a review of epidemiologic studies with specific agricultural exposure information. Eur $\mathbf{J}$ Cancer Prev. 2008;17(2):97-110. doi:10.1097/CEJ.0b013e3280 $145 \mathrm{~b} 4 \mathrm{c}$.

47. Hsing AW, Chu LW, Stanczyk FZ. Androgen and prostate cancer: is the hypothesis dead? Cancer Epidemiol Biomark Prev. 2008;17(10):2525-30. doi:10.1158/1055-9965.EPI-08-0448.

48. Hrbacek J, Urban M, Hamsikova E, Tachezy R, Heracek J. Thirty years of research on infection and prostate cancer: no conclusive evidence for a link. A systematic review. Urol Oncol. 2013;31(7):951-65. doi:10.1016/j.urolonc.2012.01.013.

49. Sutcliffe S. Sexually transmitted infections and risk of prostate cancer: review of historical and emerging hypotheses. Future Oncol. 2010;6(8):1289-311. doi:10.2217/fon.10.95.

50. Sutcliffe S, Platz EA. Inflammation in the etiology of prostate cancer: an epidemiologic perspective. Urol Oncol. 2007;25(3):242-9. doi:10.1016/j.urolonc.2006.09.014.

51. Boice JD Jr, Lubin JH. Occupational and environmental radiation and cancer. Cancer Causes Control (CCC). 1997;8(3): 309-22.

52. Kohler TS, Fazili AA, Brannigan RE. Putative health risks associated with vasectomy. Urol Clin N Am. 2009;36(3): 337-45. doi:10.1016/j.ucl.2009.05.004.

53. Strickler HD, Goedert JJ. Sexual behavior and evidence for an infectious cause of prostate cancer. Epidemiol Rev. 2001;23(1): 144-51.

54. Gann PH. Interpreting recent trends in prostate cancer incidence and mortality. Epidemiology. 1997;8(2):117-20.

55. Hankey BF, Feuer EJ, Clegg LX, et al. Cancer surveillance series: interpreting trends in prostate cancer-part I: evidence of the effects of screening in recent prostate cancer incidence, mortality, and survival rates. J Natl Cancer Inst. 1999;91(12): 1017-24.

56. Helgesen F, Holmberg L, Johansson JE, Bergstrom R, Adami HO. Trends in prostate cancer survival in Sweden, 1960 through 
1988: evidence of increasing diagnosis of nonlethal tumors. J Natl Cancer Inst. 1996;88(17):1216-21.

57. Sun X, Kido T, Okamoto R, et al. The relationship between Agent Orange and prostate specific antigen: a comparison of a hotspot and a non-sprayed area in Vietnam. Environ Health Prev Med. 2013;18(5):356-60. doi:10.1007/s12199-013-0330-1.

58. Kane CJ, Im R, Amling CL, et al. Outcomes after radical prostatectomy among men who are candidates for active surveillance: results from the SEARCH database. Urology. 2010;76(3):695-700. doi:10.1016/j.urology.2009.12.073.

59. Egger M, Schneider M, Davey Smith G. Spurious precision? Meta-analysis of observational studies. BMJ. 1998;316(7125): $140-4$.

60. Weed DL. Meta-analysis and causal inference: a case study of benzene and non-Hodgkin lymphoma. Ann Epidemiol. 2010;20(5):347-55. doi:10.1016/j.annepidem.2010.02.001.

61. Air Force Health Study. Air Force Health Study comprehensive report. An epidemiologic investigation of health effects in air force personnel following exposure to herbicides. February 1984 to March 2005: prepared for the United States Air Force (USAF) by Science Applications International Corporation (SAIC); 2005.

62. Ketchum NS, Akhtar FZ. The Air Force Health Study. An epidemiologic investigation of health effects in air force personnel following exposure to herbicides. Mortality update 1996. Brooks Air Force Base, Texas: Air Force Materiel Command; 1996.

63. Akhtar FZ, Garabrant DH, Ketchum NS, Michalek JE. Cancer in US Air Force veterans of the Vietnam War. J Occup Environ Med. 2004;46(2):123-36. doi:10.1097/01.jom.0000111603. 84316.0f.

64. Ketchum NS, Michalek JE, Burton JE. Serum dioxin and cancer in veterans of Operation Ranch Hand. Am J Epidemiol. 1999;149(7):630-9.

65. Kayajanian GM. Dioxin body burdens in operation ranch hand veterans: promotion blocking and cancer causation. Ecotoxicol Environ Saf. 2001;50(3):167-73. doi:10.1006/eesa.2001.2101.

66. Wolfe WH, Michalek JE, Miner JC, et al. Health status of Air Force veterans occupationally exposed to herbicides in Vietnam. I. Physical health. J Am Med Assoc (JAMA). 1990;264(14): 1824-31.

67. Michalek JE, Wolfe WH, Miner JC. Health status of Air Force veterans occupationally exposed to herbicides in Vietnam. II. Mortality. JAMA. 1990;264(14):1832-6.

68. Kramarow EA, Pastor PN. The health of male veterans and nonveterans aged 25-64: United States, 2007-2010. NCHS Data Brief. 2012;101:1-8.

69. McMichael AJ. Standardized mortality ratios and the "healthy worker effect": scratching beneath the surface. J Occup Med. 1976;18(3):165-8.

70. Stellman JM, Stellman SD, Sommer JF Jr. Utilization, attitudes, and experiences of Vietnam Era veterans with Veterans Administration health facilities: the American Legion experience. Environ Res. 1988;47(2):193-209.

71. Cole SR, Platt RW, Schisterman EF, et al. Illustrating bias due to conditioning on a collider. Int J Epidemiol. 2010;39(2): 417-20. doi:10.1093/ije/dyp334.

72. Pavuk M, Michalek JE, Schecter A, Ketchum NS, Akhtar FZ, Fox KA. Did TCDD exposure or service in Southeast Asia increase the risk of cancer in air force Vietnam veterans who did not spray Agent Orange? J Occup Environ Med. 2005;47(4): 335-42.

73. Pavuk M, Michalek JE, Ketchum NS. Prostate cancer in US Air Force veterans of the Vietnam War. J Eposure Sci Environ Epidemiol. 2006;16(2):184-90. doi:10.1038/sj.jea.7500448.
74. Gupta A, Ketchum N, Roehrborn CG, Schecter A, Aragaki CC, Michalek JE. Serum dioxin, testosterone, and subsequent risk of benign prostatic hyperplasia: a prospective cohort study of Air Force veterans. Environ Health Perspect. 2006;114(11): 1649-54.

75. Kahn PC, Gochfeld M, Nygren M, Hansson M, Rappe C, Velez $\mathrm{H}$, Ghent-Guenther T, Wilson WP. Dioxins and dibenzofurans in blood and adipose tissue of Agent Orange-exposed Vietnam veterans and matched controls. JAMA. 1988;259(11):1661-7.

76. National Research Council. Assembly of Life Sciences. Panel on the Proposed Air Force Study of Herbicide Orange. Review of U.S. Air Force Protocol: epidemiological investigation of health effects in air force personnel following exposure to herbicide Orange. Washington, DC: National Academies Press; 1980.

77. Institute of Medicine. Disposition of the Air Force Health Study. Washington, DC: National Academies Press; 2006.

78. General Accounting Office. Agent Orange: actions needed to improve communications of Air Force Ranch Hand Study Data and Results. GAO/NSIAD-00-31. Washington, DC: General Accounting Office; 1999.

79. U.S. House of Representatives. Agent Orange: Status of the Air Force Ranch Hand Study: hearing before the subcommittee on National Security, Veterans Affairs, and International Relations of the Committee on Government Reform. 106th Congress. House Hearing 106-163. Washington, DC: U.S. Government Printing Office; 2000.

80. American Legion. Review of the Air Force Health Study: Draft of Critique of Ranch Hand Study. Folder 01, Box 03, Admiral Elmo R. Zumwalt, Jr. Collection: Agent Orange Subject Files, The Vietnam Archive, Texas Tech University; 1991.

81. Buffler PA, Ginevan ME, Mandel JS, Watkins DK. The Air Force health study: an epidemiologic retrospective. Ann Epidemiol. 2011;21(9):673-87. doi:10.1016/j.annepidem.2011.02. 001.

82. Centers for Disease Control Veterans Health Studies. Serum 2,3,7,8-tetrachlorodibenzo-p-dioxin levels in US Army Vietnam-era veterans. The Centers for Disease Control Veterans Health Studies. J Am Med Assoc (JAMA). 1988;260(9): 1249-54.

83. Lathrop GD, Wolfe WH, Moynahan PM, Albanese RA. Epidemiologic investigation of health effects in air force personnel following exposure to herbicides: study protocol. Initial report for period October 1978-December 1982. Report SAM-TR-82-44. Brooks Air Force Base, Texas: U.S. Air Force School of Aerospace Medicine, Aerospace Medical Division (AFSC); 1982.

84. Thomas TL, Kang HK. Mortality and morbidity among Army Chemical Corps Vietnam veterans: a preliminary report. Am J Ind Med. 1990;18(6):665-73.

85. Kang HK, Dalager NA, Needham LL, et al. Health status of Army Chemical Corps Vietnam veterans who sprayed defoliant in Vietnam. Am J Ind Med. 2006;49(11):875-84. doi:10.1002/ ajim.20385.

86. Kang HK, Dalager NA, Needham LL, et al. US Army Chemical Corps Vietnam veterans health study: preliminary results. Chemosphere. 2001;43(4-7):943-9.

87. Cypel Y, Kang H. Mortality patterns of Army Chemical Corps veterans who were occupationally exposed to herbicides in Vietnam. Ann Epidemiol. 2010;20(5):339-46. doi:10.1016/j. annepidem.2010.02.003.

88. U.S. Department of Veterans Affairs. Compensation-veterans exposed to Agent Orange. http://www.benefits.va.gov/compen sation/claims-postservice-agent_orange.asp. Last updated 22 October 2013.

89. Young AL, Giesy JP, Jones P, Newton M, Guilmartin JF Jr, Cecil PF Sr. Assessment of potential exposure to Agent Orange 
and its associated TCDD. Environ Sci Pollut Res Int. 2004;11(6):347-8.

90. Jurek AM, Greenland S, Maldonado G. How far from non-differential does exposure or disease misclassification have to be to bias measures of association away from the null? Int J Epidemiol. 2008;37(2):382-5. doi:10.1093/ije/dym291.

91. Jurek AM, Greenland S, Maldonado G, Church TR. Proper interpretation of non-differential misclassification effects: expectations vs observations. Int J Epidemiol. 2005;34(3): 680-7. doi:10.1093/ije/dyi060.

92. Giri VN, Cassidy AE, Beebe-Dimmer J, et al. Association between Agent Orange and prostate cancer: a pilot case-control study. Urology. 2004;63(4):757-60; discussion 60-1. doi:10. 1016/j.urology.2003.11.044.

93. Schecter A, Needham L, Pavuk M, et al. Agent Orange exposure, Vietnam War veterans, and the risk of prostate cancer. Cancer. 2009;115(14):3369-71. doi:10.1002/cncr.24365.

94. Yi SW, Ohrr H, Hong JS, Yi JJ. Agent Orange exposure and prevalence of self-reported diseases in Korean Vietnam Veterans. J Prev Med Public Health. 2013;46(5):213-25. doi:10.3961/ jpmph.2013.46.5.213.

95. Stellman JM, Stellman SD, Weber T, Tomasallo C, Stellman $\mathrm{AB}$, Christian R Jr. A geographic information system for characterizing exposure to Agent Orange and other herbicides in Vietnam. Environ Health Perspect. 2003;111(3):321-8.

96. Ginevan ME, Watkins DK, Ross JH, O'Boyle RA. Assessing exposure to allied ground troops in the Vietnam War: a quantitative evaluation of the Stellman Exposure Opportunity Index model. Chemosphere. 2009;75(11):1512-8. doi:10.1016/j.che mosphere.2009.02.014.

97. Yi SW, Ohrr H, Won JU, Song JS, Hong JS. Serum 2,3,7,8Tetrachlorodibenzo-p-dioxin levels and their association with age, body mass index, smoking, military record-based variables, and estimated exposure to Agent Orange in Korean Vietnam veterans. J Prev Med Public Health. 2013;46(5):226-36. doi:10. 3961/jpmph.2013.46.5.226.

98. Li Q, Lan L, Klaassen Z, Shah SR, Moses KA, Terris MK. High level of dioxin-TEQ in tissue is associated with Agent Orange exposure but not with biochemical recurrence after radical prostatectomy. Prostate Cancer Prostatic Dis. 2013. doi:10.1038/ pcan.2013.33.

99. Shah SR, Freedland SJ, Aronson WJ, et al. Exposure to Agent Orange is a significant predictor of prostate-specific antigen (PSA)-based recurrence and a rapid PSA doubling time after radical prostatectomy. BJU Int. 2009;103(9):1168-72. doi:10. 1111/j.1464-410X.2009.08405.x.

100. Everly L, Merrick GS, Allen ZA, et al. Prostate cancer control and survival in Vietnam veterans exposed to Agent Orange. Brachytherapy. 2009;8(1):57-62. doi:10.1016/j.brachy.2008.08. 001.

101. Boyle CA, Decoufle P, Delaney RJ, et al. Postservice mortality among Vietnam veterans. Atlanta, GA: U.S. Department of Health and Human Services, Public Health Services, Centers for Disease Control; 1987.

102. Marshall RP, Jorm AF, Grayson DA, O’Toole BI. Posttraumatic stress disorder and other predictors of health care consumption by Vietnam veterans. Psychiatr Serv (Washington, D.C.). 1998;49(12):1609-11.

103. Schnurr PP, Friedman MJ, Sengupta A, Jankowski MK, Holmes T. PTSD and utilization of medical treatment services among male Vietnam veterans. J Nerv Ment Dis. 2000;188(8):496-504.

104. Virgo KS, Price RK, Spitznagel EL, Ji TH. Substance abuse as a predictor of VA medical care utilization among Vietnam veterans. J Behav Health Serv Res. 1999;26(2):126-39.

105. Australian Institute of Health and Welfare. Health care usage and costs. A comparison of veterans and war widows and widowers with the rest of the community. Canberra, Australia: Australian Institute of Health and Welfare; 2002.

106. Hall W. The logic of a controversy: the case of Agent Orange in Australia. Soc Sci Med. 1989;29(4):537-44.

107. Fett MJ, Adena MA, Cobbin DM, Dunn M. Mortality among Australian conscripts of the Vietnam conflict era. I. Death from all causes. Am J Epidemiol. 1987;125(5):869-77.

108. Wilson EJ, Horsley KW, van der Hoek R. Australian National 1943 Service Vietnam Veterans: mortality and cancer incidence 2005. 1944 Canberra, Australia: Australian Government, Department of Vet-1945 erans' Affairs, Australian Institute of Health and Welfare; 2005

109. O'Toole BI, Catts SV, Outram S, Pierse KR, Cockburn J. The physical and mental health of Australian Vietnam veterans 3 decades after the war and its relation to military service, combat, and post-traumatic stress disorder. Am J Epidemiol. 2009; 170(3):318-30. doi:10.1093/aje/kwp146.

110. Crane PJ, Barnard DL, Horsley KD, Adena MA. Mortality of Vietnam Veterans. The Veteran Cohort Study. A report of the 1996 retrospective cohort study of Australian Vietnam Veterans. Canberra, Australia: Australian Government, Department of Veterans' Affairs; 1997.

111. Australian Institute of Health and Welfare. Cancer Incidence Study 2003: Australian Veterans of the Korean War. Canberra, Australia: Australian Institute of Health and Welfare 2003.

112. Wilson EJ, Horsley KW, van der Hoek R. The third Australian Vietnam Veterans mortality study 2005. Canberra, Australia: Australian Government, Department of Veterans' Affairs, Australian Institute of Health and Welfare; 2005.

113. Wilson EJ, Horsley KW, van der Hoek R. Dapsone Exposure and Australian Vietnam Service: Mortality and Cancer Incidence. Canberra, Australia: Australian Government, Department of Veterans' Affairs, Australian Institute of Health and Welfare 2007.

114. Australian Department of Veterans' Affairs. Morbidity of Vietnam Veterans: a Study of the Health of Australia's Vietnam Veteran Community: volume 1-male Vietnam Veterans. Survey and community comparison outcomes. Canberra, Australia: Australian Government, Department of Veterans' Affairs; 1998.

115. Australian Institute of Health and Welfare. Morbidity of Vietnam Veterans. A Study of the Health of Australia's Vietnam Veteran Community. Volume 3 validation study. Canberra, Australia: Australian Institute of Health and Welfare; 1999.

116. Wilson EJ, Horsley KW, van der Hoek R. Cancer incidence in Australian Vietnam Veterans Study 2005. Canberra, Australia: Australian Government, Department of Veterans' Affairs, Australian Institute of Health and Welfare; 2005.

117. Boehmer TK, Flanders WD, McGeehin MA, Boyle C, Barrett DH. Postservice mortality in Vietnam veterans: 30-year followup. Arch Intern Med. 2004;164(17):1908-16. doi:10.1001/ archinte.164.17.1908.

118. Leavy J, Ambrosini G, Fritschi L. Vietnam military service history and prostate cancer. BMC Public Health. 2006;6:75. doi:10.1186/1471-2458-6-75.

119. McBride D, Cox B, Broughton J, Tong D. The mortality and cancer experience of New Zealand Vietnam war veterans: a cohort study. BMJ Open. 2013;3(9):e003379. doi:10.1136/ bmjopen-2013-003379.

120. Yi SW. Cancer Incidence in Korean Vietnam Veterans during 1992-2003: the Korean Veterans Health Study. J Prev Med Public Health. 2013;46(6):309-18.

121. Lawrence CE, Reilly AA, Quickenton P, Greenwald P, Page WF, Kuntz AJ. Mortality patterns of New York State Vietnam Veterans. Am J Public Health. 1985;75(3):277-9.

122. Anderson HA, Hanrahan LP, Jensen M, Laurin D, Yick WY, Wiegman P. Wisconsin Vietnam Veteran Mortality Study. 
Madison, WI: State of Wisconsin, Department of Health and Social Services, Division of Health, Section of Environmental and Chronic Disease Epidemiology; 1986.

123. Holmes AP, Bailey C, Baron RC, et al. West Virginia VietnamEra Veterans Mortality Study. Preliminary report. Charleston, WV: West Virginia Health Department; 1986.

124. Visintainer PF, Barone M, McGee H, Peterson EL. Proportionate mortality study of Vietnam-era veterans of Michigan. J Occup Environ Med. 1995;37(4):423-8.

125. Clapp RW, Cupples LA, Colton T, Ozonoff DM. Cancer surveillance of Veterans in Massachusetts, USA, 1982-1988. Int J Epidemiol. 1991;20(1):7-12.

126. Clapp RW. Update of cancer surveillance of veterans in Massachusetts, USA. Int J Epidemiol. 1997;26(3):679-81.

127. Breslin P, Kang HK, Lee Y, Burt V, Shepard BM. Proportionate mortality study of US Army and US Marine Corps veterans of the Vietnam War. J Occup Med. 1988;30(5):412-9.

128. Watanabe KK, Kang HK. Mortality patterns among Vietnam veterans: a 24 -year retrospective analysis. J Occup Environ Med. 1996;38(3):272-8.

129. Saracci R, Kogevinas M, Bertazzi PA, et al. Cancer mortality in workers exposed to chlorophenoxy herbicides and chlorophenols. Lancet. 1991;338(8774):1027-32.

130. Neuberger M, Landvoigt W, Derntl F. Blood levels of 2,3,7,8tetrachlorodibenzo-p-dioxin in chemical workers after chloracne and in comparison groups. Int Arch Occup Environ Health. 1991;63(5):325-7.

131. Flesch-Janys D, Berger J, Gurn P, Manz A, Nagel S, Waltsgott $\mathrm{H}$, Dwyer JH. Exposure to polychlorinated dioxins and furans (PCDD/F) and mortality in a cohort of workers from a herbicideproducing plant in Hamburg, Federal Republic of Germany. Am J Epidemiol. 1995;142(11):1165-75.

132. Manz A, Berger J, Dwyer JH, Flesch-Janys D, Nagel S, Waltsgott $\mathrm{H}$. Cancer mortality among workers in chemical plant contaminated with dioxin. Lancet. 1991;338(8773):959-64.

133. Smith AH, Patterson DG Jr, Warner ML, MacKenzie R, Needham LL. Serum 2,3,7,8-tetrachlorodibenzo-p-dioxin levels of New Zealand pesticide applicators and their implication for cancer hypotheses. J Natl Cancer Inst. 1992;84(2):104-8.

134. Littorin M, Hansson M, Rappe C, Kogevinas M. Dioxins in blood from Swedish phenoxy herbicide workers. Lancet. 1994;344(8922):611-2.

135. Fingerhut MA, Halperin WE, Marlow DA, et al. Cancer mortality in workers exposed to 2,3,7,8-tetrachlorodibenzo-p-dioxin. N Engl J Med. 1991;324(4):212-8. doi:10.1056/nejm199101243 240402.

136. Steenland K, Piacitelli L, Deddens J, Fingerhut M, Chang LI. Cancer, heart disease, and diabetes in workers exposed to 2,3,7,8-tetrachlorodibenzo-p-dioxin. J Natl Cancer Inst. 1999;91(9):779-86.

137. Collins JJ, Bodner K, Aylward LL, et al. Mortality rates among workers exposed to dioxins in the manufacture of pentachlorophenol. J Occup Environ Med. 2009;51(10):1212-9. doi:10. 1097/JOM.0b013e3181badd4e.

138. Collins JJ, Bodner K, Aylward LL, Wilken M, Bodnar CM. Mortality rates among trichlorophenol workers with exposure to 2,3,7,8-tetrachlorodibenzo-p-dioxin. Am J Epidemiol. 2009;170(4):501-6. doi:10.1093/aje/kwp153.

139. Ruder AM, Yiin JH. Mortality of US pentachlorophenol production workers through 2005. Chemosphere. 2011;83(6): 851-61. doi:10.1016/j.chemosphere.2011.02.064.

140. 't Mannetje A, McLean D, Cheng S, Boffetta P, Colin D, Pearce N. Mortality in New Zealand workers exposed to phenoxy herbicides and dioxins. Occup Environ Med. 2005;62(1):34-40. doi:10.1136/oem.2004.015776.
141. McBride DI, Burns CJ, Herbison GP, Humphry NF, Bodner K, Collins JJ. Mortality in employees at a New Zealand agrochemical manufacturing site. Occup Med (Oxford, England). 2009;59(4):255-63. doi:10.1093/occmed/kqp030.

142. McBride DI, Collins JJ, Humphry NF, et al. Mortality in workers exposed to 2,3,7,8-tetrachlorodibenzo-p-dioxin at a trichlorophenol plant in New Zealand. J Occup Environ Med. 2009;51(9):1049-56. doi:10.1097/JOM.0b013e3181b571ae.

143. Boers D, Portengen L, Bueno-de-Mesquita HB, Heederik D, Vermeulen R. Cause-specific mortality of Dutch chlorophenoxy herbicide manufacturing workers. Occup Environ Med. 2010;67(1):24-31. doi:10.1136/oem.2008.044222.

144. Manuwald U, Velasco Garrido M, Berger J, Manz A, Baur X. Mortality study of chemical workers exposed to dioxins: followup 23 years after chemical plant closure. Occup Environ Med. 2012;69(9):636-42. doi:10.1136/oemed-2012-100682.

145. Ott MG, Zober A. Cause specific mortality and cancer incidence among employees exposed to 2,3,7,8-TCDD after a 1953 reactor accident. Occup Environ Med. 1996;53(9):606-12.

146. Boers D, Portengen L, Turner WE, Bueno-de-Mesquita HB, Heederik D, Vermeulen R. Plasma dioxin levels and causespecific mortality in an occupational cohort of workers exposed to chlorophenoxy herbicides, chlorophenols and contaminants. Occup Environ Med. 2012;69(2):113-8. doi:10.1136/oem.2010. 060426.

147. Alavanja MC, Samanic C, Dosemeci M, et al. Use of agricultural pesticides and prostate cancer risk in the Agricultural Health Study cohort. Am J Epidemiol. 2003;157(9):800-14.

148. Fritschi L, Glass DC, Tabrizi JS, Leavy JE, Ambrosini GL. Occupational risk factors for prostate cancer and benign prostatic hyperplasia: a case-control study in Western Australia. Occup Environ Med. 2007;64(1):60-5. doi:10.1136/oem.2006. 027706.

149. Jones DR, Sutton AJ, Abrams KR, Fenty J, Warren F, Rushton L. Systematic review and meta-analysis of mortality in crop protection product manufacturing workers. Occup Environ Med. 2009;66(1):7-15. doi:10.1136/oem.2007.035733.

150. Consonni D, Pesatori AC, Zocchetti C, et al. Mortality in a population exposed to dioxin after the Seveso, Italy, accident in 1976: 25 years of follow-up. Am J Epidemiol. 2008;167(7): 847-58. doi:10.1093/aje/kwm371.

151. Pesatori AC, Consonni D, Rubagotti M, Grillo P, Bertazzi PA. Cancer incidence in the population exposed to dioxin after the "Seveso accident": twenty years of follow-up. Environ Health. 2009;8:39. doi:10.1186/1476-069x-8-39.

152. Leng L, Chen X, Li CP, Luo XY, Tang NJ. 2,3,7,8-Tetrachlorodibezo-p-dioxin exposure and prostate cancer: a metaanalysis of cohort studies. Public Health. 2014;. doi:10.1016/j. puhe.2013.10.006.

153. Hill $\mathrm{AB}$. The environment and disease: association or causation? Proc R Soc Med. 1965;58:295-300.

154. Kociba RJ, Keyes DG, Lisowe RW, et al. Results of a two-year chronic toxicity and oncogenic study of rats ingesting diets containing 2,4,5-trichlorophenoxyacetic acid (2,4,5-T). Food Cosmet Toxicol. 1979; 17(3):205-21.

155. Charles JM, Bond DM, Jeffries TK, et al. Chronic dietary toxicity/oncogenicity studies on 2,4-dichlorophenoxyacetic acid in rodents. Fundam Appl Toxicol. 1996;33(2):166-72.

156. Charles JM, Dalgard DW, Cunny HC, Wilson RD, Bus JS. Comparative subchronic and chronic dietary toxicity studies on 2,4-dichlorophenoxyacetic acid, amine, and ester in the dog. Fundam Appl Toxicol. 1996;29(1):78-85.

157. Munro IC, Carlo GL, Orr JC, et al. A comprehensive, integrated review and evaluation of the scientific evidence relating to the safety of the herbicide 2,4-D. Int J Toxicol. 1992;11(5):559-664. 